

\section{DISCLAIMER}

This report was prepared as an account of work sponsored by an agency of the United States Government. Neither the United States Government nor any agency Thereof, nor any of their employees, makes any warranty, express or implied, or assumes any legal liability or responsibility for the accuracy, completeness, or usefulness of any information, apparatus, product, or process disclosed, or represents that its use would not infringe privately owned rights. Reference herein to any specific commercial product, process, or service by trade name, trademark, manufacturer, or otherwise does not necessarily constitute or imply its endorsement, recommendation, or favoring by the United States Government or any agency thereof. The views and opinions of authors expressed herein do not necessarily state or reflect those of the United States Government or any agency thereof. 


\section{DISCLAIMER}

Portions of this document may be illegible in electronic image products. Images are produced from the best available original document. 


\section{Printed in the United States of America Availahle from National Technical Information Service \\ U.S. Department of Commerce 5285 Port Royal Road, Springfield, Virginia 22161 NTIS price codes-Printed Copy: A08 Microfiche A01}

This report was prepared as an account of work sponsored by an agency of the United States Government. Neither the United States Government nor any agency thereof, nor any of their employees, makes any warranty, express or implied, or assumes any legal liability or responsibility for the accuracy, completeness, or usefulness of any information, apparatus, product, or process disclosed, or represents that its use would not infringe privately owned rights. Reference herein to any specific commercial product, process, or service by trade name, trademark. manufacturer, or otherwise dnes nnt neressarily constitute or imply ito eiduiseminil, recummendation, or favorıng by the United States Government or any agency thereof. The views and opinions of authors expressed herein do not necessarily state or reflect those of the United States Government or any agency thereof. 
ORNL/TM-7192

Dist. Category UC-86

Contract No. W-7405-eng-26

\title{
CONSOLIDATED FUEL REPROCESSING PROGRAM PROGRESS REPORT FOR PERIOD OCTOBER 1 TO DECEMBER 31, 1979
}

\author{
W. D. Burch, Program Director \\ M. J. Feldman \\ Manager, Engineering Systems \\ W. S. Groenier \\ Manager, Engineering Research \\ B. L. Vondra \\ Manager, Process Research and Development \\ O. O. Yarbro \\ Manager, Technical Support \\ Report compiled by \\ W. E. Unger \\ Technical Assistant to the Program Director
}

Date Published: May 1980

NOTICE: This document contains information of a preliminary nature. It is subject to revision or correction and therefore does not represent a final report.

\footnotetext{
OAK RIDGE NATIONAL LABORATORY

Oak Ridge, Tennessee 37830 operated by

UNION CARBIDE CORPORATION for the

DEPARTMENT OF ENERGY
} 


\section{CONTENTS}

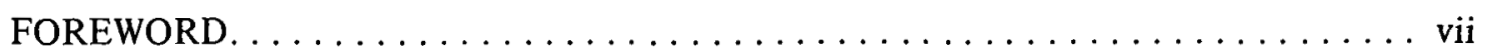

1. HIGHLIGHTS . . . . . . . . . . . . . . . . . .

1.1 Process Research and Development. . . . . . . . . . . . . . . . 1-1

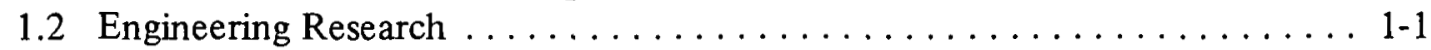



1.4 Technical Support. . . . . . . . . . . . . . .

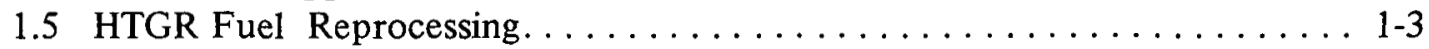

2. PROCESS RESEARCH AND DEVELOPMENT $\ldots \ldots \ldots \ldots \ldots \ldots \ldots \ldots \ldots . \ldots \ldots$

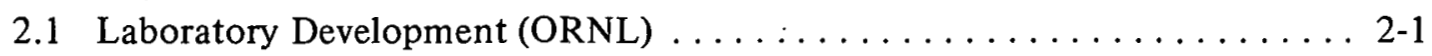

2.1.1 Pu(IV) polymer reaction in aqueous solutions. . . . . . . . 2-1

2.1 .2 Plutonium reductive stripping studies . . . . . . . . . . 2-2

2.1 .3 Solvent cleanup. . . . . . . . . . . . . . . . . . 2-2

2.1 .4 Solvent scrubbing kinetics. . . . . . . . . . . . . . $2-3$

2.1 .5 Fission product chemistry. ................... 2-3

2.1.6 Interphase transfer kinetics of uranium using

tri-2-ethylhexyl phosphate . . . . . . . . . . . . 2-4

2.1 .7 Spent solvent recycle. . . . . . . . . . . . . . . . . 2-4

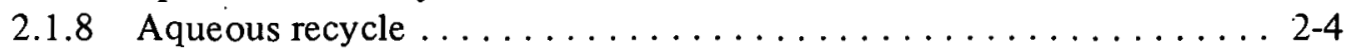

2.1 .9 Nitrogen compound chemistry . . . . . . . . . . . . . . 2-5

2.1.10 Evaluation of alternate extractants . . . . . . . . . . . 2-5

2.2 Laboratory Development (General Atomic Company) ........... 2-5



2.2.2 Zirconium scrubbing kinetics ................ 2-6

2.2.3 Effect of uranium and zirconium on TBP hydrolysis. . . . . . . 2-6

2.2.4 Titrimetric determination of thorium in solvent extraction process solutions . . . . . . . . . . . . 2-6

2.2.5 Thorium determination by neutron activation of ${ }^{232} \mathrm{Th} \ldots \ldots \ldots .2-7$

2.3 Savannah River Laboratory Process Development. . . . . . . . . . . . . . 2-7

2.3.1 Coprocessing to breeder concentrations . . . . . . . . . . . . 2-7

2.3.2 Low decontamination flowsheet. . . . . . . . . . . . . . 2-8

2.3 .3 Tritium removal tests . . . . . . . . . . . . . . . . 2-8

2.3.4 Fundamental studies of alternative extractants . . . . . . . . . 2-8

2.3.5 Pulsed-column facility . . . . . . . . . . . . . . . 2-9

2.3.6 On-line monitoring systems. . . . . . . . . . . . . . . 2-9

2.3.7 Joint SRL-PNL thorium irradiation program. . . . . . . . . . 2-10

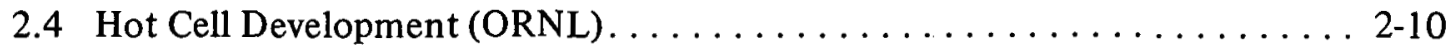

2.4.1 Flowsheet parantrics for mixed-oxide fucls . . . . . . . . . . 2-10

2.4 .2 Fuel procurement ....................... 2-11

2.4.3 Scouting studies with carbide fuels . . . . . . . . . . . . 2-11

2.4.4 Development of the CONSEPT program for process control flowsheet testing ...................... 2-12

2.4.5 Plutonium flowsheet tests.................. 2-12 
2.4.6 Solvent Extraction Test Facility . . . . . . . . . . . . . 2-14

2.4.7 Alternatives to voloxidation ................... 2-15



2.5.1 Gel-sphere conversion development. ............... 2-15

2.5.2 Direct denitration conversion development. . . . . . . . . . . 2-16

2.5.3 Product characterization ....................... 2-17





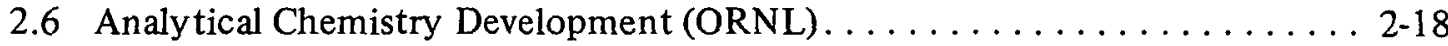

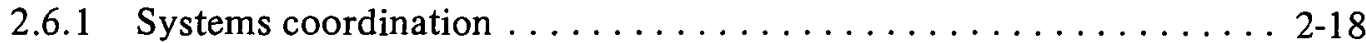

2.6.2 Chemical methods development ... . . . . . . . . . . . . . 2-19

2.6.3 X-ray fluorescence (XRF) development ................ 2-19

2.6.4 Nuclear and radiochemical me thods development. . . . . . . . . . . 2-19

2.6.5 Spark -ourco mass spcctronctry developinent. . . . . . . . . . . . . 2-20

2.6 .6 Instrumentation development. . . . . . . . . . . . . . . . . . . . . 2=20

2.7 Analytical Chemistry Development (SRL) . . . . . . . . . . . . . . . . . 2-20

2.7.1 Evaluation of the LASL $x$-ray absorption-edgc densitometer (XRAED) . . . . . . . . . . . . . . . 2-20

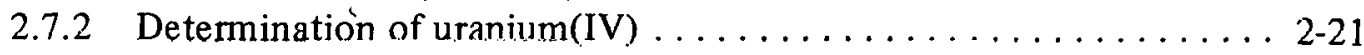

2.7.3 Thorium determination..................... 2-21

2.7.4 $\mathrm{ThO}_{2}-\mathrm{UO}_{2}$ fuel pellet characterization .............. 2-22

2.8 Materials Compatibility . . . . . . . . . . . . . . . . . . . 2-22

2.8.1 Experimental corrosion studies at Battelle Columbus Laboratories. . . 2-22

References .............................. 2-23

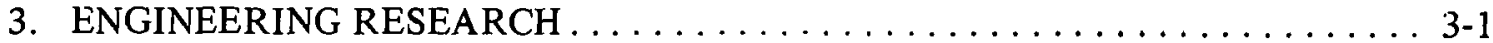

3.1 Voloxidation. . . . . . . . . . . . . . . . . . . . . 3-1

3.1.1 Full-scale experimental voloxidizer (FSEV) system. . . . . . . . . . 3-1

3.1.2 Rotary kiln heat and mass transport studies . . . . . . . . . . . . . 3-3

13.1.3 Tritium retention from voloxidizer process off-gas . . . . . . . . . 3-6

3.1 .4 Rotary seal tests .......................... 3.6

3.1.5 Rutary kiln corrosion test . . . . . . . . . . . . . . . . . . 3-8

3.2 Dissolution .............................. 3-8

3.2.1 Rotary-dissolver erosion-corrosion tests . . . . . . . . . . . . 3-8

3.2.2 Advanced rotary dissolver development . . . . . . . . . . . . . 3-9

3.2 .3 Solids suspension tests. . . . . . . . . . . . . . . . . . 3-10

3.2.4 Flow modeling studies. . . . . . . . . . . . . . . . . . . 3-10

33 Feed Preparation. . . . . . . . . . . . . . . . . . . . . . 3-12

3.3.1 Fluidic pump development . . . . . . . . . . . . . . . 3-12

3.3.3 Nitrio aoid dohydration test. . . . . . . . . . . . . . 3-12

3.3.3 Monitor development ........................... 313

3.4 Solvent Extraction . . . . . . . . . . . . . . . . . . . . . . . 3-13

3.4.1 Centrifugal contactor development............... 3-13

3.4 .2 Flowsheet engineering studies. . . . . . . . . . . . . . . . 3-15

3.4.3 Robatel contactor evaluation study. . . . . . . . . . . . . 3-15

3.4.4 Contactor improvement effort . . . . . . . . . . . . . . 3-16

3.4.5 Flowsheet and modeling tests ................ 3-16 
3.5 Off-Gas Processing. . . . . . . . . . . . . . . . . . . . . . . .

3.5.1 Fluorocarbon absorption process development . . . . . . . . 3-17

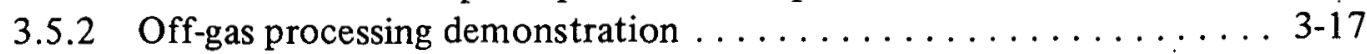

3.5 .3 Solid sorbent tests. . . . . . . . . . . . . . . . . $\ldots \ldots$

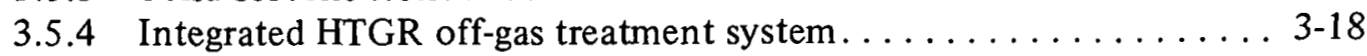

References. . . . . . . . . . . . . . . . . . . . . . . . 3-24

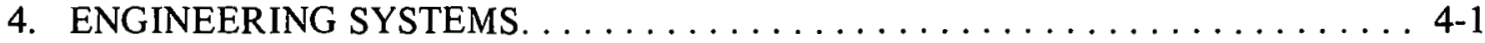

4.1 Engineering Analysis . . . . . . . . . . . . . . . . . . .

4.1.1 Study of reprocessing facilities at a nuclear energy center . . . . . . 4-1

4.1.2 Thermal analysis of irradiated fuel subassemblies . . . . . . . . . . 4-2

4.1.3 Cost impact of remote maintenance on fuel reprocessing plants . . . . 4-2

4.2 Component Development . . . . . . . . . . . . . . . . . 4-2

4.2.1 Dissolution ......................... 4-2

4.3 Systems Development. . . . . . . . . . . . . . . . . . . 4.4

4.3.1 Disassembly and cutting . . . . . . . . . . . . . . . 4-4

4.3.2 Integrated Equipment Test (IET) facility . . . . . . . . . . . 4-6

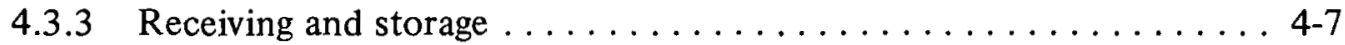

4.3.4 Special remote systems . . . . . . . . . . . . . . . 4-8

4.3.5 Remote control engineering task................. 4-10

4.3.6 Uranium for tests . . . . . . . . . . . . . . . . . 4 4-12

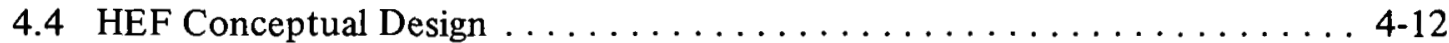

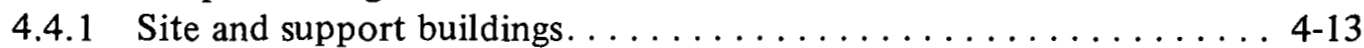

4.4.2 HEF process buildings. . . . . . . . . . . . . . . . . . . 4-13

4.4.3 General purpose cell systems. . . . . . . . . . . . . . 4-14

4.4.4 HEF process systems. . . . . . . . . . . . . . . . . 4-16

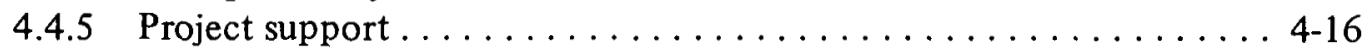

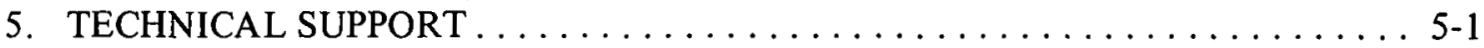

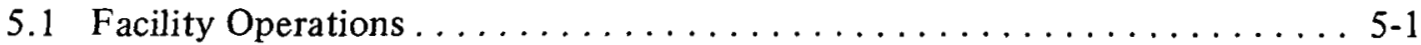

5.2 Safeguards. . . . . . . . . . . . . .

5.2.1 Dynamic accounting instrumentation studies .......... 5-2

5.2 .2 Microscopic process monitoring ................. 5-2

5.2.3 Safeguards material balance experiments on the rotary dissolver. . . . 5-3

5.2 .4 Penetration monitoring. . . . . . . . . . . . . . . . 5-3

5.2.5 Participation in the International A tomic Energy Agency's International Working Groups for Reprocessing Plant

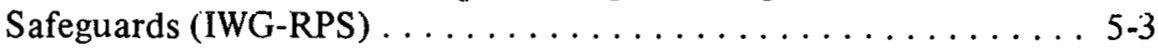

5.2.6 Safeguards demonstration in the Radiochemical Processing

Pilot Plant, Building $3019 \ldots \ldots \ldots \ldots \ldots \ldots$. . . . . . . . . . .

5.2.7 The HEF safeguards system design support. . . . . . . . . . . 5-4

5.3 Nuclear Engineering . . . . . . . . . . . . . . . . . . . 5-5

5.3.1 Interim validation report using existing, breeder-typical, $\mathrm{U}+\mathrm{Pu}$ critical benchmark data $\ldots \ldots \ldots \ldots \ldots \ldots \ldots \ldots$

5.3.2 Interim HEF criticality philosophy report. . . . . . . . . . . . 5-6

5.3.3 Uranium + plutonium solution experiments ........... 5-7

5.3.4 Uranium + plutonium oxide experiment design. . . . . . . . . . 5-7

5.3.5 Interim $\mathrm{HEF}$ in-cell radiation level report $\ldots \ldots \ldots \ldots \ldots \ldots \ldots$ 5-8 
5.4 Instrumentation and Controls Systems . . . . . . . . . . . . . . 5-8

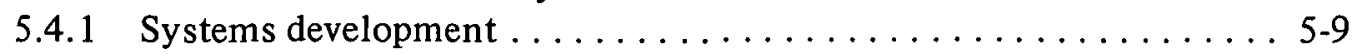

5.4 .2 Sensor development . . . . . . . . . . . . . . . . . . . . . . . 5-9

5.4 .3 Special measurements . . . . . . . . . . . . . . . . . . . 5-10

5.5 Environment and Safety . . . . . . . . . . . . . . . . . . . . . . .

5.6 IET Operational Planning $\ldots \ldots \ldots \ldots \ldots \ldots \ldots \ldots \ldots \ldots \ldots \ldots \ldots \ldots \ldots \ldots \ldots \ldots \ldots \ldots, 12$

References..................................... 5-13

6. HTGR FUEL REPROCESSING $\ldots \ldots \ldots \ldots \ldots \ldots \ldots \ldots \ldots \ldots \ldots \ldots \ldots \ldots \ldots \ldots$

6.1 Studies and Analyses............................. $6-1$

6.1.1 Evaluation of GCFR fuel reprocessing. ................ 6-1

6.1.2 HTGR fuel reprocessing development requirements ......... 6-2

6.1.3 HTGR fuel reprocessing head-end alternatives. . . . . . . . . . 6-2

6.2 Head-End Studies . . . . . . . . . . . . . . . . . . . . . . . . .

6.2.1 United States-Federal Republic of Germany Cooperative

Prograin on graphite-based nuclear fuel reprocessing $\ldots \ldots \ldots 6-2$

6.2 .2 Crushed fuel element burning .................. $6-2$

6.2.3 Particle classification, crushing, and crushed-particle burning ..... 6-3

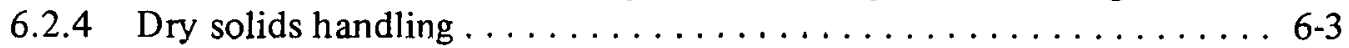

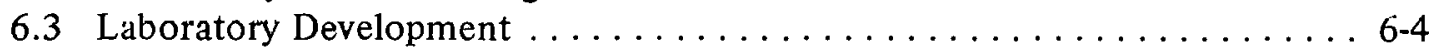

6.3.1 Dissolution of $\mathrm{ThO}_{2}$ in dissolver with airlift recirculator. . . . . 6-4

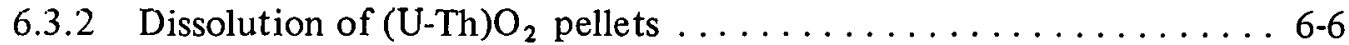

6.4 Hot Laboratory Studies. . . . . . . . . . . . . . . . . . . . . . 6-8

6.4.1 Fuel rod crushing and primary burning. $\ldots \ldots \ldots \ldots \ldots \ldots \ldots, 6,8$

6.4 .2 Long-term fission product volatility $\ldots \ldots \ldots \ldots \ldots \ldots \ldots, 6-8$

6.4.3 Processing of high-level HTGR-specific solid waste . . . . . . . . . 6-9 


\section{FOREWORD}

The DOE has concentrated all U.S. research and development on fuel reprocessing into one major program - the Consolidated Fuel Reprocessing Program (CFRP) - under the management of the Oak Ridge National Laboratory and the Oak Ridge Operations Office.

This progress report is compiled from major contributions from three previous programs: (1) the Advanced Fuel Recycle Program at ORNL; (2) the Converter Fuel Reprocessing Program at Savannah River Laboratory; and (3) the reprocessing components of the HTGR Fuel Recycle Program, primarily at General Atomic and ORNL. The coverage is generally overview in nature. Experimental details and data have been limited (1) to make the report more concise and (2) to meet the requirements which would qualify the report for unrestricted distribution in the open literature (all prior progress reports and most topical reports have been restricted to distribution under the UC-86 Applied Technology category). 


\section{HIGHLIGHTS}

\subsection{Process Research and Development}

\section{B. L. Vondra}

Studies of $\mathrm{Pu}(\mathrm{IV})$ polymerization rates in aqueous solutions have used crystalline $\mathrm{Pu}\left(\mathrm{NO}_{3}\right)_{4} \cdot x \mathrm{H}_{2} \mathrm{O}$ to prepare stock solutions. This development avoids interferences from hydrolysis products or nucleation sites present in traditionally diluted plutonium stock solutions and permits accurate evaluation of the rate process.

A promising new solvent cleanup method has been developed which uses a solid sorbent. This sorbent effectively increases the gross alpha decontamination factor to about 1750 times that obtained by equal volume aqueous wash with carbonate solutions.

The scope of work on product conversion (Task 400) has been increased to provide simultaneous development of gel-sphere and direct-thermal denitration methods at ORNL and a slurry calcination process at Savannah River Laboratory (SRL). The mixed-oxide products from these processes will be evaluated for properties suitable for fuel pellet fabrication and for adaptation to Hot Experimental Facility (HEF) operational requirements.

Performance tests at General Atomic Company on the Sharples vertical centrifuge using simulated light-water reactor (LWR) dissolver solutions were completed.

The third solvent extraction campaign in the Solvent Extraction Test Facility was completed using feed solution prepared from H. B. Robinson- 2 fuels. The first experiment in this campaign was an evaluation of HEF flowsheet conditions for LWR fuel compositions. The balance of the campaign evaluated a new, coextraction-partial partitioning flowsheet in which plutonium is reductively stripped.

A laboratory-scale pulsed-column facility has been installed in the alpha containment at SRL. Cold operations are in progress, and hot start-up is expected in March 1980.

\subsection{Engineering Research}

\section{W. S. Groenier}

New inlet section flights are being fabricated for installation in the full-scale experimental voloxidizer (FSEV) in preparation for an upcoming three-month experimental campaign. These flights consist of triangular sections with dams attached to the back edge and represent the most promising of several designs tested to minimize solids spill into the inlet breaching section of the rotary kiln.

Data from 22 gas-phase heat transfer experiments using a small rotary kiln have been correlated using a mathematical model describing the gas-phase temperature profile. This work is a part of the activity to describe heat and mass transport phenomena in rotary kiln voloxidizers.

A conductivity device has been developed which senses the water content of molecular sieve beds used to remove tritium from voloxidizer off-gases. This sensor appears to be effective in detecting breakthrough condjtions. 
An accelerated voloxidizer rotating seal test has operated successfully for $575 \mathrm{~h}$ in the aligned configuration. This is equivalent to five months of voloxidizer operation.

Initial tests of an air-jet ejector system for the removal of solid particles from a dissolver digester tank have shown that about $95 \%$ of $5-$ to $20-\mu \mathrm{m}$ stainless steel powder can be removed if a pulsed mode of operation is used.

Preliminary studies of in-line monitor requirements in the feed preparation task are concentrating on the use of a small-angle light scattering measurement for a solids monitor (downstream of centrifuges) and gas-phase or condensate analyses for iodine and fluorine monitors (in feed preparation tankage).

Initial hydraulic testing of the new (M-2) $0.5 \mathrm{t} / \mathrm{d}$ centrifugal solvent extraction contactor is complete; results agree with model predictions. Dynamic stability tests were also performed. No efforts will be required to improve dynamic balance, which was acceptable even when hold-down bolts were removed. This indicates that future designs may not require bolting in place, which will simplify remote maintenance procedures.

An analysis of the Series-200 HEF flowsheets was completed using the MATEX solvent extraction computer code. Several potential problems were identified, solutions to these were developed, and recommendations were transmitted.

Tests of an eight-stage Robatel solvent extraction contactor were completed to determine the suitability of this contactor for uranium extraction (stage efficiencies are near $100 \%),{ }^{95} \mathrm{Zr}$ fission product scrubbing [removal is equivalent to that in a $6.7-\mathrm{m}(22-\mathrm{ft})$ pulsed column], and handling of solids in the feed stream [ $1 \%$ solids in the feed led the collection of 100 to $120 \mathrm{~g}$ of 1 to $40 \mu \mathrm{m}$ glass beads in the $3.2 \ell(0.8 \mathrm{gal})$ contactor inventory volume and caused partial aqueous-phase flow blockage]. New data for flow capacity and dispersed phase holdup were obtained for pulsed columns operating in the extraction, scrubbing, and stripping modes of a Purex-type flowsheet. These columns operated in conjunction with the Robatel tests.

Elemental iodine trapping experiments on silver-substituted mordenite ( $\mathrm{AgZ})$ were completed, and trapping tests using methyl iodide were initiated. Preliminary results show iodinc loadings for $\mathrm{CH}_{3} \mathrm{I}$ to be significantly less than the $60 \mathrm{~g} \mathrm{I} / \mathrm{g}$ adsorbent found for clcmental iodine.

The in tegrated HTGR off-gas treatment system is being operated with simulated burner off-gas (BOG) and dissolver off-gas (DOG). The system was physically tied to the burner and dissolver this quarter allowing for future integrated operational campaigns. The $\mathrm{SO}_{2}$ adsorber unit has undergone component testing with hydrogen and sodium forms of Zeolon 900 molècular sicves.

\subsection{Enginecring Systens}

\section{I Feldman}

A computer program used to calculate reprocessing facility costs for the energy center study became operational.

Tests using the rotary dissolver show that the speed of rotation of the drum does not have a significant effect on the outlet stream responses to transients in flow and concentration. 


\subsection{Technical Support}

\section{O. O. Yarbro}

The Consolidated Fuel Reprocessing Program safeguards staff is contributing to the International Atomic Energy Agency International Working Group for Reprocessing Plant Safeguards in areas relating to facility design.

Preliminary calculations for safe dimensions for the Hot Experimental Facility (HEF) plutonium product storage tanks in a slab configuration were completed for use in the conceptual designs. Other geometries are being evaluated.

The prototype in-line neutron poison monitor has been completed and is currently undergoing bench testing and calibration.

Two commercially available flowmeters, one based on ultrasonics and the other on thermal effects, have been tested and found to be accurate to about 1 to $5 \%$ at flow rate near $50 \mathrm{l} / \mathrm{h}$ required for many Hot Experimental Facility applications.

Some preliminary site selection activities for the Hot Experimental Facility were initiated through a subcontract.

\subsection{HTGR Fuel Reprocessing}

\section{B. L. Vondra}

Studies have shown that reprocessing GCFR spent fuel is practicable in the HEF. Since sodium is not used in the GCFR or in the spent fuel shipping concept, the cask unloading and fuel assembly clean-up operations at the HEF, prior to water storage, are simpler and do not involve the HEF sodium waste handling system.

A study of long-term fission product volatility from irradiated fuel has followed the deposition of ${ }^{106} \mathrm{Ru},{ }^{125} \mathrm{Sb}$, and ${ }^{134-137} \mathrm{Cs}$ on metal surfaces during four 30 -d periods. The results are characterized by steep concentration gradients on condenser surfaces maintained at 350 to $500^{\circ} \mathrm{C}$ temperatures. 


\section{PROCESS RESEARCH AND DEVELOPMENT}

\section{B. L. Vondra}

The research and development activities reported in this section provide processing parameters and recommend materials of construction for both the Integrated Equipment Test (IET) and the Hot Experimental Facility (HEF) design efforts; new process options (or steps) are also being explored. An emphasis is placed on solution properties in dissolution and solvent extraction steps, and attention is being given to several aspects of plutonium chemistry and solvent properties. Hot-cell activities involve examining the voloxidation and dissolution properties of a variety of LWR, fast breeder, and thorium fuels. Testing of partial partitioning in solvent extraction flowsheets is proceeding at ORNL in glove-box mixer-settler equipment and in the Solvent Extraction Test Facility (SETF), which has an irradiated fuel capacity in the kilogram-per-day range. Thorium fuels flowsheet testing at Savannah River Laboratory (SRL) is being carried out in mixer-settlers and in a new glove-box pulsed-column facility. The product conversion program is establishing methods for converting mixed-oxide nitrate solutions to fabricable oxide powders. New analytical methods for process control are being developed and adapted where possible for in-line operation. A materials compatibility program is identifying suitable materials of construction for the IET and the HEF.

\subsection{Laboratory Development (ORNL)}

\section{J. T. Bell}

\subsection{1 $\mathrm{Pu}(\mathrm{IV})$ polymer reaction in aqueous solutions}

\section{H. A. Friedman, L. M. Toth, and M. M. Osborne}

The influence of two traditionally accepted variables has been considered in detail. Although the $\mathrm{Pu}(\mathrm{IV})$ concentration and the method of plutonium dilution have been known to affect the rate at which $\mathrm{Pu}(\mathrm{IV})$ polymerizes, the extent has never been more than qualitatively appreciated. Some authors ${ }^{1,2}$ have recognized that the rate of polymer formation was a function of the Pu(IV) concentration; however, the results found with their methods of analysis were inconsistent with other findings. Specifically, the earlier experiments were, in effect, analyzed as "percent polymer" rates.* These, however, should not vary in the initial stages of polymerization, that is, if the rate of polymer formation were first-order with respect to $[\mathrm{Pu}(\mathrm{IV})]$ as reported earlier. ${ }^{3}$ The percent polymer rates

* Fercent polymer raites definted ás: $d / d$ [poly]/[total Pu]. 
have been found to vary considerably with $[\mathrm{Pu}(\mathrm{IV})]$ concentration, thus suggesting that the rate of polymerization is greater than first-order with respect to [Pu(IV)].

Attempts to quantify the influence of sample dilution have not bccn made, probably because a suitable reference point to which dilution experiments could be compared had not been established. Crystalline $\mathrm{Pu}\left(\mathrm{NO}_{3}\right)_{4} \cdot \mathrm{xH}_{2} \mathrm{O}$ has been prepared, and it is now possible to achieve an "ideal" polymerization rate (i.e., from a sample in which hydrolysis products or nucleation sites had not been generated during the preparation of the solution) by dissolving such crystalline material in the $\mathrm{HNO}_{3}$ solution at the desired make-up concentration. All other polymerization experiments made from acid-or water-diluted plutonium stock solutions should be considerably faster. This has been found to be true-the rates in experiments prepared from traditionally diluted plutonium stock solutions are invariably (more than $20 \%$ ) faster than the "ideal" case.

\subsubsection{Plutonium reductive stripping studies}

\section{H. Lloyd and S. E. North}

Studies were continued to cvaluate plutonium reductive stripping behavior using organic feeds that contained both. plutonium and uranium. Ascorbic acid, hydroxylamine nitrate (HAN), and ascorbic acid-HAN mixtures were used as reductants at 25 and $50^{\circ} \mathrm{C}$. Particular attention was again given to dibutyl pholphate (DBP) complexed plutonium, since this species is not effectively reduced and stripped with HAN.

Previous studies with feeds that contained only plutonium showed that plutonium complexed by both tributyl phosphate (TBP) and DBP was stripped effectively at $50^{\circ} \mathrm{C}$ by mixed ascorbic acid-HAN reductants in 0.05 to $2 M \mathrm{HNO}_{3}$, but was not sufficiently stripped in $\gg 1 \mathrm{MINO}_{3}$ at $25^{\circ} \mathrm{C}$. Recent cumparable experiments with $80 \mathrm{~g} / \mathrm{k}$ of uranium in the feed showed that plutonium is effectively stripped by the mixed reductants in 0.02 to $2 \mathrm{M} \mathrm{HNO}_{3}$ at both 25 and $50^{\circ} \mathrm{C}$. High concentrations of uranium ( $80 \mathrm{~g} / \mathrm{l}$ or greater) improves plutonium reductive stripping at $50^{\circ} \mathrm{C}$ when the mixed reductant or only ascorbic acid is used.

\subsubsection{Solvent cleanup}

\section{O. K. Tallent and K. E. Dodson}

A promising new solvent cleanup method using a solid adsorbent has been developed. Tests of the adsorbent were made with both irradiated and unirradiated solvents. The irradiated solvent was passed through a solid adsorbent column initially filled with pure $30 \%$ TBP-70\% dodecane to cover the solid adsorbent. The results showed that the plutonium retention capacity of the solvent was decreased by a factor of 92 from $1.3 \times 10^{-2}$ to $1.4 \times 10^{-4}$ millimoles $/ \mathrm{ml}$ by the column treatment. The gross alpha decontamination factor obtained by the column treatment was about 1750 times greater than that obtained by an equal volume aqueous wash with either $0.23 \mathrm{M}$ sodium carbonate or $0.23 \mathrm{M}$ 
hydrazine carbonate solution. The column treatment was slightly more effective than the aqueous washes for gross gamma decontamination.

\subsubsection{Solvent scrubbing kinetics}

J. C. Mailen, D. E. Horner, S. E. Dorris, and J. K. Storey

The kinetics of solvent scrubbing to remove dibutylphosphoric acid (HDBP), uranium-DBP and zirconium-DBP from 30\% TBP-diluent by various aqueous solutions are being determined. Simulated degraded organics were made by adding HDBP to the TBP-diluent solution. In tests with metal ions, the organic solution was contacted with a nitric acid solution of the metal ion and then scrubbed several times with dilute nitric acid to remove excess metal ions. The data were analyzed assuming pseudo-first-order kinetics for the transfer.

Recent studies have compared results from Lewis cell tests with those using the rising/falling-drop technique. The two methods give equal results, indicating that rate control is chemical and not diffusional. These tests were all run with mixed sodium carbonate and sodium nitrate scrub solutions.

In general, over a concentration range of 0.20 to $0.50 \mathrm{M}$ and at both $\mathrm{pH} 7$ and $\mathrm{pH}$, the scrubbing rate constants for both hydrazine oxalate and hydrazine carbonate were about the same as those obtained using sodium carbonate. Over this range of conditions, zirconium scrubbing was lower than uranium by about a factor of 2 .

\subsubsection{Fission product chemistry}

\section{J. Pruett, L. M. Gray, and W. B. Howerton}

A new effort has been initiated to investigate the solvent extraction behavior of technetium in the Purex process. Exploratory distribution studies using $\mathrm{KReO}_{4}$ as a nonradioactive model for $\mathrm{KTcO}_{4}$ have been carried out to supplement the relatively limited amount of data available in the literature. The distribution of $\mathrm{KReO}_{4}$ between an aqueous phase and a tri- $n$-butylphosphate- $n$-dodecane (TBP-NDD) phase was studied at various concentrations of $\mathrm{HNO}_{3}, \mathrm{NaNO}_{3}, \mathrm{TBP}, \mathrm{HCl}$, and $\mathrm{UO}_{2}\left(\mathrm{NO}_{3}\right)_{2}$ in the system. The effect of varying the ratio of the volumes of the aqueous and organic phases was also investigated. The results of these experiments will be the basis for planning a similar series of experiments with $\mathrm{KTcO}_{4}$.

Polarographic techniques are being investigated to determine their potential as tools for understanding the chemistry of selected fission products. Results for $\mathrm{KReO}_{4}$ show a strong dependence of the limiting current and the half-wave potential $\left(E_{1 / 2}\right)$ on the nature of the supporting electrolyte. In perchloric acid, the limiting current increases with increasing acid concentrations, whereas $E_{1 / 2}$ becomes more anodic. The polarographic wave is distorted by large maxima, except in a narrow range of acid concentrations around $4 M$ $\mathrm{HClO}_{4}$. Lower concentrations of $\mathrm{KReO}_{4}$ increase the range of acid concentrations that yield 
undistorted polarograms. These results, which are similar to those obtained by carlier investigators, demonstrate the reliability of the equipment.

\subsubsection{Interphase transfer kinetics of uranium using tri-2-ethylhexyl phosphate D. E. Horner, J. C. Mailen, and J. K. Storey}

Lewis cell tests are being used to examine the interphase transfer kinetics of uranium between nitric acid and organic phases containing tri-2-ethylhexyl phosphate. Rates in both the aqueous-to-organic and organic-to-aqueous are being determined as functions to TEHP, $\mathrm{HNO}_{3}$, and neutral nitrate concentrations.

Preliminary results of transfers between $3.5 \mathrm{MHNO}_{3}$ and 0.05 to $0.75 \mathrm{MTEHP}$ in normal paraffin hydrocarbon indicate that the transfer rates are about a factor of 5 lower than those found in comparable tests using TBP. However, the transfer rates are still very high. If these lower rates are confirmed, solvent extraction studies in more typical process sunlatiurs will he nẹded to aseese the implication of this iffect.

\subsubsection{Spent solvent recycle}

\section{W. Holladay and W. D. Bond}

The multistage mixer-settler apparatus previously used for Purex extractions was found to be unsatisfactory for evaluating hydrazine salt solutions as solvent washing agents. Construction of simpler apparatus consisting of two mixer-settler stages is nearing completion. The material of construcion is glass which permits visual observations and easy clean-out of precipitates of "cruds" when necessary. Experimental variables to be studied include (1) $\mathrm{pH}$ values of hydrazine salt (oxalate or carbonate) solutions, (2) hydrazine concentration, (3) organic-to-aqucous flow ratios, (4) loading capacity of scrub liquid, (5) mixing speed, and (6) temperature. Initial studies are being conducted with simulated process solvent consisting of $30 \%$ TBP-NPH, $0.01 M \mathrm{HNO}_{3}, 0.001 M$ HDBP (dibutylphosphoric acid), and $0.000 \mathrm{I} M \mathrm{H}_{2} \mathrm{MBP}$ (monobutylphosphoric acid). After operating windows for key process parameters are identified, zirconium and uranium compounds of alkylphosphoric acids will be added to the spent solvent.

\subsubsection{Aqueous recycle}

\section{W. D. Arnold, W. D. Bond, and F. M. Scheitlin}

A literature survey is being conducted to identify impurities with the greatest potential for buildup in recycle nitric acid. The purpose of the survey is to determine areas where experimental data are lacking. Results thus far indicate that little attention has been given to the buildup of impurities other than organic compounds. Some work has been dont in regard to the behavior of chloride and fluoride in the recovery of nitric acid by distillation. A small nitric acid recovery facility, which successfully controls the buildup of chloride and fluoride ions in recycle acid, is currently being operated at the Y-12 plant. 


\subsubsection{Nitrogen compound chemistry}

\section{R. Bennett}

Tests have been conducted to confirm that nitrogen is one of the gaseous products of the reaction between hydroxylamine nitrate (HAN) and nitric acid.

These tests at room temperature did indeed confirm the presence of nitrogen and showed that its concentration in the gaseous phase was about $15 \mathrm{vol} \%$; the remainder was $\mathrm{N}_{2} \mathrm{O}$. Since then, measurements of the concentrations and the ratio of the two gases as a function of temperature up to $80^{\circ} \mathrm{C}$ have disclosed that both are independent of temperature and that the combined volume of the two gases is equivalent to the stoichiometric quantity of 0.5 moles/mole of HAN consumed.

\subsubsection{Evaluation of alternate extractants}

\section{W. D. Arnold and F. I. Case}

Evaluations of alternate extractants to TBP have continued. Initial test results indicate that some of them have potential advantages over TBP, including much lower aqueous-phase solubility and a lower tendency to third-phase and precipitate formation. The stability to acid hydrolysis is much greater than that of the TBP. During this quarter, tests were conducted to compare the extractants with regard to ${ }^{95} \mathrm{Zr}-{ }^{95} \mathrm{Nb}$ extraction properties and to radiolytic and hydrolytic stability in the presence of uranium.

\subsection{Laboratory Development (General Atomic Company)}

\section{R. D. Zimmerman and G. E. Benedict}

\subsubsection{Vertical centrifuge testing}

\section{J. Olguin}

The Sharples vertical centrifuge performance tests with simulated LWR dissolver solutions were completed. The following conclusions apply to the range of operating conditions under which these tests were performed:

1. The Sharples centrifuge is capable of removing $100 \%$ of the particles larger than $4 \mu$ in diameter from the simulated dissolver slurries.

2. To obtain optimum separation efficiency, the centrifuge g-force and the solids concentration should be high, and the liquid-phase density should be low.

3. The effect that particle density has on separation efficiency also depends on the physical shape of the particle. Particles with irregular shapes have increased drag, and once they collect on the bowl wall, they have less tendency to re-enter the effluent stream.

Future tests with the vertical centrifuge will be performed in conjunction with a cross-flow inertia filter to increase the efficiency of submicron particulate removal. 


\subsubsection{Zirconium scrubbing kinetics}

G. E. Benedict, G. J. Hosbjor, and R. G. Wilbourn

Experiments were initiated to study the scrubbing of zirconium with nitric acid from $30 \%$ TBP solutions that contain uranium. The organic-phase uranium levels selected for study are equivalent to 40,60 , and $80 \%$ of solvent saturation. The work is being done to determine whether nitric acid concentration and solvent saturation have a significant influence on zirconium transfer rates being measured by the rising-drop technique. Thirteen tests were completed using column lengths of 30 and $60 \mathrm{~cm}$ to give variable drop-residence times. Zirconium analyses and data reduction are not yet complete.

\subsubsection{Effect of uranium and zirconium on TBP hydrolysis}

R. G. Wilbourn and G. E. Benedict

In continued studies of the rate of TBP liydrolysis, the cffects of nitruus acid, tetravalent uranium $\left(\mathrm{U}^{4+}\right)$, and small amounts of zirconium on the hydrolysis rate were determined.

Nitrous acid was found to have an insignificant effect on the TBP hydrolysis ratc. The rate of dibutyl phosphate (DBP) and monohutyl phosphate (MBP) formation in the presence of organic-phase $\mathrm{HNO}_{2}$ at concentrations to $0.63 \mathrm{M}$ was determined to bc $<3$ $\mathrm{ppm} /$ day.

Test results with zirconium showed that zirconium at a concentration of only about 1 $\mathrm{g} / \mathrm{l}$ greatly enhanced the TBP hydrolysis rate. This supports the earlier findings of a large zirconium effect in tests made at $0.1 \mathrm{M}$ zirconium concentration.

Since some solvent extraction flowsheets rely on the production of tetravalent uranium as a plutonium reductant, the effect of $\mathrm{U}^{4+} \cap n$ TBP hydrolysis was determined. The effect of $\mathrm{U}^{4+}$ was large, in fact much larger than was obtained previously with an equivalent amount of thorium in the solvent phase.

\subsubsection{Titrimetric determination of thorium in solvent extraction process solutions}

\section{R. G. Wilbourn and S. A. Dunlap}

The feed solutions prepared for use in planned solvent extraction runs contain uranium and thorium. The initial heavy metal ratio in the first column aqueous feed (1 AF) has a uranium-to-thorium ratio of about 10:1. This high level of unanium muy causic interference in the direct EDTA thorium titrimetric procedure in use at GA; consequently, an indirect method was evaluated for possible use.

In the indirect approach, a known excess of $0.1 \mathrm{M}$ EDTA is added to samples, and the amount of free EDTA remaining following thorium complcxation at $\mathrm{pH} 10$ is Jelermined by titration with $0.01 \mathrm{M}$ cadmium nitrate solution. The addition of ascorbic acid is required to maintain uranium in a soluble form at $\mathrm{pH} 10$. A cadmium specific ion electrode is used to determine the titration end point. A sharp break in the potential measured for the 
cadium ion-reference electrode couple occurs at about $340 \mathrm{mV}$; this value is used as the end point.

The results of titration tests with standards having a constant concentration of thorium but different uranium concentrations showed no interference from uranium up to a uranium-to-thorium mole ratio of about 15 . The sharp inflection at the end point permits an accurate and precise measurement of thorium in process solutions.

\subsubsection{Thorium determination by neutron activation of ${ }^{232} \mathrm{Th}$}

\section{S. A. Dunlap}

The success of a previously reported method for the measurement of low-level uranium by neutron activation analysis prompted a study of a similar approach for the determination of thorium. The method is based on the following reaction:

$$
{ }^{232} \mathrm{Th} \text { irradiation }{ }^{233} \mathrm{~Pa}
$$

The gamma energy due to ${ }^{233} \mathrm{~Pa}$ is determined by gamma ray spectrometry. The sensitivity of the method for thorium was found to be inadequate to permit a low-level measurement (lower limit of detection $\sim 0.1 \mathrm{~g} / \mathrm{\ell}$ ). The poor sensitivity is due in part to the lower specific activity of the isotope ${ }^{233} \mathrm{~Pa}$ (as compared to ${ }^{239} \mathrm{~Pa}$ formed in the uranium determination).

\subsection{Savannah River Laboratory Process Development}

\section{J. D. Spencer and S. F. Peterson}

\subsubsection{Coprocessing to breeder concentrations}

\section{C. Thompson}

Two miniature mixer-settler tests of a flowsheet to produce a plutonium product with $25 \%$ plutonium as a percent of heavy metals with $U($ IV) as reductant were completed. Although the products contained 28.5 and $28.0 \%$ plutonium, losses to the uranium product were high (3.78 and $0.57 \%$ ).

The first test involved multiple acid strip streams. The desired acidity in the product was 2.5 to $2.8 \mathrm{M}$; however, the observed acidity was $4.22 \mathrm{M}$. The high acidity meant that the product contained less uranium and more plutonium than desired. The high acidity in the mixer-settler caused high plutonium distribution coefficients and thus, high plutonium in the uranium product.

In the second test, only one strip stream was used to reproduce the earlier test. Plutonium in the uranium stream was less than one tenth of that found in the previous test. 
Stage analyses indicated that all the U(IV) was consumed before it reached the lower stages. Additional U(IV) could reduce the plutonium in the uranium stream to an acceptable range.

\subsubsection{Low decontamination flowsheet M.C. Thompson}

Additional results from earlier tests of the low decontamination flowsheet confirmed

the trends reported previously, that is, ${ }^{106} \mathrm{Ru}$ decontamination factor (DF) increases, ${ }^{154} \mathrm{Eu}$ DF decreases, and ${ }^{137} \mathrm{Cs}$ DF is unaffected by increasing acid concentration in the feed at constant flow ratios. Changes in organic saturation with uranium at constant $2 \mathrm{M} \mathrm{HNO}_{3}$ in the feed had no effect on ${ }^{137} \mathrm{Cs}$ or ${ }^{154} \mathrm{Eu}$ decontamination. The ${ }^{106} \mathrm{Ru}$ decontamination changed little, although an increase was expected between 56 and $66 \%$ saturation.

\subsubsection{Tritium remuval tests}

\section{J. B. Pickett}

Tests of tritium removal, dissolution, and residue characterization continued in the SRL High-Level Caves with Elk River Fuel. Initially, 95.4\% $\mathrm{ThO}_{2}-4.6 \% \mathrm{UO}_{2}$ irradiated to about $12,000 \mathrm{MWd}$ and cooled for about 12 years. These tests have been used to determine the effects of particle size, heating temperature and time, oxidation (with air or oxygen), heating under vacuum or inert gas, and agitation.

Four tests were completed in the voloxidation equipment in cell 8 , and two were completed in cell 13 with glass roasting and dissolution equipment. These tests were made to study what effects, if any, that heating several different particle-size fractions (at $600^{\circ} \mathrm{C}$ for $10 \mathrm{~h}$ and in the presence of air) would have on tritium removal. The evolved tritium was collected on molecular sieves; the tritium remaining with the thoria-urania material was determined following dissolution in Thorex solution. The results of these tests indicate that tritium removal is significantly more difficult with thorium-based fuels than with uranium-based fuels.

\subsubsection{Studies of alternative extractants}

\section{J. Reif, M. C. Thompson, and J. R. Cadieux}

A litcrature survey of alternative extractants for coprocessing flowshccts was completed. Several likely candidates were selected for lab-scale experiments.

$\mathrm{N}, \mathrm{N}$-disubstituted amides studied by Siddall and coworkers ${ }^{4,5}$ were better than TBP in many respects. In particular, $\mathrm{N}, \mathrm{N}$-dihexyl octanamide was most promising for process applications.

$\mathrm{N}, \mathrm{N}$-diethyl dodecanamide will also be tested. Distribution coefficients for a number of metal ions, including $\mathrm{Th}^{4+}, \mathrm{U}^{6+}$, and $\mathrm{Zr}^{4+}$ have been measured for this reagent. Recent data $^{6}$ suggest that esters of phosphorous and hypophosphorous acids may have advantages as extractants. The affinities of these compounds for uranium, plutonium, and thorium lie 
between those of trialkyl phosphates and trialkyl phosphine oxides. The hexyl esters of both acids, $\mathrm{C}_{6} \mathrm{H}_{13}\left(\mathrm{C}_{6} \mathrm{H}_{13} \mathrm{O}\right)_{2} \mathrm{PO}$ and $\left(\mathrm{C}_{6} \mathrm{H}_{13}\right)_{2}\left(\mathrm{C}_{6} \mathrm{H}_{13} \mathrm{O}\right) \mathrm{PO}$, and the ethyl-substituted ester, $\mathrm{C}_{2} \mathrm{H}_{5}\left(\mathrm{C}_{2} \mathrm{H}_{5} \mathrm{O}\right)_{2} \mathrm{PO}$, will be tried as extractants.

$\therefore$ Laboratory preparations for the synthesis and purification of the $\mathrm{N}, \mathrm{N}$-dihexyl octanamide were begun. Complexometric and potentiometric titration procedures for thorium and uranium have been set up to expedite scouting experiments.

\subsubsection{Pulsed-column facility}

\section{J. Reif, M. C. Thompson, and J. R. Cadieux}

A laboratory-scale Pulsed-Column Facility (PCF) within alpha containment is nearing completion. The design work has been completed, and installation is about $80 \%$ complete. Cold operation was begun, and hot startup is expected in March 1980. On-line monitoring systems for hot operation are being designed based on mixer-settler tests. A system using gamma detection for on-line assay of plutonium is promising.

The PCF is composed of four 1-in.-diam, 7- to 8-ft-high columns. Two of the columns have multiple feed points, one is end fed only, and the fourth is an electropulse column for producing $\mathrm{U}(\mathrm{IV})$ from $\mathrm{U}(\mathrm{VI})$. The columns will be pulsed pneumatically with variable frequency and amplitude. The total flow of the combined phases will be about $250 \mathrm{ml} / \mathrm{min}$. All feed lines will be equipped with heat exchangers to control fluid temperature. In addition to the extraction contactors, containment will include a batch solvent washing system and an evaporator-condenser for recovery and reuse of heavy metals. All cold feeds will be delivered from a hood outside of the containment area.

The PCF includes on-line devices for monitoring exit stream density, alpha activity, and gamma activity. In addition, feed and column temperatures and feed flow rates are measured continuously. All monitoring systems are read by dedicated microprocessors programmed to provide desired outputs.

\subsubsection{On-line monitoring systems}

\section{J. R. Cadieux}

A low energy photon (LEP) spectrometer which will be used for on-line measurement of plutonium concentrations in PCF process streams was received and tested. The system includes an intrinsic germanium detector with a large active area $\left(>2000 \mathrm{~mm}^{2}\right)$, a 4096-channel Pulse Height Analyzer (designed and fabricated at SRL), and a PET microcomputer controller.

Preliminary tests were completed on both "bagged out" samples and liquid streams from solvent extraction tests with minimixer-settlers. For process stream tests, the plutonium solutions (1BP stream, not coprocessed) were surveyed while passing through a stainless steel loop. Experiments with coprocessed solutions are planned, and a plastic flow cell is being designed. This cell will reduce the absorption of low-energy gamma-rays by the loop and take full advantage of the active area of the detector. Plutonium sensitivity should increase fivefold. 


\title{
2.3.7 Joint SRL-PNL thorium irradiation program
}

\section{J. B. Pickett, J. L. Steimke, and D. S. Cramer}

A joint program between the Savannah River Laboratory (SRL) and Battelle-Pacific Northwest Laboratory (PNL) has been defined to prepare and characterize irradiated $\mathrm{ThO}_{2}-\mathrm{UO}_{2}$ reference case ceramic fuel pellets. The test material will be a proliferation-resistant composition of $80 \% \mathrm{ThO}_{2}-20 \% \mathrm{UO}_{2}$. The irradiated materials will be used for head-end, dissolution, and extraction studies at SRL; irradiation performance will be characterized by PNL.

The original irradiation plan called for the test assemblies to be inserted in a Savannah River Plant production reactor in May 1980. This irradiation has been delayed until July 1980 due to the sequential steps required for the sol-gel hybrid pellets (i.e., $2.07 \%{ }^{235} \mathrm{U}$ production, sol-gel microsphere preparation at ORNL, and hybrid pellet fabrication by PNL). The delay had been anticipated earlier, therefore the original uranium enrichment was reduced to compensate for the irradiation beginning at the second reactor subcycle. The current plan will provide approximately 6 months exposure with a burnup of about $14,000 \mathrm{MWd} / \mathrm{MTHM}$ for most of the material.

The axial neutron flux for the two test assemblies has been calculated, beginning at the second subcycle. Based on the calculated flux distribution, the 30 -in. rodlets will be loaded to provide the desired heating profile. Two of the rodlets will experience 16 to $18 \mathrm{~kW} / \mathrm{ft}$; at least half of the pellets in the third rodlet in each column will not exceed a nominal heat rating of $16 \mathrm{~kW} / \mathrm{ft}$. This design is calculated to provide irradiated pellets which have not been thermally restructured. Most of the material, however, will experience an average temperature similar to that expected in commercial LWR's operating at approximately 14 $\mathrm{kW} / \mathrm{ft}$.

\subsection{Hot-Cell Development (ORNL)}

\author{
V. C. A. Vaughen
}

\subsubsection{Flowsheet parametrics for mixed-oxide fuels}

J. H. Goode, R. G. Stacy, J. R. Travis, and C. S. Webster

Shearing parametrics. Shearing of the $\mathrm{P}-15\left[(\mathrm{U}, 20 \% \mathrm{Pu}) \mathrm{O}_{2}\right], 1300 \mathrm{GJ} / \mathrm{kg}(15,000 \mathrm{MWd} / \mathrm{t})$ fuel was started during this report period to provide feed materials for parametric voloxidation and dissolution experiments in the next quarter. Cutting of the rods into $12.7 \mathrm{~mm}$ (0.5-in.)-long pieces released about $36 \%$ of the total fuel contents, of which about $40 \%$ was in fragments sized larger than $1 \mathrm{~mm}$. In comparison, as much as $65 \%$ of the dislodged, higher burnup PNL-3 mixed-oxide fuel was larger than $1 . \mathrm{mm}$. 
Dissolution parametrics. Ten dissolution experiments were made with the low sintering temperature $\left(\sim 1540^{\circ} \mathrm{C}\right) \mathrm{PNL}-3$ fuel $\left[(\mathrm{U}, 25 \% \mathrm{Pu}) \mathrm{O}_{2}, 5200 \mathrm{GJ} / \mathrm{kg}(60,000 \mathrm{MWd} / \mathrm{t})\right]$ using nitric acid. Three similar dissolutions were made with the high-sintered fuel $\left(1650-1675^{\circ} \mathrm{C}\right)$. The amounts of undissolved plutonium were about $1 \%$ for both cases, as determined by a final $8 \mathrm{M}$ $\mathrm{HNO}_{3}-0.05 M \mathrm{HF}$ leach. After the final leaches, the residues weighed about $2 \%$ of the original $(\mathrm{U}+\mathrm{Pu})$ weight and contained less than $0.1 \%$ of the original $\mathrm{Pu}$.

\subsubsection{Fuel procurement}

\section{J. H. Goode}

About $50 \mathrm{~kg}$ of irradiated Dresden-1 (BWR) fuel has been received for use in the Solvent Extraction Test Facility (SETF). The procurement of a short-cooled Brown's Ferry (BWR) fuel element was delayed by cask certification problems. The Interagency Agreement between the Department of Energy and the Tennessee Valley Authority has been extended to obtain a short-cooled element in FY 1980. Also, negotiations have been initiated with the Babcock and Wilcox Company for the procurement of Cycle-4 Oconee fuel. Negotiations were started with Hanford Engineering Development Laboratory (HEDL) for the procurement of irradiated advanced oxide breeder fuel types for hot-cell studies.

Calculations using the ORIGEN code were made for the purpose of estimating the fission product contents of the four batches of HEDL P-15 fuel rods that will be used in the hot-cell parametric studies.

\subsubsection{Scouting studies with carbide fuels}

\section{J. H. Goode, R. G. Stacy, J. R. Travis, and C. S. Webster}

Oxidation tests of declad, unirradiatcd uranium carbide (UC) fuel were made at several temperature levels $\left(450,600\right.$, and $\left.700^{\circ} \mathrm{C}\right)$ and feed gas oxygen concentrations $(9,21$, and $100 \% \mathrm{O}_{2}$ ). To date, the runs with greater $>840 \mu \mathrm{m}$-sized fragments have indicated that $450^{\circ} \mathrm{C}$ and the lower feed gas $\mathrm{O}_{2}$ concentrations (9-21\%) were not sufficient to complete the conversion of uranium carbide to $\mathrm{U}_{3} \mathrm{O}_{8}$; product weight gains and analyses of the off-gas for $\mathrm{CO}-\mathrm{CO}_{2}$ content indicated less than $50 \%$ of the $\mathrm{UC}$ had reacted. Both $\mathrm{x}$-ray diffraction tests on the product (which indicated that only about half of the uranium was converted to $\mathrm{U}_{3} \mathrm{O}_{8}$ ) and chemical analysis (which indicated that about half of the original carbon was still present in the product) suggested that the reacted $U C$ formed $\mathrm{U}_{3} \mathrm{O}_{8}$ while the remainder was unaffected.

In another test using $\mathrm{CO}_{2}$ as the principal oxidant gas, the temperature was stepped at 100-degree increments (between 500 and $800^{\circ} \mathrm{C}$ ) over a 5 -h period. About $84 \%$ of the product from the $\mathrm{CO}_{2}$ oxidation was smaller than $75 \mu \mathrm{m}$ and was identified of $\mathrm{UO}_{2}$. The remaining sieve fractions of product from that run were identified as unreacted $U C$ or as $\mathrm{UC}-\mathrm{UO}_{2}$ mixtures.

Oxidations made at 600 and $700^{\circ} \mathrm{C}$ resulted in larger product weight gains (90 to $100 \%$ of theoretical based on complete conversion to $\mathrm{U}_{3} \mathrm{O}_{8}$ ). Chemical analysis indicated that less 
than $0.5 \%$ of the carbon remained in the product. The initial heatup was made in air and ended with $100 \%$ oxygen. When $100 \%$ oxygen was used at the start, the UC ignited and burned too rapidly for control of the temperature, as implied by the evolution of large fractions of $\mathrm{CO}$ in the off-gas. During one run made with $<150-\mu \mathrm{m}$ sized UC fines, the uncontrolled burning at the start was hot enough to melt a $1 / 4$-in. hole in the sintered stainless steel frit on the inlet side of the reaction chamber.

Dissolution studies. Fragments of UC and two of the products (one fully oxidized, one

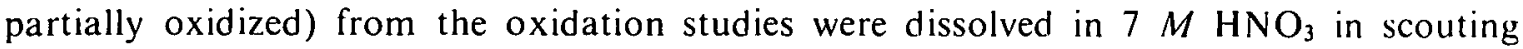
studies to develop methods suitable for in-cell use. Stepwise addition of the acid was necessary to control the vigorous reaction when unoxidized UC was present; the $\mathrm{U}_{3} \mathrm{O}_{8}-\mathrm{HNO}_{3}$ reaction was easily controlled. The consumption of nitric acid varied with the amount of carbon present: pure UC. 5.1 mole $\mathrm{H}^{+} /$molc uranium dissolved; partly uxidized UC-3.4 mole $\mathrm{H}^{+} /$mole uranium dissolved (run $\mathrm{CFR}-\Lambda$ ); and oxidized UC-2.9 mole $\mathrm{H}^{\prime}$ /mole uranium dissolved (run CFR-D). When the partly oxidized $\mathrm{UC}-\mathrm{U}_{3} \mathrm{O}_{8}$ mixture from run CFR-A was dissolved, about $70 \%$ of the total carbon was found in the sodium hydroxide scrubber, and the remainder was found in the solution. Carbon compounds which remained in the solution during dissolution of pure UC may have accounted for the precipitation of roughly $5 \%$ of the uranium as a uranyl organic compound upon standing.

\subsubsection{Development of the CONSEPT program for process control flowsheet testing}

\section{A. D. Mitchell}

The CONSEPI program is a new computer model for CONtroller-run Solvent Extraction Process Testing. Programming problems with the plutonium reduction reactions encountered last quarter, arose when the mechanics of plutonium reduction were adapted from the SEPHIS-MOD4 program. The overall mass balances for the plutonium did not close because the reaction products were calculated separate from the stage-wise mass balances. The problem was resolved by turning the term for the integrated extent of reaction into a constant generation term in the mass balance. Solving the mass balance produces a complex weighting factor for the generation term. The weighting factonr is a function of the aqueous flow rate and volume of the stage. This method has been tested and works satisfactorily.

\subsubsection{Plutonium flowsheet tests}

\section{W. D. Bond and B. A. Hannaford}

A second flowsheet experiment (run PX-3) was completed with a feed solution that had a U:Pu ratio typical of LWR fuel solutions. The flowsheet included coextraction with $30 \% \mathrm{TBP}$ in normal paraffin hydrocarbon (NPH) diluent in the first mixer-settler bank, partial partitioning in the second bank using hydroxylamine nitrate (HAN) with hydrazine (HYE) holding reductant for reducing plutonium, and uranium stripping in the third bank 
(Fig. 2.1). The experimental conditions for run PX-3 were almost identical to those for an earlier run (PX-2) except that the acid concentration of the scrub solution (1 AS) was about 1 $M$ instead of $0.5 \mathrm{M}$. The effect of varying the strip solution (1BX) flow rate on product composition was examined in this run. In the earlier run (PX-2), the amount of uranium stripped with the plutonium was controlled primarily by varying the organic backscrub ( $\mathrm{BSS})$ flow rate.

The experimental response of uranium concentration in the product stream was somewhat weakly coupled to the $1 \mathrm{BX}$ rate. The $\mathrm{Pu} /(\mathrm{U}+\mathrm{Pu})$ ratio at the end of the run was near a steady value of 0.25 . Plutonium losses to exit streams $1 \mathrm{AW}, 1 \mathrm{CU}$, and $1 \mathrm{CW}$ were 0.0003 , 0.006 , and $0.004 \%$ respectively. The losses generally continued to decrease with time.

Two Mettler densitometers monitored the B bank (Fig. 2.1). For the 1 BP product stream a flow-type electrical conductivity cell supplied by J. E. Strain of the ORNL Analytical Chemistry Division provided an excellent measure of acid concentration. The resulting calculation of heavy metal concentration from density measurements and acid concentration provided the information needed for composition control. Metal concentrations, as calculated, were biased on the high side by about 1 to $2 \mathrm{~g} / \mathrm{l}$ at the 15 to $19 \mathrm{~g} / \mathrm{l}$ level, which is not

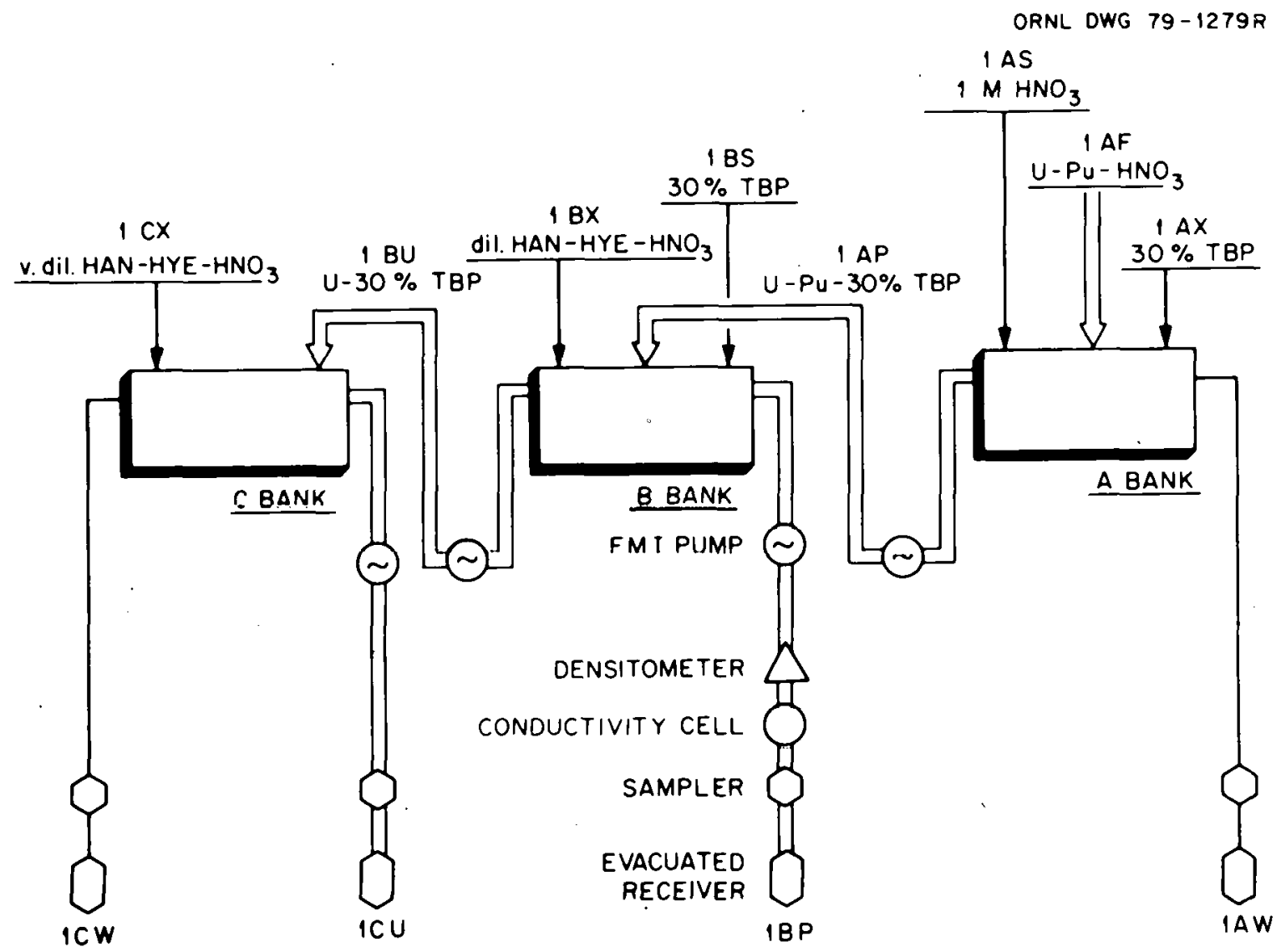

Fig. 2.1. Equipment flowsheet for plutonium-uranium partitioning experiment PX-3. A bank: 6 extraction stages, 10 scrub stages; $B$ bank: II partitioning stages, 5 organic backscrub stages; $C$ bank: 16 strip stages. Densitometer for middle backscrub stage not shown. 
a significant error for control purposes. The second Mettler densitometer was used to continuously monitor the heavy metal concentration of the organic phase in the middle stage of the organic backscrub section. It accurately measured heavy metal concentration to within $0.6 \mathrm{~g} / \mathrm{l}$ at the $48 \mathrm{~g} / \mathrm{l}$ level.

\subsubsection{Solvent Extraction Test Facility}

L. J. King, D. E. Benker, J. E. Bigelow, E. W. Brown, E. B. Cagle, F. R. Chattin, E. D. Collins, S. C. McGuire, D. B. Owsley, R. G. Ross, H. C. Savage, R. C. Shipwash, C. E. Waddell, and A. V. Wilder

The third SETF campaign was completed in December 1979. The campaign included three experiments, each consisting of a scrics of solvent extraction test runs. The first experiment, $3-S X-1$, was an evaluation of HEF flowshect conditions for LWR fucl compositions. The second and third experiments of the campaign, 3-SX-2 and 3-SX-3, evaluated a new, coextraction-partial partitioning flowsheet in which the plutonium is reductively stripped using nitrous acid as the reducing agent.

Experiment 3-SX-1. In this experiment, the coextraction-costripping and partial partitioning cycles of the HEF flowsheet were evaluated using a feed solution prepared with LWR fuel from the $H$. B. Robinson-2 reactor.

The flowsheets for the codecontamination and partitioning cycles were similar to those described earlier for processing FBR fuels except that the acidity in some stages was changed and HAN reductant was not included in the strip solutions. On the hasis of end stream samples, the latter changes did not cause any apparent difficulty (yields of stripped plutonium and uranium were $99.992 \%$ and $99.55 \%$ ). However, stage samples showed that the effectiveness of the stripping was significantly less than'in the earlier test with reductant present.

The codecontamination cycle product solution was divided into three batches. Each one was processed through a batch reduction of plutonium, followed by solvent extraction at a temperature of $28^{\circ} \mathrm{C}$ to selectively extract most of the uranium. These runs showed better results at lower acidities.

Experiments 3-SX-2 and 3-SX-3. The flowsheet for these experiments included (1) coextraction and scrubbing of the uranium and plutonium in the A-bank. (2) partial partitioning in the B-bank, and (3) an organic backscrub stream to regulate the fraction of uranium stripped with the plutonium. The balance of the uranium was stripped in the $\mathrm{C}$ bank.

In two runs demonstrating partial partitioning in the first cycle, the yields of stripped plutonium and uranium in the B-bank ranged from 90.90 to $90.93 \%$ and 11.7 to $14.6 \%$ respectively (concentration factor of 6.7-8.2). About $97 \%$ of the plutonium leaving the B-bank in the solvent stream was stripped with the uianium in the C-bank. In the second uranium cycle, the B-bank product solution (U,Pu) contained $99.96 \%$ of the plutonium and $11.3 \%$ of the uranium fed to that cycle. This solution would be recycled. In demonstrating the second plutonium cycle, again using the same flowsheet, yields of stripped plutonium were $99.97 \%$ and $4.8 \%$, respectively, and the concentration factor (CF) was 9.3 . 
Results from the 3-SX-2 test series indicate that two cycles of partial partitioning can give high yields of plutonium and a $U /(U+P u)$ concentration that is higher than $25 \%$.

\subsubsection{Alternatives to voloxidation \\ D. O. Campbell and W. L. Pattison}

Three additional heat treatment experiments were completed with LMFBR fuel from EBR-2. These included tests in different non-oxidizing atmospheres.

Although tritium results are not yet complete, there appears to be some correlation of tritium retention with time and temperature, but probably not with the gas atmosphere. The total tritium found is much less with LMFBR fuel than with LWR fuel, typically about $4 \times 10^{3} \mathrm{~Bq} / \mathrm{g}$ fuel of dissolved compared to about $7 \times 10^{6}$ because nearly all the tritium is lost from the fuel during irradiation in LMFBR's. The total tritium found was about $2.2 \times$ $10^{4} \mathrm{~Bq}( \pm 20 \%)$ except in two experiments, F3 and F4, and these two differed by factors of about 3 , one higher and one lower.

In a few cases, a very small amount of tritium was detected in solutions from dissolution of cladding, but this was never more than $5 \%$ of the total present. In contrast, half or more of the ${ }^{14} \mathrm{C}$ found was associated with cladding.

In general, it appears that high temperatures and long periods of time are necessary for removing $90 \%$ of the tritium from LMFBR fuel. At very high temperatures, tritium is removed more effectively, but there is also appreciable volatilization of gamma-emitting fission products, especially cesium and ruthenium. Thus, suitable conditions for tritium removal by nonoxidative heat treatments occupy a narrow range.

The insoluble residue remaining after dissolution in $7 \mathrm{M} \mathrm{HNO}_{3}$ constituted about $0.8 \%$ of the weight of fuel. In addition, there was a residue from dissolution of the cladding in 9 $M \mathrm{HCl}$, which amounted to about $1.5 \%$ of the cladding weight. There was no apparent correlation between the weight of insoluble material and the heat treatment conditions.

\subsection{Product Conversion}

\section{R. E. Norman}

This task is focused on the development of engineering technologies for converting $\mathrm{U}-\mathrm{Pu}$ in nitrate process streams to solid oxides suitable for fuel pellet fabrication. Two product conversion methods, gel-sphere and direct-thermal denitration, have been selected for simultaneous development at ORNL. A third method, using a slurry calcination process, is under development at SRL. These, together with other candidate processes, will be evaluated as a preliminary step toward selecting a reference process for the HEF.

\subsubsection{Gel-sphere conversion development}

The gel-sphere conversion process utilizes internal gelation in the preparation of $\mathrm{UO}_{2}=\mathrm{PuO}_{2}$ spheres. An ammonia donor and a complexing agent are mixed with the 
heavy-metal nitrate solution at a temperature near $0^{\circ} \mathrm{C}$ to form a broth. Gelation of broth droplets occurs rapidly in an immiscible liquid at $>40^{\circ} \mathrm{C}$. Previous work on this process under the Fuel Refabrication and Development Program provides a good base for specific equipment concepts and technology required for its application in the HEF.

Chemical flowsheet development (M. H. Lloyd, E. D. Collins, R. L. Fellows, S. E. Shell, S. A. McCosh, and D. H. Newman). A variety of experiments with both pure uranium feeds and plutonium-uranium feeds $(\mathrm{Pu} / \mathrm{U}+\mathrm{Pu}=0.25)$ have shown that most characteristics, both before and after sintering, are strongly dependent on the urania crystallite composition and morphology that develops during sphere gelation and drying. It was also shown that the urania crystallite morphology can be varied from very small rod-shaped crystals $(\sim 80-\AA$ wide and $900-\AA$ long) to larger platelet crystals $(\sim 1000 \AA$ to $8000 \AA$ in diameter) by appropriate alterations in the chemical makeup of the broth, the physical process variables, and the drying procedures.

The primary emphasis in present development studies is to prepare gel-derived feed material for pellet pressing; medium-sized microspheres (sintered diameter $=200$ to $400 \mu$ ) are considered to be preferable. Efforts to prepare this size range in existing glove box equipment (with only minor modifications) have not been successful; however, a forming system for producing the smaller spheres is being designed and fabricated.

Process and equipment development (A. D. Ryon, R. D. Spence, P. A. Haas, V. L. Fowler, and K. E. Sullivan). The principal objectives of this experimental program are the development of equipment needed for associated laboratory flowsheet studies and the development of a design basis for equipment necded for the preparation of kilogram quantities (U, $\mathrm{Pu}) \mathrm{O}_{2}$ spheres. Many of the equipment concepts developed last year will be used as a base for this program; however, there are important constraints such as criticality criteria and working in glove boxes. Different flowsheet conditinns surch as the use of a different gelling medium and the production of spheres of the required size for pellet pressing must also be considered. Most of the testing will be done with uranium only to expedite the work and minimize the cost.

Testing of methods of preparing medium-sized spheres ( $400 \mu$ dry) has been started to provide simple equipment that can be used in the flowsheet studies. Several different metering devices are being tested to feed the broth to the forming nozzles.

\subsubsection{Direct denitration conversion development}

Lab-scale studies (J. C. Mailen, D. Lee, D. R. McTaggart, and O. K. T'allent). Laboratory studies are underway to examine the kinetics of thermal denitration during the conversion of mixed uranyl-plutonium nitrates to oxides. The experimental method couples time-of-flight mass spectrometry (MS) with thermal gravimetric analysis (TGA). Using this technique, decomposition rates of nitrate solids and the composition of associated off-gases are directly determined. Specific samples of uranyl nitrate hexahydrate were prepared for analysis by the TGA-MS system and a second existing TGA system for plutonium studies is being reactivated. Another system which denitrates concentrated uranyl nitrate solutions 
by $\mathrm{drop}$-wise impingement of the solution on a hot $\left(500\right.$ to $\left.600^{\circ} \mathrm{C}\right)$ metal plate has been satisfactorily tested.

Process and equipment development (P. A. Haas, A. D. Ryon, and R. D. Arthur). The objective of these studies is to develop and demonstrate thermal denitration as a process for converting nitrate product streams to oxides during the recycle of nuclear fuels. The purified metal nitrate solutions must be converted into oxide materials having properties that will be acceptable for subsequent fuel refabrication. Since existing denitration processes typically yield $\mathrm{U}, \mathrm{Pu}$, or Th oxides with poor ceramic properties, the denitration procedures and equipment must be improved. The problems associated with criticality control and remote operation and maintenance must be identified. Acceptable solutions to these problems will require demonstration.

In simple batch denitration tests of metal nitrate-nitric acid solutions, certain additıves have shown large and promising effects on the appearance and BET surface areas of $U$, U-Th, and U-Ce oxides.

Batch studies are continuing in an effort to obtain more information on the effects of the additives. Three $\mathrm{UO}_{3}$ products and two $(\mathrm{U}, \mathrm{Th}) \mathrm{O}_{x}$ products with a $\mathrm{U}: \mathrm{Th}$ mole ratio of 3 were submitted for assessment of pellet preparation bchavior for a range of additive concentrations. Samples of product oxides were examined by scanning electron microscope and $\mathrm{X}$-ray diffraction techniques. Feed samples were also submitted for analyses using the TGA-MS system for off-gas characterization. Procedures and results for past or current uses of rotary kilns at various DOE sites are being reviewed with the objective of applying rotary kilns for a direct denitration flowsheet.

\subsubsection{Product characterization}

\section{S. M. Tiegs and W. B. Stines}

This subtask is concerned with the evaluation of the product prepared under the gel-sphere and direct denitration subtasks. The work is of a screening nature to help guide the process development effort. Detailed product evaluation will be performed by Pacific Northwest Laboratories.

The importance of crystallite morphology on pellet sintering was demonstrated for urania microspheres produced by the urania-plutonia gelation flowsheet. Wet gel spheres were ultrasonically disperșed, deposited on a grid, and examined by scanning electron microscopy. Successful pelletizing results were obtained with some spheres but not with - others.

\subsubsection{Building 3019 facility modifications}

\section{F. E. Harrington, J. R. Parrott, D. F. Williams, and F. L. Daly}

The object of this subtask is to perform cleanup and modifications to prepare areas in Building 3019 for engineering-scale $(\mathrm{U}, \mathrm{Pu}) \mathrm{O}_{2}$ product conversion development. Work in FY 1980 will center on preparing space for a feed and scrap recovery system and a gel-derived mixed-oxide line. In addition, conceptual design, licensing, criticality, and other engineering support work necesssary for approved operation of the facility will be carried 
out. Interface milestone agreements with the HEDL Technical Management Center call for monthly shipments of dry $(75 \% \mathrm{U}, 25 \% \mathrm{Pu}) \mathrm{O}_{2}$ gel-derived spheres to PNL or $\mathrm{HEDL}$ as follows: $300 \mathrm{~g}$ of heavy metal per month beginning March 1981 and $1 \mathrm{~kg}$ of heavy metal per month beginning June 1982. A single 6-kg heavy metal shipment is a June 1983 milestone. Investigations are in progress to determine the extent, cost, and schedule of the required cleanup and modifications to meet these program obligations.

\subsubsection{Product conversion development at SRL}

\section{J. D. Spencer, M. K. Jones, and W. J. Jenkins}

A test facility was installed at the SRL semiworks to study the effect of scaleup on the slurry calcination conversion process. The process converts uranium or uranium-plutonium nitrate solutions to oxide powder by first precipitating the heavy metal (HM) with ammonia and then calcining the slurry in a fluidized bed reactor. Production-scale throughput (100 kg of uranium per day per line) was demonstrated in the test facility at design calcination conditions (off-gas at $550^{\circ} \mathrm{C}$ ).

A finishing process development facility (FPDF) was constructed at SRL to determine whether production-sized cquipment can be operated at conditions that yield the desirable product. The facility contains prototype reprocessing equipment; feedstock for the process is uranyl nitrate. The test program is designed to demonstrate production-scale throughput so that the finishing process can be integrated into a $10-\mathrm{MTHM} / \mathrm{d}$ reprocessing complex.

Production-scale throughout has been achieved in the semiworks test facility in a series of short (3- to 4-h) uranium production tests that yielded several kilograms of uranium oxide product. The goal slurry feed rate of $16.5 \mathrm{l} / \mathrm{h}$ was attained at design slurry concentration $\left(250 \mathrm{~g} / \ell\right.$ of uranium) and calciner off-gas temperature $\left(550^{\circ} \mathrm{C}\right)$. The throughput is limited by heat transfer in the calcination step.

The facility is being modified to simplify the process and improve performance. A new calciner is being fabricated with additional heating capability. A static mixer is being studied as an equipment alternative to the precipitator vessel. An electrostatic precipitator will be installed to separate the oxide product from the calciner off-gas stream.

\subsection{Analytical Chemistry Development (ORNL)}

\section{A. Cóstanzo}

\subsubsection{Systems coordination}

\section{J. L. Marley}

The Reference Sample Plan for Analytical Chemistry and Process Control of the Hot Experimental Facility, Modified Purex Flowsheet (200 Series) has been completed. The plan defines the analytical chemistry requirements of the process and presents the status of analytical research and development tasks. The information is being used in analytical chemistry layout and equipment planning. 


\subsubsection{Chemical methods development}

\section{A. Costanzo}

Determination of $\mathrm{Cr}(\mathrm{VI})$ in dissolver solutions (C. S. MacDougall). A precipitation-spectrophotometric technique for the determination of $\mathrm{Cr}(\mathrm{VI})$ in corrosiontest solutions is being evaluated. Recovery of $\mathrm{Cr}(\mathrm{VI})$ is accurate to $\pm 3 \mu \mathrm{g}$ at the 10 -to- $100-\mu \mathrm{g}$ level. The presence of $\mathrm{Al}(\mathrm{III})$ does not interfere with the determination. The effects of ruthenium are now being examined.

Chromatography (J. M. Keller). The gas chromatograph (in Building 2026) to be used for the analysis of gaseous products from the combustion of irradiated uranium carbide has been assembled and evaluated. A standard gas mixture of $60 \%$ carbon monoxide $-40 \%$ carbon dioxide was used to determine calibration precision. Four injections of $250 \mu \mathrm{l}$ yielded a $95 \%$ confidence limit of $\pm 1.15 \%$ for the integrated area of the CO peak and $\pm 0.75 \%$ for the $\mathrm{CO}_{2}$.

An evaluation of the customized Varian 3700 gas chromatograph equipped with flame ionization detectors (FID), a thermionic specific detector (TSD), and a CDS-111 chromatography data system was initiated. The instrument was customized by separating the control electronics from the column oven and pneumatics so that sample injections could be accomplished from a glove box. The electronics and pneumatics have been tested and are functionally adequate. Cost estimates were requested from Varian to adapt the instrument to automated control by the CDS-111. The evaluation of a nitrogen-phosphorous specific detector will begin when suitable phosphorous-containing organic compounds are received.

\subsubsection{X-ray' fluorescence (XRF) development}

\section{J. H. Stewart, Jr.}

The laboratory x-ray fluorescence (XRF) system in Building 2026 was successfully calibrated for the analysis of mixed uranium and thorium aqueous and TBP-dodecane solutions; routine sample analysis was initiated. Preliminary studies for the XRF determination of rhenium in $\mathrm{HNO}_{3}, \mathrm{HCl}$, and $\mathrm{TBP}$ solutions have been completed. Analysis of the $6 \mathrm{M} \mathrm{HCl}$-rhenium solution requires further investigation to compensate for a $10 \%$ (relative) negative bias. Supporting rhenium analyses by atomic absorption, colorimetric, and neutron activation techniques are underway.

The ${ }^{57} \mathrm{Co}-\mathrm{Ge}$ XRF analyzer was received and installed at the end of December. Final acceptance testing is underway. The control board for the automated glove-box unit contained a defective capacitor and has been returned to United Scientifics for repair.

\subsubsection{Nuclear and radiochemical methods development}

\section{C. Bate and J. R. Stokely}

New apparatus for the analysis of ${ }^{14} \mathrm{C}$ in reactor fuel solutions and gas samples has been installed in the analytical support laboratory in Building 3019. The apparatus has been in routine use for about two months and is performing satisfactorily; carbon-14 
analysis time has been reduced about one-half, and the reproducibility of analytical results has improved significantly.

A paper entitled "Determination of Technetium-99 in Mixed Fission Products by Neutron Activation Analysis" was presented at the 23rd Conference on Analytical Chemistry in Energy Technology. The paper will be published in the proceedings.

\subsubsection{Spark-source mass spectrometry development}

\section{R. J. Warmack, W. H. Christie, and J. A. Carter}

All preliminary steps for the installation of the high-level spark-source mass spectrometer have been completed. The tracks have been received, the liner has been completed, and the master/slave manipulators have arrived. Installation is expected to be completed within the next three months.

\subsubsection{Instrumentation development}

\section{N. Klatt and D. E. Goeringer}

Hot-cell analytical instrumentation development. The development of a new remote pipetting system was in itiated this quarter. The system will operate in a closed-loop control mode. The control unit is a 6502 microcomputer system which utilizes BASIC as the programming language. The feedback signal is the output from a linearly variable displacement transducer which directly senses the plunger position. The prototype mechanical system has been assembled. Electronic systems for the stepping motor controller and the analog-to-digital converter have been designed, and prototype assemblies have been constructed. Assembly language routines which provide the digital signals to and from these modules were written. Proper operation of the electronic modules and software routines for each subunit was verified.

General analytical instrumentation development (W. R. Laing). The wet oxidation apparatus for measuring organic species containing ${ }^{14} \mathrm{C}$ in dissolver solutions has been redesigned and standardized with a labeled, long-chain organic acid. Recoveries of 85 to $90 \%$ were obtained. Fifteen dissolver solutions, both spiked and unspiked, have been

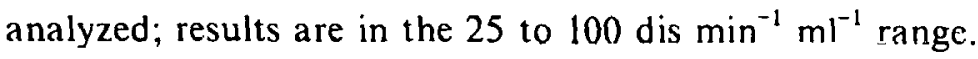

\subsection{Aualytical Chemistry Development (SRL)}

\section{J. D. Spencer, M. L. Hyder, and T. J. Anderson}

\subsubsection{Evaluation of LASL x-ray absorption-edge densitometer (XRAED) W. C. Mosley}

The experimental portion of the joint SRL-Los Alamos Scientific Laboratory (LASL) evaluation of the XRAED was completed, and the instrument was shipped back to LASL. A draft of a portion $(80 \%)$ of the final report covering mixed solutions has also been 
prepared. The results of the study were presented at the American Nuclear Society Topical Conference on Measurement Technology for Safeguards and Material Control, Kiawah Island, South Carolina, November 1979. The study showed that for synthetic U-Pu solutions, the XRAED can assay uranium solutions greater than $20 \mathrm{~g} / \ell$ to within $\pm 0.8 \%$ $(2 \sigma)$ and plutonium to within $\pm 3 \%$ at $10 \mathrm{~g} / \ell$ and $\pm 12 \%$ at $2 \mathrm{~g} / \ell$. Suitability of the XRAED for safeguards accounting has not yet been established, although process control applications appear to be feasible. A firmer assessment awaits the availability of LASL personnel to discuss the experimental results.

\subsubsection{Determination of Uranium(IV)}

\section{E. W. Baumann}

A procedure for the colorimetric determination of $U(I V)$ and/or total uranium with Arsenazo 111 has been developed. In a strong acid solution (e.g., $4 \mathrm{M} \mathrm{HCl}$ ), Arsenazo III forms a colored complex with U(IV) but not with U(VI). The molar extinction coefficient of the complex at $665 \mathrm{~nm}$ is about 100,000. Total uranium can be determined after a reduction step with metallic zinc in $\mathrm{HCl}$ in the presence of ascorbic acid.

Initial comparisons of the determinations of U(IV) by the colorimetric method and by the ceric titration method look promising. An extension of the method to determine U(IV) in the organic phase after the $\mathrm{U}(\mathrm{IV})$ has been extracted into aqueous $4 \mathrm{M} \mathrm{HCl}$ is being investigated.

\subsubsection{Thorium determination}

\section{E. W. Baumann}

To provide a high precision thorium method that can be used remotely, potentiometric titrations with ion-selective electrodes (ISES) as indicators are being investigated. Work has continued with the objective of improving the rate of response at the equivalence point over the precise but slow CdSE in the Cu-EDTA system investigated earlicr.

Other electrodes of the sulfide type ( $\mathrm{Ag}_{2} \mathrm{~S}$ matrix containing another metal sulfide), in addition to the CUSE and CdSE, were evaluated in the Cu-EI)'A titration system. The $\mathrm{PbSE}$ showed no advantage; however, the $\mathrm{Ag}_{2} \mathrm{~S}-\mathrm{SE}$ showed a more rapid response in the EDTA titration, both in the presence and the absence of Cu-EDTA.

Experiments were also conducted to investigate fluoride-SE in two systems. One system, the simple titration with $\mathrm{NaF}$, may not be precise enough because of acid buffer effects. The other, a more promising system, uses TTHA as titrant, with NaF added as indicator.

Precise automatic titration in any of these systems is not possible with the present equipment, which offers only the capability for presetting the voltage at the end point. The advantages of automated systems that offer equilibrium titrations and recognition of the equivalence point inflection are being considered. The development of the photometric detector for colorimetric titration is also continuing. 


\subsection{4 $\mathrm{ThO}_{2}-\mathrm{UO}_{2}$ fuel pellet characterization}

\section{W. C. Mosley}

Scanning electron microprobe (SEMQ) analysis of $\mathrm{ThO}_{2}-\mathrm{UO}_{2}$ pellets has characterized the behavior of $\mathrm{CaO}$ additions and has also uncovered compositional differences between $\mathrm{ThO}_{2}-\mathrm{UO}_{2}$ pellets from two different sources.

Pellets prepared at Battelle-Pacific Northwest Laboratory (PNL) containing $\mathrm{CaO}$ as a dissolution aid were analyzed. Between 0 and 0.5 wt $\% \mathrm{CaO}$, increasing numbers of $\mathrm{CaO}$ inclusions were seen with increasing $\mathrm{CaO}$ content.

The SEMQ analysis also showed compositional differences between pellets from PNL and those from CGE (Canadian General Electric Company), which might explain a 1.5-h induction period during the dissolution of the CGE pellets. The outer 150 to $200 \mu \mathrm{m}$ portion of the ClE pellets was rharacterized by a structuric different from that of the intcrior and by llie presence of traces of Fe, S, Na, F, Mg, $\Lambda \mathrm{l}$, and Si not present in the interior. Both features were absent in the PNL pellets.

\subsection{Materials Compatibility}

\section{J. C. Griess}

The experimental work for this task is carried out at Battelle Columbus Laboratories under subcontract to ORNL. During FY 1979, part of the experimental program was conducted at Westinghouse Advanced Reactor Division, also under subcontract to ORNL. The latter work was completed during FY 1979, and a draft of the final report has been submitted to ORNL.

\subsubsection{Experimental corrosion studies at Battelle Columbus Laboratories}

\section{J. A. Beavers, W. K. Boyd, and W. E. Berry}

Tests in $5.5 M$ hydriodic acid (HI). Constant-strain-rate strese corrosion cracking tests were conducted in boiling $5.5 M \mathrm{HI}$ with the four most corrosion-resistant materials-zirconium, Hastelloy C-276, Hastelloy G, and Inconel 625. None of the materials showed any tendency to crack. Corrosion of the above materials was also determined during a simulated dissolution-iodine recovery cycle which consisted of exposing specimens to boiling $5.5 \mathrm{M} \mathrm{HI}$ for $50 \mathrm{~h}$, distilling off most of the $\mathrm{HI}$, cooling to room temperature, adding $\mathrm{HNO}_{3}$ and $\mathrm{Al}\left(\mathrm{NO}_{3}\right)_{3}$, and continuing the exposure for $200 \mathrm{~h}$. Corrosion penetrations per cycle were less than $0.5,0.6,1.4$, and $1.9 \mu \mathrm{m}$ for zirconium, Inconel 625 , Hastelloy $\mathrm{G}$, and Hastelloy $\mathrm{C}-276$ respectively. Thus, any of the four materials is suitable for a secondary dissolver vessel that uses HI for dissolving plutonium. This phase of the corrosion program has been completed, and a topical report is being prepared.

Off-gas corrosion studies. Extension of the off-gas studies at $40^{\circ} \mathrm{C}$ has resulted in the same trends noted at room temperature; that is, most of the iron and nickel-base alloys containing little or no molybdenum develop either solid or liquid deposits on their surfaces, 
depending on the water content, even at low iodine concentrations. When exposed to laboratory air, the solids become liquid, and random pitting occurs under the liquid. Titanium, zirconium, and iron- and nickel-based alloys containing high concentrations of molybdenum have remained free of significant attack in all cases.

Nitinol connectors. A test specimen consisting of two short lengths of $38-\mathrm{mm}$ (1.5-in.) schedule 80 type $304 \mathrm{~L}$ stainless steel pipe joined by a Nitinol connector was exposed to boiling $4 \mathrm{M} \mathrm{HNO}_{3}$ for $2000 \mathrm{~h}$. Since Nitinol has poor corrosion resistance in nitric acid, a type $304 \mathrm{~L}$ stainless steel liner was placed between the outer wall of the pipes and the Nitinol. Intergranular attack extending three to four grains deep was noted on the ends of the pipes that were butted together, but on all other type $304 \mathrm{~L}$ stainless steel surfaces, attack was no more than one grain deep. In a previous test under the same conditions (except in $8 \mathrm{MHNO}_{3}$ ), end-grain attack as deep as $6 \mathrm{~mm}$ was observed, and intergranular attack, two to four grains deep, was noted on the other surfaces. Although not determined by analysis, it was suspected that $\mathrm{Cr}(\mathrm{VI})$ formed in the latter case and contributed to the attack.

$\mathrm{Cr}(\mathrm{VI})$ in nitric acid solutions. The presence of $\mathrm{Cr}$ (VI) in hot nitric acid solutions accelerates the corrosion of many alloys. It is therefore important to know under what conditions $\mathrm{Cr}(\mathrm{VI})$ can form in nitric acid. Experiments were started to determine the rate of $\mathrm{Cr}(\mathrm{III})$ oxidation to $\mathrm{Cr}(\mathrm{VI})$ in different concentrations of nitric acid. A principal problem has been the lack of a suitable analytical method for determining the concentration of $\mathrm{Cr}(\mathrm{VI})$ in the presence of relatively large concentrations of $\mathrm{Cr}(\mathrm{III})$. Based on color changes only, $\mathrm{Cr}(\mathrm{III})$ was not oxidized to $\mathrm{Cr}(\mathrm{VI})$ in boiling $6 \mathrm{M} \mathrm{HNO}_{3}$; however, oxidation did occur in 9 and $12 M$ solutions. The addition of $\mathrm{Ru}(\mathrm{III})$ appeared to increase the rate of oxidation in the two or more concentrated solutions. Once it is possible to determine and control the concentration of $\mathrm{Cr}(\mathrm{VI})$ in nitric acid solutions, its effect on the corrosion of materials will be evaluated.

\section{References}

1. A. Brunstad, The Polymerization and Precipitation of P(IV) in Nitric Acid, HW54203 (December 1957).

2. V. L. Schuelein, Parameters for Pu Polymer Formation in Nitric Acid, AR H-SA-233 (May 1975).

3. J. T. Bell, D. A. Costanzo, and R. E. Biggers, J. Inorg. Nucl. Chem. 35, 623 (1973).

4. T. H. Sidall III, Application of Amides as Extractants, USAEC Report DP-541, E. I. du Pont de Nemours and Co., Savannah River Laboratory, Aiken, S.C. (1961).

5. T. H. Sidall III, J. Phys. Chem. 65, 1863 (1961).

6. U. V. Rublerv and T. V. Stepanove, Zhur. Anal. Khimii 33, 1347 (1978). 


\title{
3. ENGINEERING RESEARCH
}

\author{
W. S. Groenier
}

The various engineering research studies summarized here represent the first phase of the equipment development program and provide a basis for further design and development of specific engineering test components. Emphasis is placed on the identification, study, selection, development, and characterization of unit processes through the application of basic or fundamental experimental engineering techniques.

Studies of the voloxidation, dissolution, feed preparation, solvent extraction, and off-gas treatment processes are in progress, and development efforts are described. Work directed toward voloxidizer and solvent extraction equipment development is also reported.

Most ongoing activities are reported in summary fashion, with the intent being to place details in topical reports.

\subsection{Voloxidation}

\section{E. Whatley}

The voloxidation process is being developed as a head-end method for removing tritium from spent uranium reactor fuel prior to aqueous processing. Based on experimental work, it appears that this objective can be met by reacting the oxide fuel with oxygen or air in a temperature range of 720 to $920 \mathrm{~K}$. The release of tritium and, to a lesser extent, some of the other fission products occurs when $\mathrm{UO}_{2}$ is restructured to $\mathrm{U}_{3} \mathrm{O}_{8}$ during oxidation. The early removal of tritium from the fuel into a relatively small volume is desirable to avoid mixing the tritium as water with aqueous streams in subsequent process steps. A secondary benefit of voloxidation is the oxidation of residual sodium in the fuel prior to dissolution.

An investigation of the applicability of rotary kilns to the voloxidation process has been continued by (1) performing heat transfer tests using a small rotary kiln, (2) continuing a kiln-seal evaluation study and an erosion-corrosion test to evaluate candidate materials of construction, and (3) evaluating several improved rotary kiln inlet flight design concepts. Tests of a $0.5-\mathrm{t} / \mathrm{d}$ voloxidizer system are described; this major effort features the test and evaluation of commercial components. The continuing evaluation of molecular sieves for tritium retention is also described.

\subsubsection{Full-scale experimental voloxidizer (FSEV) system} T. D. Welch, B. B. Spencer, and M. E. Whatley

An experimental voloxidation system scaled to $0.5 \mathrm{t} / \mathrm{d}$ has been provided to study (in nonradioactive experiments) certain important process parameters and the applicability of some full-scale standard commercial equipment components, to extend and verify basic data on heat and mass transport in the voloxidation system, and to address the problems of process control. 
Operations. Modifications, including drum thermocouples, telemetry, and inlet flight installation, are on schedule and a three-month experimental campaign will begin in January.

The most promising inlet flight design to date, which consists of a triangular section with a dam attached on the back edge, is being fabricated for installation in the FSEV. Table 3.1 presents the results of several experiments with these flights in a 0.46-m-diam, $1.14-\mathrm{m}-$ long test drum. No lodging between flights was detected in experiments with shroud feed.

Table 3.1. Material spill from the voloxidizer inlet at a loading of $15 \%$ using new inlet flights

$\left.\begin{array}{clcc}\hline \begin{array}{c}\text { Spacing between } \\ \text { flights, } \\ \mathrm{cm}\end{array} & \begin{array}{c}\text { Feed } \\ \text { type }\end{array} & \begin{array}{c}\text { Feed } \\ \text { rate, } \\ \mathrm{g} / \mathrm{min}\end{array} & \begin{array}{c}\text { Spill, } \\ \mathrm{g}\end{array} \\ \hline 2.86 & \text { Sand } & 1000 & 0 \\ & & 1700 & 2.8 \\ & \text { Shroud } & 2000 & 119 \\ & \text { Sand } & 4000 & 0 \\ & \text { Hulls } & 400 & 0 \\ 3.81 & \text { Shroud } & 400\end{array}\right)$

${ }^{a}$ Cone piece included with new design inlet flights.

Data analysis. The run-time and eleven other accumulated variables in the FSEV data sets are reinitialized after each interruption in the Bristol computer execution. A computer program has been written to correct these data. Data from FSEV runs four through nine have been corrected and recorded on nine-track magnetic tape on the ORNL IBM-360 computer, where they may be accessed by analysis programs.

Some software packages that will use the data have been written. One package reads and decódes the numbers that represent an "operating $\log ^{\prime}$ " and writes the results in explanatory prose to produce a printed log. Other packages read the data and plot the temperature history. of the different heating zones for an entire run, and others plot the differential pressure and flow rate through the off-gas filter as a function of time. These plots have been useful in the analysis of experiments performed to obtain data on off-gas filters. Additional software packages will continue to be written to do various other data analyses.

Dictionaries have been written that list the signal names, the engineering units, and the physical description of each data point to improve documentation of the FSEV data. The rapid evolution in the Bristol software development and in the data taken has required that a dictionary be written for each run through run seven. Dictionaries for runs four through seven are complete, and dictionaries for runs eight and nine are the same as for run seven. 
A computer routine has been written to produce microfiche copies of the data to provide a printed backup of the FSEV data that requires little storage space. All of the data sets (i.e., for runs four through nine) have been copied from magnetic tape in this manner.

Instrumentation (W. F. Johnson and S. S. Gould). Startup and shutdown procedures have been written for the oxygen analyzers.

The drum temperature telemetry system has been received and is being tested for functional operability with a host unit process controller. Time and cost estimates have been generated for installation of the unit. The drum thermocouple installation task is complete.

The color CRT software has been written and tested for project approval on a Bristol UCS-3000 unit process controller. The software package has been written to facilitate future changes to all available displays with simplicity as an overriding criterion throughout the effort. A presentation is planned to provide an overview of the system's capabilities and the necessary instructions for all future update maintenance.

A fail-safe lockout has been installed on the oxygen analyzer to prevent the sensors from overheating in the event that the off-gas system fails. The off-gas system has been used as the means of pulling an oxygen sample through the oxygen analyzer.

An alarm was installed to alert the operating personnel in the event of time-out of a watch dog timer at the Bristol UCS-3000 unit process controller. This lockout/alarm urges the operator to initiate the appropriate action and locks out the material feeder functions until that action has been accomplished.

An accelerometer-based unit is being assembled to monitor the shroud feeder. The primary function of the unit is to provide information to the Bristol as each piece of shroud is fed. It may be expanded at a later date to sense fuel stoppages within the inlet and outlet chutes.

\subsubsection{Rotary-kiln heat and mass transport studies \\ B. B. Spencer and M. E. Whatley}

A total of 45 gas-phase heat transfer experiments have been completed. These were performed at rotational speeds ranging from 1.2 to $7.0 \mathrm{rpm}$, air flow rates from 0 to 1.49 scfm and maximum kiln wall temperatures from 300 to $400^{\circ} \mathrm{C}$. No solids were used in any of these experiments.

A second solution to the differential equation describing the gas-phase temperature profile at steady-state conditions has been generated. Computer coding has been completed for this second solution. Correlations made by this model and by the previous model are in agreement. Both models, however, converge on values of the heat transfer coefficient and dispersion coefficient only when the air flow is in a countercurrent direction to the flow of solids, if solids were present.

Empirical expressions have been developed to correlate the data from the 22 runs where the model did converge. These equations show that the dispersion coefficient decreases with increasing rotational speed and that the heat transfer coefficient increases with an increase in the dispersion coefficient. Both coefficients increase with increased gas velocity.

Figures 3.1 and 3.2 compare the calculated Schmidt number to the experimental Schmidt number, and the calculated Nusselt number to the experimental Nusselt number. The diagonals are lines of perfect agreement. The data show a temperature dependence 


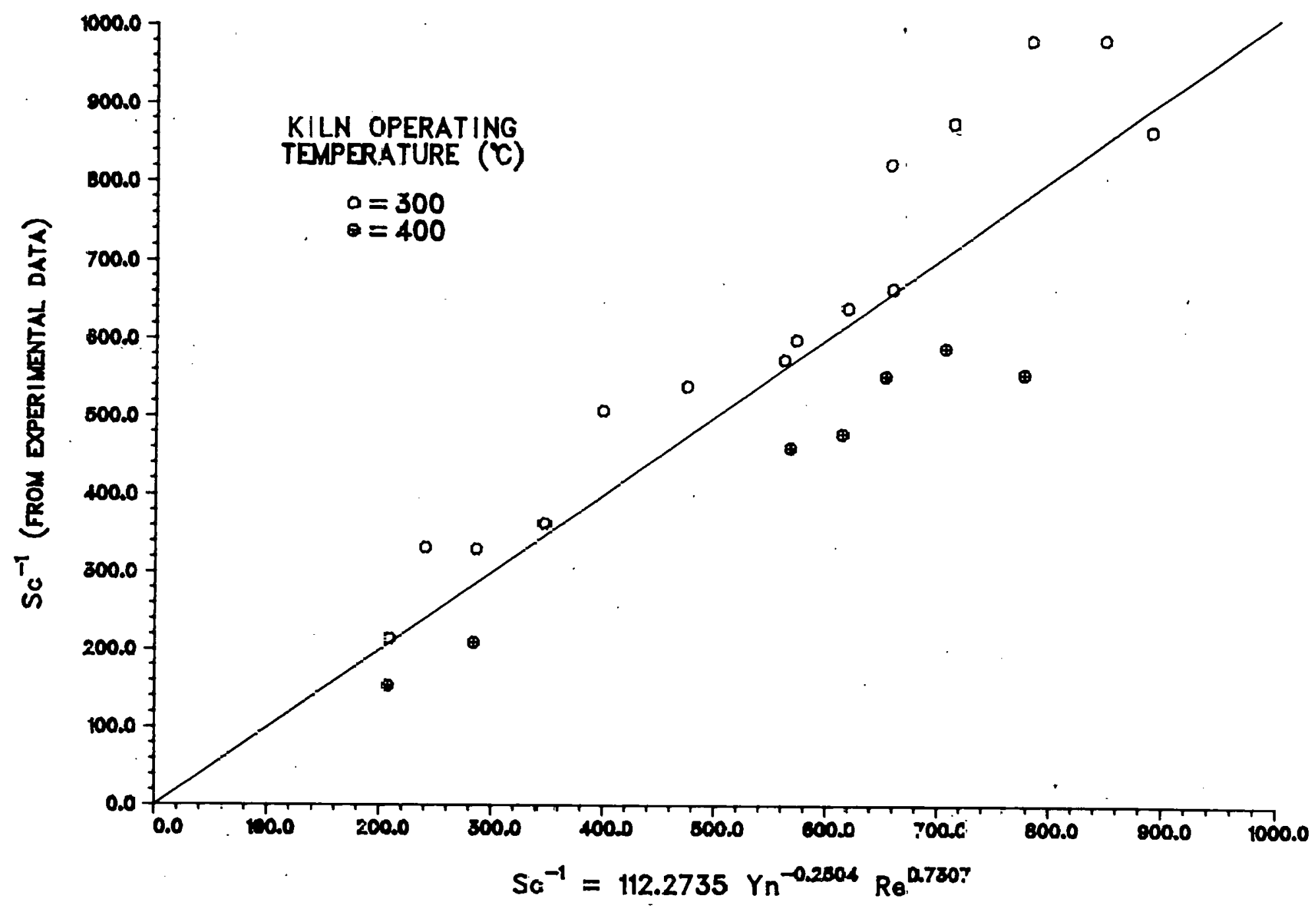

Fig. 3.1. Correlations of Schmidt number. 
ORNL DWG. 79.18974

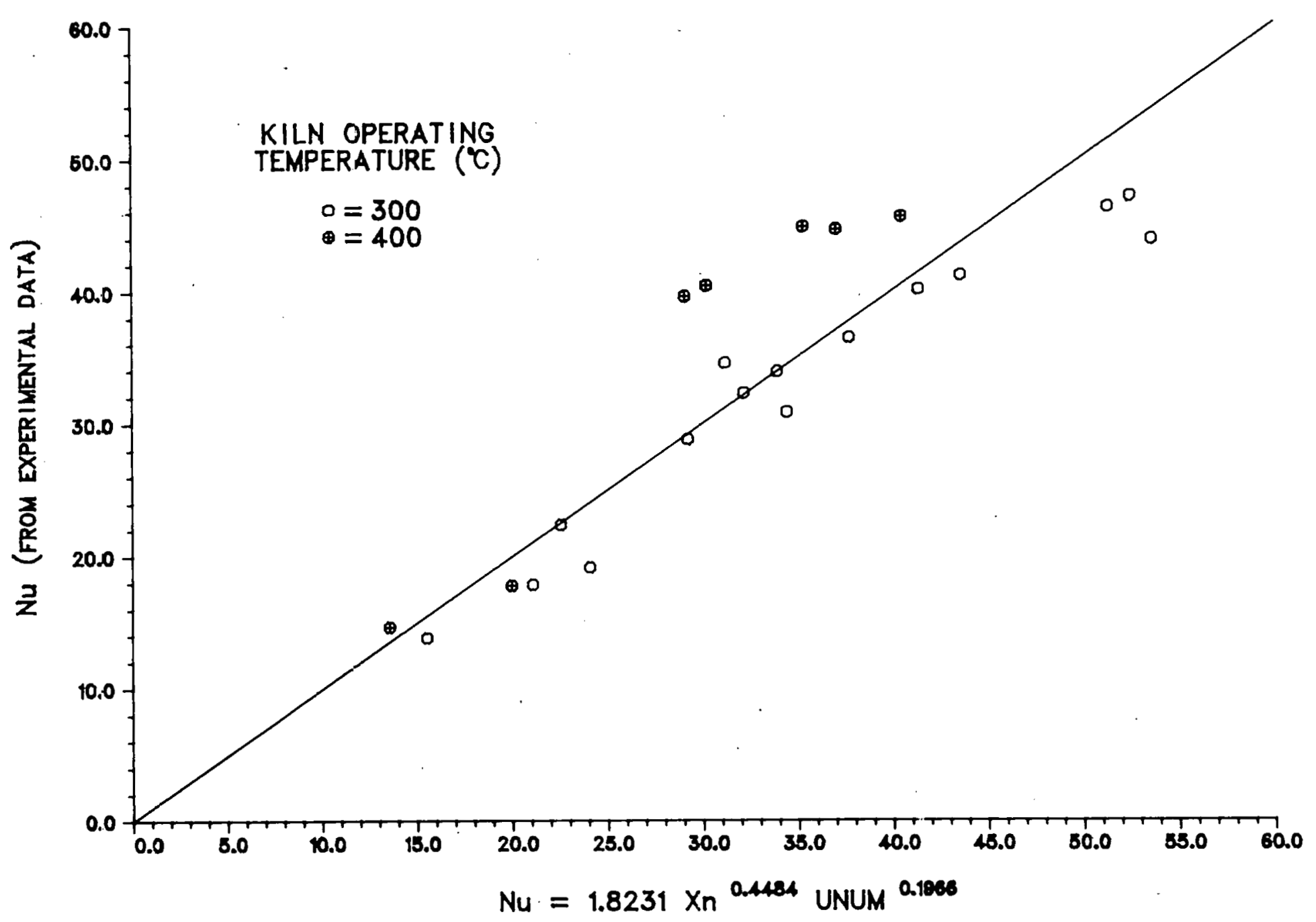

Fig. 3.2. Correlation of Nusselt number. 
which is believed to be the result of thermal radiation affecting the temperature measurement of the gas phase. A method is being developed to make up for this. However, the experimental Schmidt number varies an average of $16.2 \%$ from the calculated value with a maximum deviation of $37.7 \%$. The experimental Nusselt number varies $12.3 \%$, on the average, from the calculated value with a maximum deviation of $36.1 \%$.

The equipment used to measure the gas phase residence time distribution (RTD) has been set up. The RTD is being measured using the impulse-response technique with methane as the tracer. Nine experiments have been performed. These runs featured kiln rotational speeds of 2.0 to $7.0 \mathrm{rpm}$ and air flow rates of 0.34 to $1.05 \mathrm{scfm}$. The Analytical Chemistry Division at ORNL has analyzed samples from four of the experiments. Computer codes are being written to aid in the analysis of the data.

\subsubsection{Tritium retention from voloxidizer process off-gas W. D. IIolland}

This activity is being performed under subcontract at Tennessee Technological University to determine the effect of iodine on the operation of a water vapor removal systcm for the treatment of voloxidizer off-gases. A 2 -in.-diam by 30 -in.-long bed of molecular sieve (or other dessicant) pellets is being used to remove water vapor from an air stream containing iodine. Experiments are conducted at gas flow rates and iodine and water vapor concentrations designed to match the expected values of these parameters in a voloxidizer off-gas drying system. Comparative evaluations of several candidate drying agents are featured. In FY 1980, continued studies are aimed at the design of larger packed-bed drying systems to remove tritiated water from voloxidizer off-gases. Current efforts involve the development of a mathematical model to describe bed performance, the development of measurement techniques to determine water loading of the bed, and an investigation of the role of the binder material used in pelletized molecular sieves on iodine adsorption during drying.

A review of the current literature is being made to select the best approach toward modeling a packed-bed adsorption system. Most treatments are restricted to ideal systems involving negligible heat effects and linear equilibrium relations. These will require modification to adequately represent the off-gas drying system.

A small device to measure electrical properties of the packing material has been fabricated and is currently being tested in a prototypical bed. This device consists of two 2-in.long concentric cylinders of titanium tubing. The outer cylinder is 1.8 -in. ID and the inner cylinder is 1.2-in. OD. The packing material fills the annular space between the cylinders when installed in the bed.

The electrical resistance bctween the cylinders is continuously recorded during loading of the bed. Initial trials show a sharp drop in resistance as the material between the cylinders loads with water. Further testing on the device in the presence of iodine-containing moist air is planned.

\subsubsection{Rotary seal tests}

\section{J. G. Morgan}

Among the most important mechanical features of the rutary-kiln voloxidizer design are the mechanical rotating seals that isolate the kiln atmosphere from the cell atmosphere. Under normal operating conditions, each seal (one at each end of the rotating tube) should leak less than $0.5 \mathrm{scfm}$ into the system when the internal vacuum is about 2 in. $\mathrm{H}_{2} \mathrm{O}$. Firm design criteria have not yet been established for the seals, since any inleakage is detrimental 
from the point of view of the process. Further, the degree to which the leakage is limited will depend on the results of conceptual design studies.

In the conceptual design of the prototypical voloxidizer, isolation from the cell atmosphere is achieved by means of inlet and discharge seals. A graphite ring bears against the rotating kiln flange and acts as a sealing surface with a 2 -in.-wide face. The ring is mounted in the center of a corrugated stainless steel diaphragm, 0.020 -in. thick. The outer circumference of the diaphragm is welded to a metal ring which is bolted to a structural member in a fixed position. The diaphragm accommodates movement of the seal as the kiln expands or runs eccentric.

A full-size prototype of this seal was tested in the experimental seal test stand. The graphite ring was made of Great Lakes Carbon grade HLM. Through the use of compression springs, the graphite ring exerts $300 \mathrm{lb}$. of force against the rotating stainless steel kiln flange. The resultant force is distributed to another rotating flange through six cam followers. The outside diameter of the corrugated diaphragm assembly is $58 \mathrm{in.}$ and that of the graphite seal ring is $25.5 \mathrm{in}$.

The first test, in a planned series, was successfully completed during this quarter with the following operating conditions:

1. Seal alignment was concentric with the kiln flange centerline with zero tilt and no longitudinal displacement.

2. The operating temperature of all components was $200^{\circ} \mathrm{F}$.

3 . The atmosphere surrounding the seal was maintained at $5 \%$ relative humidity to simulate cell conditions.

4. The test was operated for $575 \mathrm{~h}$ with the kiln flange rotating at $6 \mathrm{rpm}$. This is equivalent to five months operation of the voloxidizer, which rotates at $1 \mathrm{rpm}$.

Air leakage past the rotating seal face was measured during operation as a function of pressure drop $(\triangle \mathrm{P})$ across the seal. Typical values were $0.40 \mathrm{scfm}$ at $5 \mathrm{in} . \mathrm{H}_{2} \mathrm{O} \triangle \mathrm{P}$ and 0.17 scfm at 2 in. $\mathrm{H}_{2} \mathrm{O} \triangle \mathrm{P}$. The maximum leak rate, for design purposes, had been set at $0.5 \mathrm{scfm}$ at 5 in. $\mathrm{H}_{2} \mathrm{O} \triangle \mathrm{P}$.

Post-test examination of the components led to the following observations:

1. The graphite seal face presented a smooth, lapped appearance across its entire surface, with the exception of one small depressed area.

2. Three of the six rotating cam followers were inoperable due to seized bearings.

3. The rotating stainless steel bearing flange showed a small area where the graphite seal had contacted it only lightly.

Two design changes have been made and will be incorporated in the next test. The bearing flange thickness has been increased from $3 / 8$ in. to $3 / 4$ in. The cam followers will be replaced with graphite wear pads using the same grade of graphite as the seal ring. In the next test, the kiln flange will be tilted about $1^{\circ}$ and dropped slightly below its previous centerline position. 


\subsubsection{Rotary-kiln corrosion test \\ W. D. Holland and M. E. Whatley}

Two identical drums (18-in.-diam x 20-in.-long) fabricated from type 316 stainless steel and Incoloy $800 \mathrm{H}$ are being used to evaluate these materials for rotary-kiln service. The current test program has been temporarily suspended during modifications of the experimental equipment. The changes being made will allow the test drums to be exposed to iodine-containing moist air and will also allow the introduction of small amounts of sodium oxide.

The results of the test program during the past year show no apparent corrosion or erosion on the type 316 stainless steel or the Incoloy $800 \mathrm{H}$ surfaces. A statistical analysis of the data obtained during the testing program will be made and reported to verify this conclusion.

\subsection{Dissolution}

\section{J, O, Kirkmạn}

The objective of the dissolution task is to ensure that LMFBR fuels can be dissolved in nitric acid to give high metal recoveries. Criticality control and off-gas considerations require dissolver design and operation to be performed within rather narrow limits. Continuous dissolving methods, which appear to offer superior solutions to these and other problems, are being emphasized.

During this reporting period, emphasis has been placed on the ongoing development of a continous rotary dissolver. In addition, work has continued on an advanced dissolver design concept and on the development of a method for providing solids agitation in a digester tank.

\subsubsection{Rotary-dissolver erosion-corrosion test W. E. Eldridge}

All four support bearings and two thrust bearings in the 4-ft-diam rotary dissolver have been replaced with stainless steel bearings. During checkout, we were unable to achieve the reverse mode of rotation; this problem was identified as cam seizure and has been corrected. A certain amount of vibration was evident as the drum rotated in either direction. This was traced to roller slippage on the thrust bearings and was corrected by securing stainless steel plates to both sides of both rollers to capture the bearings. The drum has operated successfully without vibration since this modification was made.

In conjunction with the dissolver erosion-corrosion tests, bench-scale corrosion tests using five specimens of the same materials used in the dissolver are underway as a control. A 100-h run was completed with the specimens fully immersed in $8 M^{-H_{N O}}$ at a temperature of $100^{\circ} \mathrm{C}$. A minor leak in the reflux unit occurred, allowing the acid concentration to rise to $15.2 M$ by the end of the run. Analyses of the specimens were completed by the Metals and Ceramics Division, and the corrosion results were comparable to tabulated data. A new reflux unit was constructed to allow the positioning of specimens in both the vapor and liquid phases (Fig. 3.3). A 100-h run was made using the new reflux unit with five different material specimens and a liquid phase consisting of $8 M \mathrm{HNO}_{3}$ at a temperature of $100^{\circ} \mathrm{C}$. The material specimens are SS $304 \mathrm{~L}$, SS $316 \mathrm{~L}$, Incoloy 825 , E-Brite 26-1, and 
ORNL DWG. 79-7136R1

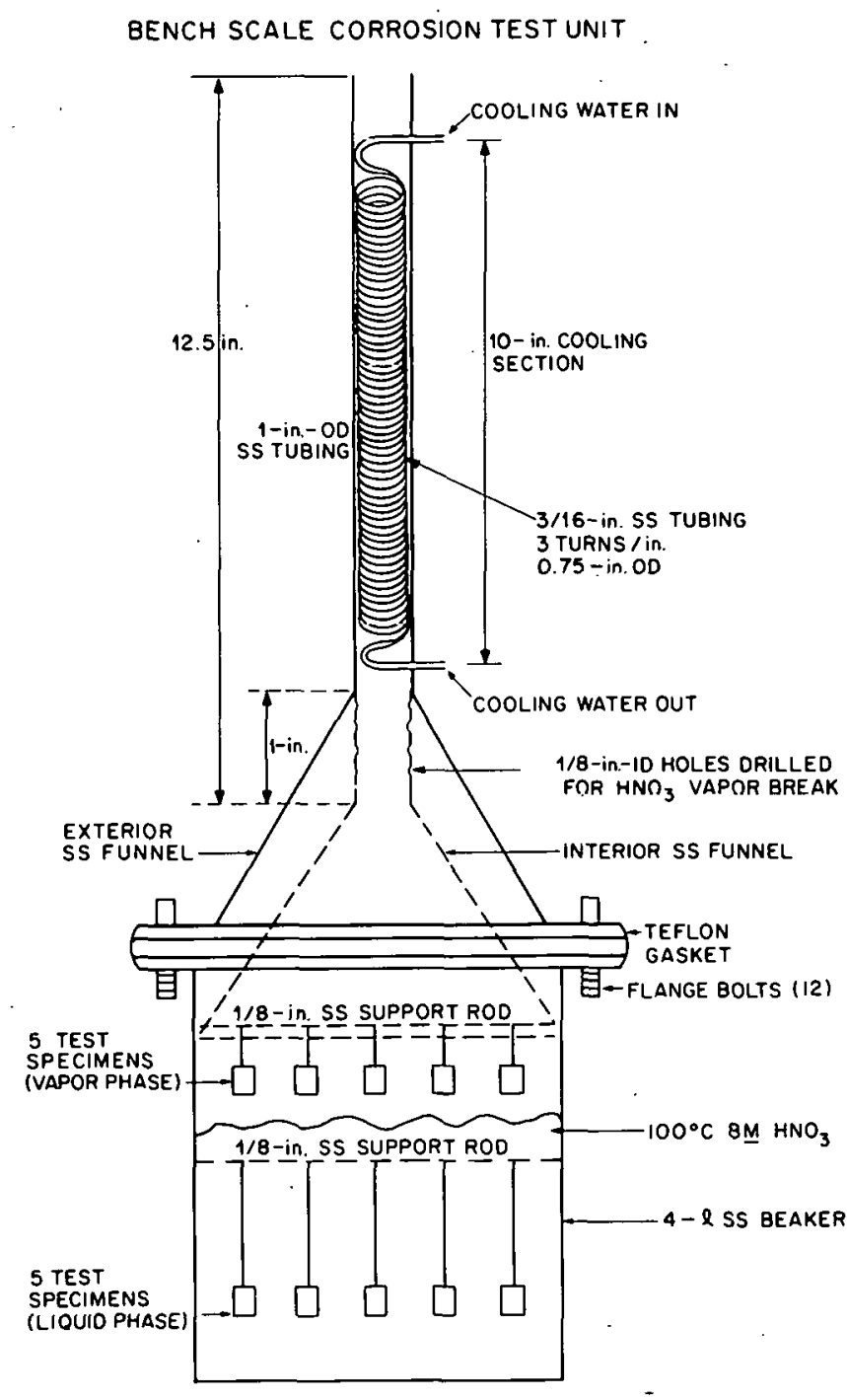

Fig. 3.3. Bench-scale corrosion test unit.

Titanium 75A. After reviewing specimen data analyses, new material specimens will be tested in a series of 100-h runs.

Instrumentation (W. F. Johnson and G. R. Wetherington, Jr.). A power calculator was designed to monitor the load on the drum drive dc motor. This device will activate an alarm when the load on the motor exceeds a preset value. Final installation should be completed by mid-January.

\subsubsection{Advanced rotary dissolver development}

W. E. Eldridge

Preliminary calibration tests begun on the advanced rotary dissolver model have demonstrated that the power demand on the drum drive dc motor is not greatly affected by the 
quantity of material in the drum. Designs are underway to improve not only the drum drive mechanism, but the dissolver drum as well. These plans include a redesign of the present drum to facilitate removal and replacement of drum internals. Upcoming testing will concentrate on material transfer and dispersion characteristics as a function of feed rate.

\subsubsection{Solids suspension tests}

\section{B. E. Lewis}

A digester tank test stand has been fabricated to study various means of suspending solids in a simulated dissolver solution. Suspension of solids will be accomplished by either air pulsing, air sparging, or air lift circulation at a controlled flow rate. All major equipment items and building services have been installed. A view of the equipment at its present state of installation is shown in Fig. 3.4. A small centrifuge will be used to clarify the digester tank solutions for solids content analysis, and a demister with cooling coils has been installed in the off-gas line to remove liquid entrainment produced by the various solids suspension devices. Procurement of all instrumentation is complete and installation has bcgun.

Checkout of the major equipment components is proceeding as the instrumentation installation continues. The solution make-up tank has been calibrated, and the air-jet ejector system particle removal efficiency was experimentally determined for the air lift suspension mode while the tank was being emptied. In the tests, $20 \mathrm{~g}$ of 5 to $20 \mu \mathrm{m}$ stainless steel powder was added to about $15 \ell$ of water in the digester tank. The solution was sparged for approximately $10 \mathrm{~min}$ prior to ejecting. The solution from the digester was then transferred into the centrifuge for clarification. With a continuous air lift circulation, about $52.5 \%$ of the solids was removed from the tank after three additions. An additional $15 \mathrm{l}$ of water was added to the tank to remove the remaining solids. The air lift and ejector were operated as before, with the exception of closing the ejector outlet periodically to allow a pulse of liquid and entrained air to back flow into the digester tank. When this method of fluid/solid transfer was utilized, about $94.8 \%$ of the solids was removed. While this shakedown test does not represent a complete analysis of the solids removal problem, it would appear that a pulse type of solids suspension scheme may be preferred.

Instrumentation (S. S. Gould and W. R. Miller). A software support package is being generated by I \& C personnel for the Engineering Research Unit Process Controller (ERUPC) to provide monitoring and control of the digester tank test stand. Data logging will initially be handled via a Techtran data cassette recorder. The information stored on the cassette tapes will then be transferred to thel DEC 10 System for final analysis.

l'he photocell particle concentration sensor system has been subjected to a series of acceptance tests. It was not clear, from the experiments done, whether the instrumentation would be capable of accurately measuring the concentration of suspended solids; however, it is believed that the photocell system will be a viable method for comparing the overall performance of the various solids suspension devices.

\subsubsection{Flow modeling studies \\ B. E. Lewis}

The dissolver stagewise material balance program, MATL. BAL, has been debugged and is running. Plotting capabilities have been added to the code to provide a graphical representation of the concentration profiles of the fuel and dissolvent as they progress through 
ORNL PHOTO. 5065-79

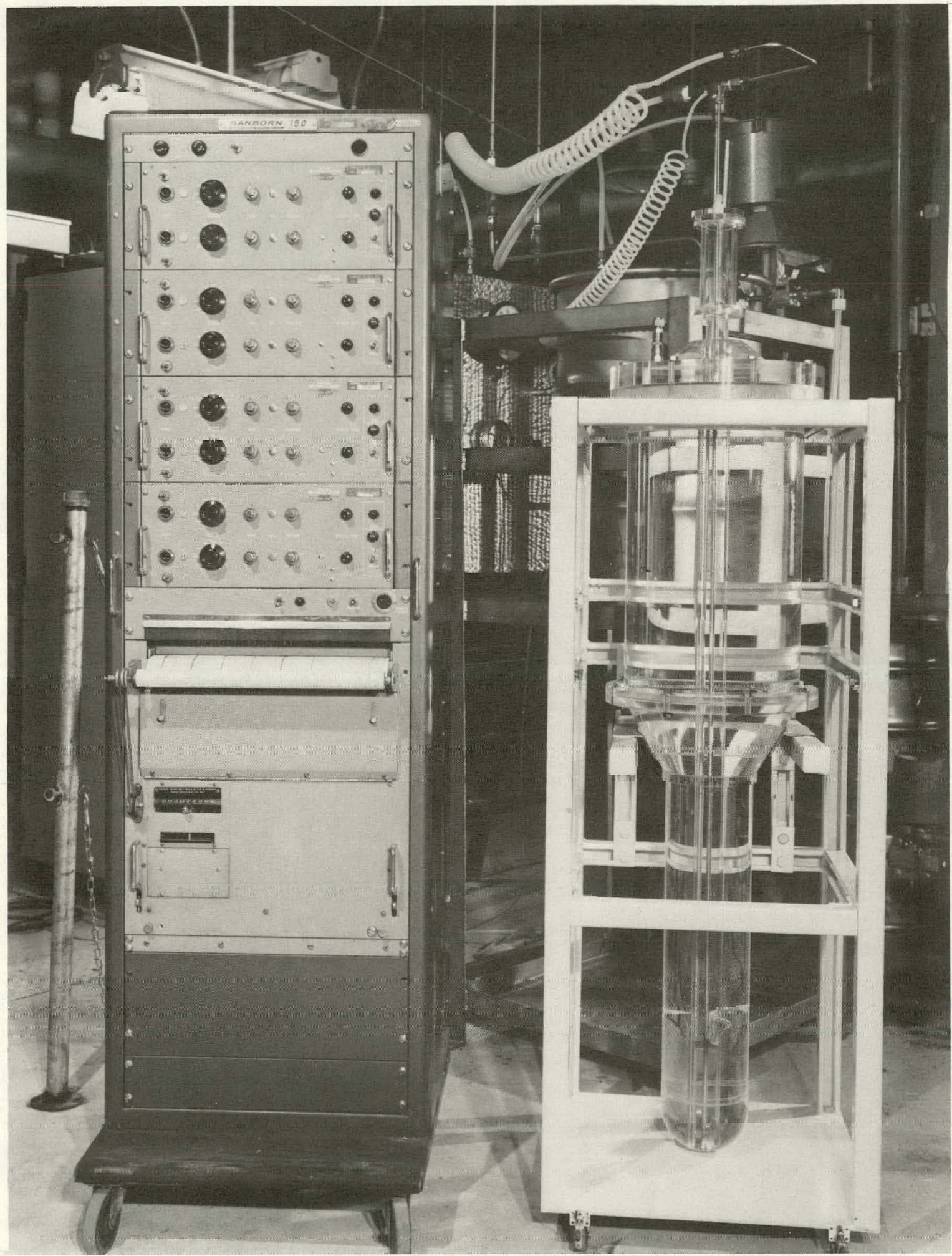

Fig. 3.4. Digester tank test stand. 
the dissolver. This type of graphic output enables rapid comparisons to be made between different runs. We are presently running the latest version of the code to determine its sensitivity to changes in dissolution rates. The program will continue to be improved and updated as additional information becomes available.

The development of a code to predict the output response to a step change in input concentration and flow rate for the rotary dissolver is also continuing. Initially there appeared to be a rotational rate effect on the step-change response for the dissolver; however, experiments conducted on the pilot-plant-scale dissolver showed the overall effect on outlet concentration to be negligible. The present code gives an estimate of the step-change concentration profile through the dissolver which leads the experimental data by several minutes. A different solution of the differential material balance equations is being attempted to eliminate the time discrepancy.

\subsection{Feed Preparation}

\section{W. S. Groenier}

The aqueous feed discharged from the primary dissolver system will contain solids (undissolved fission products, corrosion products, etc.) and will require clarification prior to solvent extraction. Preparation of the feed for solvent extraction will also include adjustment of the plutonium valence and the nitric acid concentration, as well as treatment to remove iodine. This task also encompasses the development of a variety of other processes associated with the liquid portion of fuel reprocessing, such as secondary dissolution methods (with more corrosive reagents and for fuel constituents not soluble in the primary dissolver), accountability systems, and fluid transfer and metering systems.

Several new activities have begun. These include sensor developments for solids and for iodide and fluoride ions in liquid streams and tankage, and a test of a modified nitric acid dehydration system having application to the Iodox off-gas treatment process.

\subsubsection{Fluidic pump development \\ R. M. Counce}

Engineering studies of the transfer of fluid by fluidic pumping have continued. New data have been obtained over a wide range of pumping heads $\left(0\right.$ to $\left.1.6 \times 10^{5} \mathrm{~Pa}\right)$ and motivating pressures $\left(0\right.$ to $\left.2.8 \times 10^{5} \mathrm{~Pa}\right)$. This experimental work is being analyzed and a topical report is in preparation. Also, efforts are underway to obtain development information on fluidics and to procure an advanced fluidic pump through the USDOE/ UKAEA LMFBR Reprocessing Technology Agreement.

\subsubsection{Nitric acid dehydration test R. M. Counce}

A new activity has been initiated to study the production of hyperazeotropic nitric acid ( 80 to 90 mass $\%$ ) from azeotropic nitric acid ( $~ 67$ mass $\%$ ) by an extractive distillation process using magnesium nitrate as the solvent. The scheme under study is a two-stage process with solvent recycle consisting of an extraction pot and a solvent recovery pot. This simplified scheme should be more reliable and controllable than the previous column concept, thus being more amenable to remotized operation. 


\subsubsection{Monitor development}

\section{R. L. Anderson, H. H. Ross, and C. Feldman}

An activity has been initiated for the development of various in-line instruments for application in the feed preparation portion of the process. One part of this activity concerns the development of solids monitors for lines between the dissolver and the HA solvent extraction contactor. A trace solids monitor is needed for the clarified output of centrifuges, and a slurry solids monitor is needed upstream of centrifuges. A survey of commercial instruments has been initiated, and one commercially available instrument has been identified for possible application in the monitoring of trace solids. This instrument is based on small-angle light scattering and appears to be adaptable to in-line use, including radiation hardening. A second approach, ultrasonic correlation, is being investigated for possible application in solids concentration and particle size monitoring of slurries.

A second part of this activity. includes the development of an iodide monitor for the digester output and a fluoride monitor for the centrifuge output. A study of potential techniques has been initiated for the in-line determination of iodine as $\mathrm{I}_{2}, \mathrm{I}^{-}$; or $\mathrm{IO}_{3}^{-}$. As a result of personal contact with several people experienced in the behavior and measurement of iodine species in fuel reprocessing plants, it is felt that a direct radioactivity measurement would probably be impossible. The literature is being surveyed for information relating to the behavior of the various iodine species under expected conditions. Efforts have been directed toward liberating the iodine species from the liquid and making a measurement in the gas phase or in the condensate. Experiments are planned to determine if the free acid monitor under development in Task 860 can be adapted for this use.

\subsection{Solvent Extraction}

\section{E. Whatley}

The development of solvent extraction techniques for the Purex process recovery of advanced fuels is continuing at Argonne National Laboratory (ANL). The primary objective of the program is to design, fabricate, and test an annular centrifugal contactor of critically safe dimension to reprocess advanced fuels at a rate of about $0.5 \mathrm{t} / \mathrm{d}$. The program also includes a supporting laboratory effort.

At ORNL, efforts are underway to improve and apply the SEPHIS and MATEX computer codes for flowsheet engineering studies.

Additional work is in progress at the General Atomic Company (GA) to perform contactor improvement studies, test flowsheets, and test instrument application concepts.

\subsubsection{Centrifugal contactor development}

\section{G. J. Bernstein, R, A. I.ennard, R. H. Pelton, and A. A. Zeigler (ANL)}

Efforts to develop centrifugal contactors have continued. Current emphasis is being placed on the study of an annular contactor with a 12-cm-diam rotor. 'l 'Tis unit is expected to be the basis for the design of a multistage contactor which is capable of processing 0.5 $t / d$ of fast breeder fuel. Program plans include the design and construction of the multistage contactor at Savannah River Laboratory (SRL) based upon the results of ANL studies. Previous work emphasized a 9-cm contactor. 
A continuing objective of the ANL work is the development of mathematical models for predicting the performance of any size centrifugal contactor under various operating conditions.

The 12-cm contactor (M-2). Fabrication of the 12-cm contactor was completed during this quarter, and the unit was installed in the test facility. A smaller angle bracket was chosen to support the motorized spindle on the mounting plate as part of our effort to find a compact arrangement for a multistage contactor array.

Tests were made to measure the dynamic stability of the motorized spindle and rotor assembly. With the rotor empty, the measured vibrations were within allowable values at all rotor speeds except for the region of 2000 to $2200 \mathrm{rpm}$, suggesting that some harmonic in the support plate frame or the spindle itself is the source of the higher vibration. Since the contactor is intended to operate with the motor running at $60 \mathrm{~Hz}$, normal operating speed would be $1800 \mathrm{rpm}$ and no effort was made to imprnve dynamic balance. Vibration meusurcments made with the rotor nunning full of water were very satisfactory for operating under mixıng and separating conditions.

A test was performed with the empty rotor to mcasure its stability when nperating in a "free-standing" condition. The bolts holding the spindle angle bracket to the mounting were weighted with steel blocks to compensate for the weight of the overhung spindle. Under these conditions, vibration velocity measured at $1800 \mathrm{rpm}$ was acceptable, and the assembly showed no tendency to move, suggesting that it may be possible to design spindle supports for the multistage array that do not require bolting in place. Such a design would simplify remote handling of the spindle-rotor assembly.

Preliminary hydraulic tests were performed to measure maximum capacity using $30 \%$ $\mathrm{TBP} / \mathrm{n}$-dodecane and dilute nitric acid at an organic-to-aqueous $(\mathrm{O}: \mathrm{A})$ ratio of 1 and a rotor speed of $1750 \mathrm{rpm}$. The dispersion number model, developed from the results of testing the $2-\mathrm{cm}, 9-\mathrm{cm}$, and $25-\mathrm{cm}$ contactors, predicted a maximum throughput of $23 \mathrm{l} / \mathrm{min}$ at $1 \%$ maximum cross contamination. Test results showed $<2 \%$ aqueous contamination in the organic effluent and about $0.25 \%$ organic contamination in the aqueous effluent stream. Additional tests will be performed over a range of $\mathrm{O}: \mathrm{A}$ ratios and throughputs.

The liquid rise over the aqueous and organic weirs was measured using aqueous phasc in both cases. The results conformed very closely to the predictions based upon the model developed from the earlier contactor studies.

The $25 \mathrm{~cm}$ contactor. Hydraulic tests of the $25-\mathrm{cm}$ contactor were rompleted. Except for the tests at an O:A ratio of 1 , this unit could not be tested at maximum capacity because of limitations in capacity of the pumping system. A capacity of $120 \mathrm{l} / \mathrm{min}$ (total phases) was demonstrated at an O:A ratio of 1 and a rotor speed of $1200 \mathrm{rpm}$.

In the course of these tests, additional data were obtained that permitted extension of the model for determining the height of liquid in the Couette (annular) mixing zone. The unit has been shipped to SRL for further testing.

The 4-cm contactor. Fabrication drawings of an annular centrifugal contactor that has a 4-cm-diam rotor were completed. This contactor is expected to be a convenient size for studying the effect of third-phase formation in a dynamic system. The rotor will incorporate a replaceable aqueous weir that will provide some freedom in positioning the emulsion band (or a third phase) within the rotor. A removable bottom is also being used to permit inspection of the interior of the rotor following any tests that might lead to an accumulation of solid particles. 


\subsubsection{Flowsheet engineering studies}

\section{R. T. Jubin and M. E. Whatley}

The MATEX computer code was used to examine the HS, HA, 1A, 1B, 1C, 2A, 2D, $2 \mathrm{~S}$, and $3 \mathrm{~A}$ columns from the 200-series HEF flowsheets. Using the flowsheet conditions, the HA, 2A, 2D, and $3 \mathrm{~A}$ columns can be expected to perform satisfactorily as evidenced by the computer simulation.

The HS column can meet the flowsheet values on the early draft reference flowsheet but will not satisfy those in the current 200 -series flowsheets. By increasing the intermediate feed acid concentration from $2.0 \mathrm{M}$ to $5.0 \mathrm{M}$, the aqueous product stream concentration is reduced to recycle only about $9 \%$ of the plutonium and $18 \%$ of the uranium to the HA contactor.

The $1 \mathrm{~A}$ and $1 \mathrm{~B}$ columns were examined as a single column containing 24 stages. The feed stream contained $95 \%$ of the plutonium as $\mathrm{Pu}(\mathrm{III})$ and $5 \%$ as $\mathrm{Pu}(\mathrm{IV})$. Initial studies assumed no reductant in the combined column. In the case using flowsheet values, virtually all of the $\mathrm{Pu}(\mathrm{IV})$ went overhead in the organic product stream. By reducing the acid concentration in the intermediate scrub feed stream to $0.3 \mathrm{M}$, all the $\mathrm{Pu}$ (III) and $64 \%$ of the $\mathrm{Pu}(\mathrm{IV})$ exits in the aqueous product stream.

The SEPHIS computer code, after modifications to improve the plutonium distribution coefficients, was used to handle the reduction of $\mathrm{Pu}(\mathrm{IV})$ to $\mathrm{Pu}(\mathrm{III})$ in the $1 \mathrm{~A}-1 \mathrm{~B}$ columns. In the flowsheet configuration, the operation of the columns depends on the introduction of sufficient quantities of reductant to reduce all of the Pu(IV) fed to the system.

The $2 \mathrm{~S}$ column flowsheet conditions result in a high uranium loss to the aqueous stream. An eight-stage contactor was simulated to reduce the uranium loss by adding a clean TBP stream having about $5 \%$ of the total organic flow to allow the aqueous to be stripped of uranium. Additional nitric acid was added to both of the aqueous feed streams. The amount of acid added can be used to control the uranium losses. When both streams are $5 \mathrm{M}$, virtually no uranium is lost to the aqueous stream.

The $1 \mathrm{C}$ column was reexamined to determine if it could be reduced in height from 12 to 8 stages. The results indicate that by increasing the previously recommended stripping solution flow rate by $10 \%$, the product quality will not be noticeably affected. This amounts to a $20 \%$ flow increase over the flowsheet conditions.

\subsubsection{Robatel contactor evaluation study}

R. D. Zimmerman, G. E. Benedict, D. R. Engler, A. Freeman, and S. Perone (General Atomic Company)

The Robatel centrifugal contactor is the only commercially available short-residencetime contactor suitable for solvent extraction processing of irradiated nuclear materials. Using the Robatel centrifugal contactor installed in the GA pilot plant, experimental testing has been completed to determine the suitability of this contactor for extracting uranium, for scrubbing ${ }^{95} \mathrm{Zr}$ fission products, and for measuring its capacity for solids without plugging.

The Robatel contactor was used in the extraction or scrub mode, whereas other variables were investigated in a $6.7-\mathrm{m}(22-\mathrm{ft})$ cylindrical column.

The extraction efficiency of the eight-stage Robatel cannot be determined using normal Purex flowsheets because the uranium concentration reaches the limit of detectability $\left(10^{-4} \mathrm{~g} / \ell\right.$ using activation analysis) after only four stages. Earlier testing on this 
unit, using flowsheets modified to give detectable uranium in the aqueous raffinate, indicated the Robatel stage efficiency to be near $100 \%$.

No significant differences have been noted in the scrub section zirconium decontamination when using either a $6.7-\mathrm{m}(22-\mathrm{ft})$ pulsed column or the eight-stage Robatel contactor.

The ability of the Robatel centrifugal contactor to handle feed solids is of interest and a necessary part of evaluation testing. A test run was made to determine the volume of solids required to plug the unit and to determine any operational problems caused by partial plugging. The Robatel contactor became completely plugged for aqueous phase flow when $200 \mathrm{~g}$ of 1 - to 40 -micron glass beads were contained in the machine. It was estimated that partial aqueous-phase flow blockage occurred with about 100 to $120 \mathrm{~g}$ of beads in the contactor. The total holdup volume of the contactor is $3.2 \ell(0.8 \mathrm{gal})$, and the tap density of the beads used was $1.65 \mathrm{~g} / \mathrm{cm}^{3}$.

The power requirement of the Robatel centrifugal contactor was measured using an ammeter with output recorded on a strip chart. Typically, the operating amperage ranged from $4 \mathrm{~A}$ at $1000 \mathrm{rpm}$ to $10 \mathrm{~A}$ at $2000 \mathrm{rpm}$. The strip chart recording also proved to be useful in monitoring the internal condition of the contactor. The amperage and the rpm were responsive to flow rate changes.

\subsubsection{Contactor improvement effort}

\section{R. D. Zimmerman, G. E. Benedict, and D. R. Engler (General Atomic Company)}

Along with the Robatel contactor tests, pulsed columns were operated in the extraction, stripping, and scrub modes. Flow capacities, dispersed phase holdup measurements, and concentration profiles were obtained.

Efficiency determinations are not yet complctc; stage calculations are being performed by comparing analytical uranium concentrations to concentrations predicted by the SEPHIS computer code.

\subsubsection{Flowsheet and modeling tests}

\section{R. D. Zimmerman, G. E. Benedict, and D. R. Engler (Coneral Atomic Company)}

Solvent washing with hydrazine carbonate is being considered as a method for reducing the salt content of reprocessing wastes. Sodium carbonate is presently used in this service. Hydrazine carbonate can be decomposed to gaseous wastes. In recent tests, hydrazine carbonate $\left(0.25 \mathrm{M}\right.$ solution) could not be heated to a temperature of $55^{\circ} \mathrm{C}$ without decomposition. This would limit its use in pulsed-column solvent wash contactors, since an elevated temperature appears to be necessary to achieve adequate washing kinetics. Data reduction on these tests is nearing completion.

The SEPHIS/THOREX computer code predicts the distribution coefficient between aqueous and organic (tributyl phosphate) phases for uranium, thorium, and nitric acid. A study is in progress to verify the SEPHIS computer code equilibrium correlation and provide a basis for future modeling development. A flowsheet with a uranium-to-thorium ratio of 10:1 is being used in pulsed columns. Nine runs have been made using standard nozzle plates to establish a baseline. Profile samples were taken in the extraction and stripping columns. Operating and equilibrium lines will be determined for uranium and for thorium. Three runs have been made using the rosette plate, which has been found to have a higher capacity than the standard nozzle plate. 


\subsection{Off-Gas Processing}

\section{J. Stephenson}

This task consists of the development of various processes for the treatment of reprocessing plant off-gases to ensure that environmental goals are met. Work includes the continued development of the noble gas and ${ }^{14} \mathrm{C}$ selective absorption process, the formulation of plant engineering design criteria, a study of the chemical effects of impurities in the fluorocarbon solvent, and an extended investigation of the distribution coefficients of the noble gases in the fluorocarbon solvent.

The use of solid sorbents for various off-gas purification applications is also being evaluated. Tests of advanced sorbent materials are underway at ORNL, and work on an integrated HTGR off-gas treatment system is proceeding at General Atomic Company. Savannah River Laboratory is beginning a new effort that will lead to an off-gas processing demonstration using a sidestream of a radioactive off-gas stream at the Savannah River Plant.

\subsubsection{Fluorocarbon absorption process development}

\section{J. Stephenson, B. E. Kanak, and D. K. Little (ORGDP)}

An analysis of pilot plant data taken earlier this year revealed a potential improvement in the combination column design. It was found that the diameter of the intermediate section of the column should be better matched to that of the absorber section for optimum operation of both sections. As a result, the existing 3-in.-diam intermediate section was enlarged to $4 \mathrm{in}$. The net effect of this modification is to allow higher process solvent and feed gas flow rates. An increase in throughput of about $30 \%$ is expected at an optimum solvent flow of about $1.6 \mathrm{gpm}$ vs the previous value of $1.1 \mathrm{gpm}$.

As with the three-column process, a rigorous differential mass and heat transfer model is being developed to describe the operation of the combination column. The operating campaign is now underway.

\subsubsection{Off-gas processing demonstration}

J. D. Spencer, S. F. Peterson, A. J. Hill, Jr., and M. C. Thompson (Savannah River Laboratory)

A literature survey and program has been started to identify potential processing systems that could be applicable to each off-gas isotope. Various sites engaged in off-gas processing work have been visited to observe equipment in operation and to discuss plans and details relative to the most advanced technology.

Preliminary criteria developed for an objective evaluation of all the processes for an integrated off-gas facility include (1) decontamination factors, (2) operability and reliability, (3) maintenance, (4) safety, (5) compatibility, and (6) initial and operating costs. Each criterion will consist of several specifications, and additional criteria may be added to ensure a complete evaluation.

Process requirements, especially decontamination factors, are being investigated. At present, Environmental Protection Agency regulations which cover only ${ }^{85} \mathrm{Kr}$ and ${ }^{129} \mathrm{I}$ help to determine the required factors. The removal of ${ }^{3} \mathrm{H}$ and ${ }^{14} \mathrm{C}$ will depend on the processes used and their interference with ${ }^{85} \mathrm{Kr}$ removal. The $\mathrm{NO}_{x}$ content of the off-gas may have to be lowered to $<1 \mathrm{ppm}$ to prevent interference with some processes for the removal of other components. 
The concentrations of the various components present in the SRP off-gas have been determined and compared with the off-gas from an LWR reprocessing plant. All components except tritium are present in reasonable concentrations. The tritium will have to be added as HTO.

\subsubsection{Solid sorbent tests}

\section{R. T. Jubin}

Within the HEF reference flowsheet, there are several places where solid sorbents can potentially be used to treat off-gases. Modern sorbents, such as metal substituted mordenites and silicic acid, are to be evaluated for those applications.

Three additional runs with silver mordenite $(\mathrm{AgZ})$ were completed this quarter to obtain data on the removal of elemental iodine from air for comparison with reported values. The test bed consistcd of four 1 -in.-thick beds, each 2 -in. in diameler. The air flow rate was $20 \mathrm{slpm}$. The total iodine loadings were determined by activation analysis. These tests indicated a maximum loading of about $60 \mathrm{mg} I_{2}$ per $\mathrm{g}$ of bed material, a value that compares well with other available data.

Testing of $\mathrm{AgZ}$ as a potential trap for $\mathrm{CH}_{3} \mathrm{I}$ began this quarter. A total of 12 runs were made using four to six 1-in.-thick beds in the 2-in.-diam main filter. The runs were made with an air tlow rate of 20 slpm and a filter temperature of $150^{\circ} \mathrm{C}$. Two methods of sorbent pretreatment were employed. In one case, a $2-\ell / \mathrm{min}$ flow of dry air was passed through the bed at a temperature of $200^{\circ} \mathrm{C}$ for $24 \mathrm{~h}$. In the second case, about $4 \% \mathrm{H}_{2}$ in argon was used in place of air.

The first five runs were made for equipment check-out purposes and to determine parameter values for the statistically designed set of experiments to follow. These experiments will examine the effects of $\mathrm{CH}_{3}$ I concentration, relative humidity, bed pretreatment, $\mathrm{NO}$ and $\mathrm{NO}_{2}$ concentration, and filter temperatures on the removal of $\mathrm{CH}_{3} \mathrm{I}$ from an off-gas stream. A summary of the first 12 runs is presented in Table 3.2. Eleven additional runs are required to complete the statistical set. Iodine loadings determined by tracer analysis using ${ }^{131} 1$ are in the process of being checked by activation analysis for total iodine content. No definitive statements can be made at this time regarding gencral trends other than that higher loadings are achieved at higher temperatures.

\subsubsection{Integrated HTGR off-gas treatment system}

R. D. Zimmerman, U. S. Park, C. J. Everline, P. W. Newman, R. D. Crabtree, P. M. Hirsch, and J. A. Oita (General Atomic Company)

When a nuclear fuel cycle containing ${ }^{232} \mathrm{U}$ or ${ }^{232} \mathrm{Th}$ is contemplated, the impact of the decay chain of ${ }^{232} \mathrm{U}$ or ${ }^{232} \mathrm{Th}$ must be considered; this is because the isotope daughter products have relatively short half-lives and several energetic gamma rays. The decay chain is shown in Fig. 3.5. The most significant element of this chain, ${ }^{220} \mathrm{Rn}$, is a gas at ambient temperature with a half-life of $55.6 \mathrm{~s}$. The elements above ${ }^{220} \mathrm{Rn}$ are all solids with very low vapor pressures; the daughters below ${ }^{220} \mathrm{Rn}$ decay rapidly and emit several energetic gamma rays.

Radon-220 in the spent fuel element does not pose any problem while in storage, since it rapidly decays in place into its solid daughter product. However, since radon- 220 evolves from the fuel and its solutions into the off-gas stream during processing, treatment is necessary. Although the amount of ${ }^{220} \mathrm{Rn}$ in the fuel element at any instance is very small, it 
Table 3.2. $\mathrm{CH}_{3} \mathrm{I}$ loading on silver mordenite as determined by ${ }^{131} \mathrm{I}$ tracer analysis

\begin{tabular}{|c|c|c|c|c|c|c|c|c|c|c|c|}
\hline \multirow[b]{2}{*}{ Conditions } & \multicolumn{10}{|c|}{ Run } & \multirow[b]{2}{*}{12} \\
\hline & 1 & 3 & 4 & 5 & 6 & 7 & 8 & 9 & 10 & 11 & \\
\hline Temperature, ${ }^{\circ} \mathrm{C}$ & 150 & 150 & 100 & 100 & 100 & 100 & 100 & 100 & 150 & 150 & 100 \\
\hline Pretreatment $\left(24 \mathrm{~h}\right.$ at $\left.200^{\circ} \mathrm{C}\right)$ & Air & Air & $\mathrm{H}_{2}$ & $\mathrm{H}_{2}$ & $\mathrm{H}_{2}$ & $\mathrm{H}_{2}$ & Air & Air & Air & Air & $\mathrm{H}_{2}$ \\
\hline NO content, $\%$ & 3 & 3 & & & & & 3 & 3 & & & 3 \\
\hline $\mathrm{NO}_{2}$ content, $\%$ & & & & & 1.3 & 1.3 & 1.3 & 1.3 & & & \\
\hline $\mathrm{CH}_{3} \mathrm{I}$ concentration, $\mathrm{mg} / \mathrm{m}^{3}$ & 3000 & 750 & 750 & 1000 & 500 & 500 & 500 & 500 & 500 & 500 & 500 \\
\hline Dewpoint, ${ }^{\circ} \mathrm{C}$ & $\mathrm{BDA}^{a}$ & $\mathrm{BDA}$ & BDA & BDA & BDA & BDA & $\mathrm{BDA}$ & $\mathrm{BDA}$ & 36.7 & 37.8 & 39.5 \\
\hline \multicolumn{12}{|l|}{ Bed loading $\left(\mathrm{mg} \mathrm{CH}_{3} \mathrm{I} / \mathrm{g}\right)$ in } \\
\hline Segment 1 & 1.78 & 6.70 & 43.8 & 25.5 & 2.88 & 3.67 & 1.94 & 2.98 & 8.90 & 5.27 & 6.49 \\
\hline Segment 2 & 2.16 & 3.79 & 15.6 & 19.8 & 2.52 & 2.98 & 1.89 & 2.92 & $6: 55$ & 3.38 & 3.86 \\
\hline Segment 3 & 1.71 & 0.58 & 1.55 & 13.6 & 2.56 & 2.05 & 1.56 & 2.62 & .2 .74 & 1.59 & 1.12 \\
\hline Segment 4 & 1.17 & 0.0051 & 0.107 & 1.43 & 1.59 & 1.27 & 0.79 & 1.82 & 0.85 & 0.46 & 0.19 \\
\hline Segment 5 & & & & & 0.49 & 1.28 & 0.22 & 0.85 & 0.14 & 0.09 & 0.036 \\
\hline Segment 6 & & & & & 0.001 & $<0.001$ & 0.005 & 0.12 & $<0.001$ & 0.002 & 0.002 \\
\hline
\end{tabular}

${ }^{a}$ Bone dry air. 


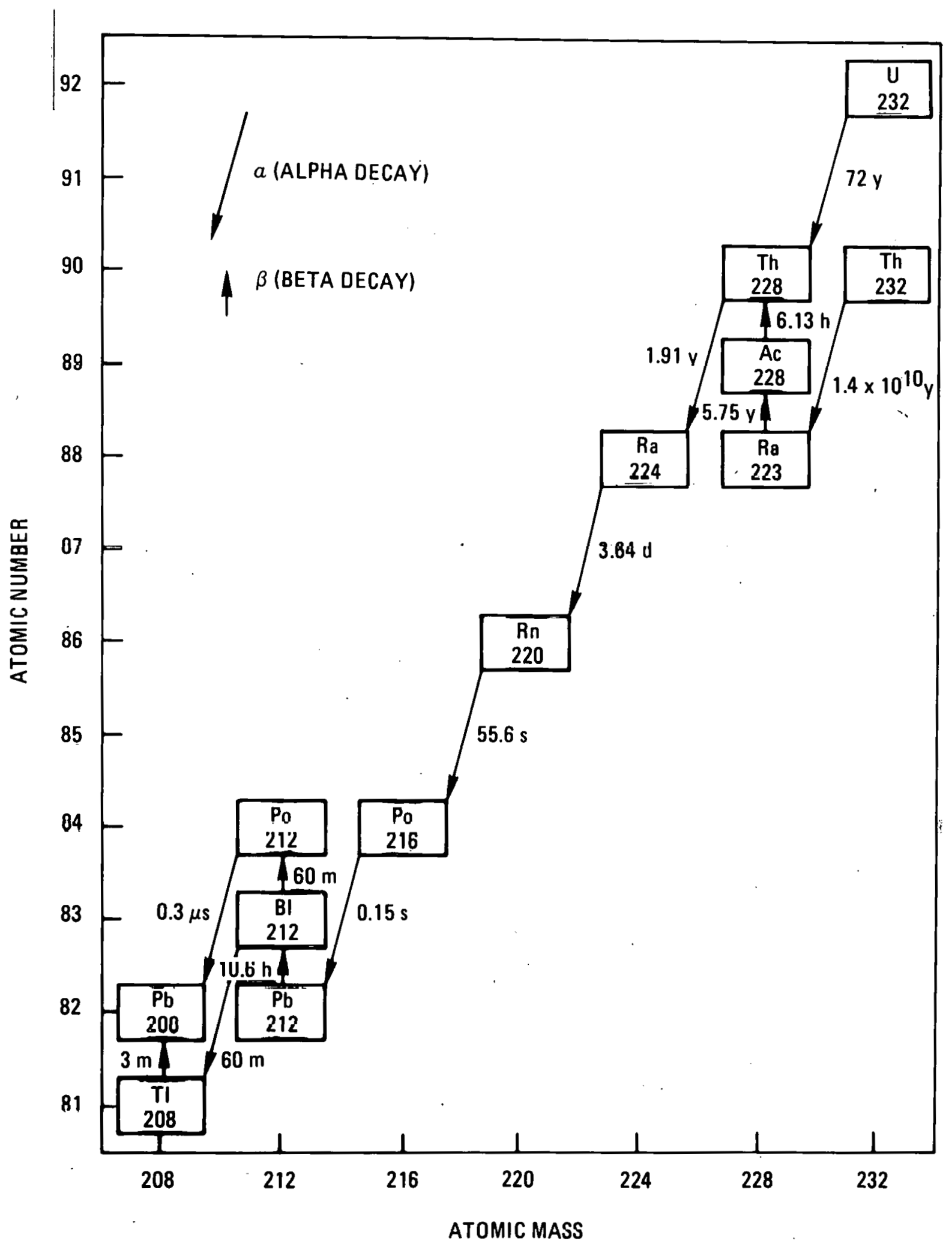

Fig. 3.5. Decay chain for ${ }^{232} \mathrm{U}$ and $232 \mathrm{Th}$. (Courtesy General A tomic Company) 
is continuously generated from its predecessors (an equilibrium concentration of ${ }^{220} \mathrm{Rn}$ can be restored in a few minutes after the complete removal of ${ }^{220} \mathrm{Rn}$ from the source material).

A delay bed using the chromatographic action of molecular sieve adsorbents has been developed and feasibly demonstrated in a laboratory-scale unit. ${ }^{1}$ Because of the small mass of the daughter products $(<1 \mathrm{~g} /$ year from a full-scale commercial reprocessing plant), the front end of the bed does not get saturated, and a stationary adsorption front profile is established, which permits continuous operation despite chromatographic separation being, in principle, a batch operation. In reality, however, the decontamination factor (DF) will decrease with time, as observed experimentally, ${ }^{1}$ due to the adsorption of other impurities; therefore, an occasional regeneration of the bed will become necessary.

To demonstrate the technical feasibility of this process on an engineering scale, an adsorption-decay bed (0.36-m-diam by 3.5 -m-long) has been installed in the GA off-gas system. A ${ }^{220} \mathrm{Rn}$ gas generator has been designed to provide radon to the system. All backup calculations for the determination of source size, shielding requirement, size of detection windows, and the length of detection time vs resolution have been documented. Efforts are underway to obtain ${ }^{232} \mathrm{U}$ source material from OKNL for this test.

At present, the integrated off-gas system operates on simulated burner off-gas (BOG) and dissolver off-gas (DOG); however, for a future integrated operation, the BOG and DOG systems must be physically tied to the burner and the dissolver respectively. All materials ordered during the last quarter have been received, including the BOG and the DOG compressors. The DOG compressor has a special inner surface coating and treatment to minimize corrosion from nitric oxides and moisture. The system was completed and installed on schedule during this quarter.

Two field-mounted iodine analyzers (Mast* model 724-5 and 724-6) have been installed and are being calibrated using permeation tubes in a Dynacalibrator* system. Meter readings and the calculated calibration gas concentration from known permeation rates agree very well. Detection of iodine concentration less than $0.1 \mathrm{ppm}$ would seem possible without using a radioactive tracer.

A CVC* time-of-flight (TOF) mass spectrometer has been received and installed; however, much wiring and assembly remain to be done. The TOF mass spectrometer is known to have better sensitivity than quadra-pole mass spectrometers; furthermore, it is suitable for process monitoring. Trace elements in the off-gas stream, that is, iodine, methyl iodide, and krypton, will be analyzed with this instrument.

The experimental runs on the off-gas system are being conducted according to the urfgas system activity plan. Activities in the BOG unit test have begun this quarter and will continue into next quarter. The combined BOG and DOG systems, as installed in the pilot plant, are shown schematically in Fig. 3.6. Each individual process unit, except for the $\mathrm{SO}_{2}$ adsorption process and the staged $\mathrm{CO} / \mathrm{HT}$ oxidation, has been verified for its feasibility using laboratory-scale equipment. To establish the feasibility of the latter two processes, the experiment began with the $\mathrm{SO}_{2}$ adsorption unit.

A higher-than-normal concentration of $\mathrm{SO}_{2}$ in the $\mathrm{BOG}(20 \mathrm{ppm})$ was used because of the lower detection limit of the analyzer. Lower $\mathrm{SO}_{2}$ concentrations will be tested later during a detailed component test. A typical breakthrough curve is shown in Fig. 3.7.

The test results indicate several important points which are listed below. (A more detailed analysis is in progress.)

*Trade names of Mast Development Company, Metronics, and CVC Pivducts, Inc., rcspcctivcly. 


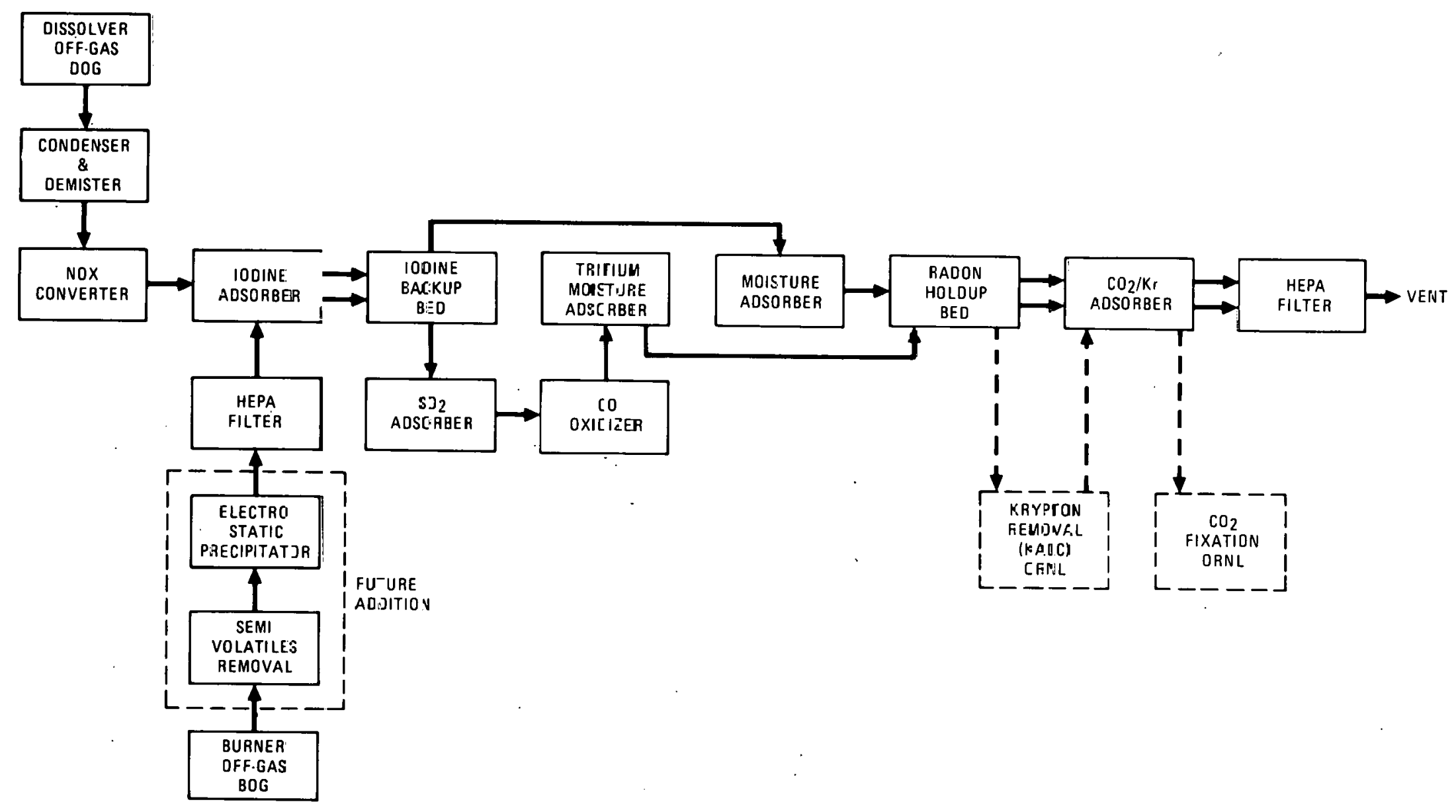

Fig. 3.6. Flow of the integrated ECG and DOG systems. (Courtesy General Atomic Company) 




Fig 3.7. Typical $\mathrm{SO}_{2}$ breakthrough curve. (Courtesy General Atomic Company) 
1. Because of the significant coadsorption of $\mathrm{CO}_{2}$, the dynamic equilibrium adsorption capacity of $\mathrm{SO}_{2}$ from $\mathrm{CO}_{2}$ is much less than that from $\mathrm{N}_{2}$ (or air).

2. Zeolon $900 \mathrm{Na}$ has nearly three times as much adsorption capacity than Zeolon $900 \mathrm{H}$ for $\mathrm{SO}_{2}$ from $\mathrm{CO}_{2}$, that is, 29.9 vs 10.9 and $9.06 \mathrm{mg} / \mathrm{g}$. In the presence of excess oxygen and moisture, the adsorbed $\mathrm{SO}_{2}$ on Zeolon $900 \mathrm{Na}$ can form $\mathrm{Na}_{2} \mathrm{SO}_{3}$ and $\mathrm{Na}_{2} \mathrm{SO}_{4}$. Although the BOG stream is normally very dry, some moisture can reach the $\mathrm{SO}_{2}$ bed during a process shutdown. It would be advisable to desorb moisturc from the bed after a long downtime. Chemical analyses are in progress for the analysis of $\mathrm{Na}_{2} \mathrm{SO}_{3}$ and $\mathrm{Na}_{2} \mathrm{SO}_{4}$ in the samples taken.

3. The length of mass transfer zone (LMTZ) expands with an increase in bed depth. Usually, the LMTZ is independent of bed length because of the balancing effect of diffusional resistance and the self-sharpening tendency of the band with a favorable isotherm. Considering the fact that the breakthrough curve is a typical Srhumann-Furnas rourve, ${ }^{2}$ which is based on a linear isotherm, the process is extremely limited by diffusion in solids.

4. The implied linearity of the isotherm (mentioned above) is very encouraging, since it also implies that a good separation of $\mathrm{SO}_{2}$ can be anticipated at a lower $\mathrm{SO}_{2}$ concentration.

5. The expansion of LMTZ with bed length means that the efficiency of the bed decreases with an increase in bed depth. Any increase in the bed capacity should be achieved by an increase in bed diameter (and not in the bed length), which will reduce the LMTZ because of a lower superficial velocity. Also, the use of multiple beds of small size instead of a long bed would be required in a scale-up, which, in turn, requires a rigorous economic analysis.

6. No observable difference in $\mathrm{SO}_{2}$ adsorption is noticed for Zeolon $900 \mathrm{Na}$ after three regenerations. Regenerations were performed using heated $\mathrm{CO}_{2}$ at $200^{\circ}$ to $250^{\circ} \mathrm{C}$.

7. The breakthrough is very sensitive to the temperature fluctuations. As the bed temperature drops, the front end of the bed starts to adsorb an addilional amount of $\mathrm{SO}_{2}$, resulting in a reduced effluent concentration.

\section{References}

1. H. S. Meyer, "HTGR Fuel Ropronsssing, Head-Find Off-rạs Treatment," paper presented at the AIChE 82nd National Meeting, Atlantic City, New Jersey, August 29September 1, $10,76$.

2. C. R. Furnas, Trans. AIChE 24, $142(1,930)$. 


\title{
4. ENGINEERING SYSTEMS
}

\author{
M. J. Feldman
}

The scope of the work performed in the area of Engineering Systems spans the development of prototype equipment and the conceptual design of the Hot Experimental Facility (HEF). The design of prototype equipment is based on other research and development efforts, primarily those of the Process Research and Development and the Engineering Research sections of the CFRP. These efforts include the development of individual equipment items and systems and the interaction between various equipment items in series. The Integrated Equipment Test (IET) facility provides for the synergistic testing of equipment and also the testing of the remote operation capabilities and characteristics of these components and systems.

The conceptual design of equipment and systems to be incorporated into the HEF will be derived from these development efforts.

The status of each of these efforts, including the conceptual design for the HEF, will be reported quarterly.

\subsection{Engineering Analysis}

\section{J. Feldman}

Engineering Analysis performs studies and analyses in broad areas that overlap individual tasks and provide background and recommendations for decisions pertaining to programmatic guidance and directions.

\subsubsection{Study of reprocessing facilities at a nuclear energy center M, I, Haịre and D, C.. Hampson}

The study of reprocessing facilities at a nuclear energy center has been interrupted since last January in order to support the Nonproliferation Alternative Systems Assessment Program (NASAP). The objective of this support activity was to develop relative costs for reprocessing alternative nuclear fuels based upon the economic data developed in the energy center study. The results of the NASAP work were reported last quarter. The NASAP support activity was terminated this quarter with the publication of a final report on The Economics of Reprocessing Alternative Nuclear Fuels, ORNL/Sub-7501/4, and with the presentation of a paper under the same title at the national AiChE meeting in San Francisco in November 1979.

A computer program used to calculate reprocessing facility costs for the energy center study became operational. The program is now being expanded to include the calculation of costs for several additional reprocessing configurations. A final report on Reprocessing in Nuclear Energy Centers: General Licensing Requirements, ORNL/Sub-7501-3, was issued. 


\subsubsection{Thermal analysis of irradiated fuel subassemblies}

\section{J. Haire and C. A. Rhodes}

Efforts are underway to evaluate various techniques for cooling irradiated FBR fuel subassemblies in the disassembly/shear system. Simple bounding calculations where nitrogen cell gas flows perpendicularly across the exterior of the subassembly indicate that this method of cooling can reduce a CRBR fuel rod temperature (at 90-day decay) only about $50^{\circ} \mathrm{C}$. Because the fuel rod temperature is reduced so little by this upper bound condition, this technique for cooling the subassembly was abandoned. Analyses are now underway to evaluate subassembly cooling by forcing gas axially through the subassembly.

\subsubsection{Cost impact of remote maintenance on fuel reprocessing plants U. C. Hampson}

Science Applications, Incorporated (SAI), Richland, Washington, has concluded a one-year study of the cost impact of remote maintenance in fuel reprocessing plants. The study objective was to evaluate the cost effectiveness of various remote options in a commercial plant design. The draft of a summary report has been reviewed and comments are being incorporated into a final report.

\subsection{Component Development.}

\section{E. D. North}

Component Development work is a follow-on to the Engineering Research effort. The Component Development mission is to design, fabricate, and demonstrate the performance of pilot-plant process equipment capable of remote operation and maintenance.

The dissolution task is currently active, and it is anticipated that the solvent extraction, feed preparation, and product conversion tasks will be activated in the near futurc.

\subsubsection{Dissolution \\ J. Q. Kirkman}

The Component Development cffort in the dissolution area is directed toward designing, constructing, and testing a $0.5-\mathrm{t} / \mathrm{d}$, pilot-plant-scale dissolver system. This unit consists of a remotely maintainable rotary dissolver integrated with the necessary support equipment.

Prototypical rotary dissolver. Although work during this report period was concentrated primarily on instrumentation and control activities related to the entire dissolution system, two separate tests involving the dissolver were conducted.

The first set of tests was an extension of previous investigations studying the response of the liquid outlet stream to simultaneous step changes in liquid inlet flowrate and inlet concentration. The objective of the tests was to determine the effect of drum rotational speed on the outlet stream response to transients in flow and to their concentration in the dissolver inlet stream.

The second series of tests involved operation of the acid recovery system with hot nitric acid to establish conditions which would concentrate the acid leaving the dissolver to 
the same level as the original feed acid concentration. The key components required are the dissolver product digestion tanks, where acid is distilled, and the $\mathrm{NO}_{\boldsymbol{x}}$ scrubbing system, where acid in the vapor is condensed as a product. The purpose of this development work is to reduce waste disposal charges by recovering and recycling the nitric acid. The recovery process will initially be useful during future dissolver mechanical reliability tests. These tests are designed to accumulate operating hours on the dissolver and basically involve long-term, continuous operation at temperature and normal nitric acid feed flow.

Dissolver support systems and process equipment. Necessary support systems have been integrated with the rotary dissolver to form an operable dissolution process. The support systems include a feed system, product collection system, product clarification system, $\mathrm{NO}_{x}$ scrubbing system, and a digital control system. The dissolver support system was described in previous quarterly reports.

The dissolver support systems and process equipment were incorporated in the prototypical rotary dissolver tests described above. All components performed satisfactorily.

The product tank diversion valve, whose mechanical failure was reported last quarter, has been repaired and reinstalled. Needle valves have been placed in the air cylinder operating lines, slowing the valve stroke time and thereby decreasing the deceleration forces imposed on the mechanical linkages. Valve operation has been satisfactory since modification.

Dissolver instrumentation (D. M. Fleischer, W. F. Johnson, J. A. McEvers, R. F. Spille, R. M. Tate, R. W. Tucker, Jr., G. R. Wetherington, Jr., and W. L. Zabriskie). Instrumentation efforts during this report period have involved software development activities, hardware development work, and experimental investigations of the temperature effects on flow elements.

Software activities focused on two major tasks. First, the source program for the dissolver system unit process controller has been reorganized, updated, and converted to provide the ability to printout on demand all key constants and parameters in the control program. In addition, for documentation purposes, a permanent record can be made of all program changes. The second software task involved the development of a color CRT display which graphically presents the basic dissolver system parameters. Key information (such as flowrates and concentrations) is presented in a manner that is quickly and easily understond.

Hardware development work has been focused on the design of a compact instrumentation module for use in tanks. Basically, in one removable package, the module provides the dip tubes necessary for tank level and density measurements. The objectives of this work are to improve the accuracy of level and density measurements and provide an easily replaceable instrument arrangement.

A careful calibration of dissolver system flow meters with water at four different temperatures showed that the system was very sensitive to temperature changes, probably due to changes in viscosity. Viscosity changes are expected not only from variations in temperature, but also from concentration changes. Investigations are underway to correlate the observed data and to devise a method by which true flowrate can be calculated from observed capillary pressure drop, measured fluid temperature, and measured concentration. 


\subsection{Systcms Development}

\section{N. R. Grant}

The Systems Development work is directed toward the development of certain major mechanical components and systems required for fuel reprocessing. The goal of Systems Development is to design, fabricate, and operate pilot-scale, prototypic, remotely operable equipment.

The tasks assigned to this area are the disassembly and cutting systems, the voloxidation equipment, the Integrated Equipment Test (IET) facility, the receiving and storage systems, the special remote systems, the remote control engineering systems, the waste handling systems, and the procurement of depleted uranium fuel to be used for tests, equipment, and process development.

\subsubsection{Disassembly and cutting}

S. A. Meacham (Westinghouse Advanced Reactors l)ivision), E. C. Bradley, D. K. Lorenzo, B. S. Weil, and W. F. Johnson

The disassembly and fuel cutting efforts are responsible for the mechanical preparation of fuel materials for the succeeding steps of voloxidation and dissolution. To accomplish this objective, the task will develop equipment that will remove the undesired components, such as inlet and outlet nozzles, from the fuel assembly and will cut the remaining portion of the assembly into short pieces. The sheared product will expose the contained fuel for subsequent oxidation (in the voloxidizer) and leaching (in the dissolver). The goal of the task is to produce the necessary design, equipment, and data required for the successful operation of prototype units in the IET and similar equipment in the Hot Experimental Facility (HEF).

\section{Disassembly systems}

Disassembly machine. The Disassembly System Integration Study was the topic of several progress reviews held this quarter with Sundstrand Energy Systems, Inc. The objective of this study is to evaluate the requirements of the individual disassembly equipment subsystems and to determine the development approach for integrating these subsystems.

After a preliminary evaluation of several approaches, a "multistation" system, which uses dedicated, single-purpose equipment was selected. Station 1, the disassembly station, consists of a fuel lay-down mechanism with cooling, a rotation drive with cooling, laser cutter and plasma torch positioning and drive equipment, inlet noz.7le removal mechanism, and a transfer table which could also be used to provide cooling. Station 2 , the shear feed station, uses the same transfer table as part of the feed bed and also includes fully enclosed shear feed with cooling and gas circulation equipment and movable side restraints for directing the fuel into the shear.

Disassombly instrumentation and control (W. F. Juhrisur, L. E. Ottinger, and G. $R$. Wetherington, $J r$.). Preliminary investigations were begun to determine applicable measurement techniques to use on the disassembly systems. This includes instrumentation for the various cooling systems and position control for the laser cutting head. 
Plasma torch. Several stainless steel dummy end plug subassemblies were successfully cropped by the PT-250 (Linde Division, Union Carbide Corporation) plasma torch using a constant spacing between the torch and the work. Cuts were also made with the torch locked in a fixed position over the subassembly. The internal compensating circuitry of this torch accommodated the variations in the torch-to-work spacings resulting from the corners and flats of the rotating subassembly. Testing of the PT-250 was completed when four prototypic 3-ft subassemblies were cropped adjacent to the simulated lower end fitting.

The PT-7 (Linde Division, Union Carbide Corporation) plasma torch has been reinstalled and test circumferential cuts are being made on stainless steel subassemblies. Transverse plasma torch cutting of the subassembly will be performed next quarter, which will complete the experimental test program for this torch.

Plasma torch instrumentation and control (W. F. Johnson, L. E. Ottinger, and G. R. Wetherington, $J r$.). Testing was completed of potential radio frequency (rf) interference effects on in-cell equipment adjacent to a plasma torch. The last tests exposed a Bristol UCS-3000 unit process controller and a microprocessor development package to electrical variations caused by the plasma torch arc. Both units continued to operate and control correctly. A summary report of all the experiments is being prepared.

Attempts to measure the plasma torch cutting power were hampered because of instrument and installation problems. Heavier wiring was installed between the instruments and the plasma torch, the weld current relay was modified to allow proper operation, and the power calculator has been repaired, calibrated, and reinstalled. Since the PT-250 plasma torch power supply operates similar to a constant current source, the torch voltage and torch power will be measured and recorded and used as indications of torch operation.

Laser cutting development. Laser optical materials underwent ${ }^{60} \mathrm{Co}$ irradiation this quarter at Argonne National Laboratory. The test set consisted of two groups of coated zinc selenide window material and two groups of metallic mirrors. Some oxidation occurred on the copper mirrors and their reflectivity is affected in the wavelength region of visible light. Although a $\mathrm{CO}_{2}$ laser beam (infrared wavelength) would not be affected, oxidation of copper mirrors would interfere with optic train alignment since visible light is uscd for this purpose. The effects on the absorptivity (a measure of absorbed laser energy) of zinc selenide as a laser window substrate were evaluated. Two anti-reflection coatings, $\mathrm{PbF} / \mathrm{ZnS}$ and $\mathrm{ThF}_{4} / \mathrm{ZnSe}$, were tested.

Laser cutting tests examined the precision of location of the focusing mirror relative to the work. In addition, cropping the hardware from PWR and CRB $\bar{R}$ dummy subassemblies was successfully demonstrated.

Six slitting cuts were conducted on the laser demonstration unit as a check-out test of its capabilities. Three cuts were made while using the active follower (stand-off spacer), and three cuts were made with the passive follower. The active follower requires no further modification; however, some design changes would be made to improve the passive system.

The United Technologies Research Center (UTRC) laser subcontract was extended and a report on the work performed to date was submitted. The extension will permit (1) further delailed testing of the laser demonstration, (2) a demonstration of current disassembly scenarios, (3) a study of methods for remote alignment verification, and (4) a study of methods for verifying the success of the laser cutting operation in a hot cell.

\section{Shear systems}

Remote shear development. The experimental plan for the water-base hydraulic fluid irradiation tests is being reviewed. An order for the stainless steel sample containers has been 
placed, and the sample preparation phase of the tests will begin when the containers are received.

Birdsboro shear. The experimental plan for FY 1980 calls for the design and fabrication of one tooling set which incorporates the features selected for the remote shear. The tooling will be tested in the Birdsboro shear using full-scale dummy assemblies that have been disassembled by the plasma torch and laser. In addition, the experimental plan includes shearing dummy assemblies that contain a mixture of iron and magnetite. This material was required by the dissolver task in order to have a sheared product that contains a dissolvable substance as a stand-in for urania.

\subsubsection{Integrated Equipment Test (IET) facility}

J. G. Stradley, H, W. Harvey, J. B. Kendall (Exxon Nuclear Company), and E. L. Nicholson

The IET task consists of the design and construction of modifications and additions to an existing area at ORNL (7600 area) to provide an experimental engineering laboratory where systems testing on process equipment can be studied and evaluated, and where remote handling and maintenance procedures can be developed.

The project is comprised of three basic parts. The first of these establishes an area where specific process equipment pieces that have evolved from development efforts can be joined together with supporting process equipment and operated as an integrated system. This portion of the IET facility is designated as the Integrated Process Demonstration (IPD). The second part consists of the construction of special facilities where testing of the remote operation and maintenance capabilities of process equipment can be performed. This area is named the Remote Operation and Maintenance Demonstration (ROMD) and consists of a cell mock-up area complete with simulated shielding, viewing systems, manipulators, cranes, and transfer devices. The third part is the General Plant Facility (GPF), which is comprised of structural modifications, utility system expansions, and construction of auxiliary facilities, all of which are required to support the IPD and ROMD experimental progrants.

Planned experimental programs for the IET facility constructed by this project do not use plutonium or fission products, but instead make use of natural uranium, process gases, and trace amounts of radioactivity.

This project interfaces closely with other elements of the CFRP in that process equipment being evaluated in this facility is supplied in a large part by separately funded Component Development and Systems Development efforts within the program.

The status of the Title II design for the three phases is as follows:

1. The IPD design effort (without the Iodox system) is behind schedule ( $88 \%$ actual vs $96 \%$ scheduled). Design efforts on the Iodox and magnesium nitrate systems are being continued.

2. 'The design for ROMD is $95 \%$ complete vs $99 \%$ scheduled.

3. The GPF design is complete and a contract has been awarded for the required work. The contractor started in July, and is approximately $30 \%$ complete, with completion scheduled for May 1980.

It is now planned to have one contractor for installation of the IPD and ROMD lineitem equipment items. This contract is scheduled to be awarded by June 1980 .

Integrated Process Demonstration (IPD). The tanks, heat exchangers, evaporators, piping, and other IPD equipment items furnished by the line-item are being procured by 
UCC-ND for installation by the contractor. Title II design is $88 \%$ complete and procurement is in progress for all the major pieces of equipment except the Iodox system.

Bids on the distributed data acquisition and control system are still being reviewed, and it is anticipated that a contract for this system will be awarded in March 1980.

The design of the piping and instrumentation continues. Several of the advance procurement items have arrived. Numerous other items will be completed by their vendors during the next quarter.

Remote Operation and Maintenance Demonstration (ROMD). Work continues by PaR Systems, Inc., on the contract for the integrated crane and manipulator system.

The remote shielding walls, horizontal transfer devices, remote mirrors, vertical transfer device, and television system are all in the procurement cycle.

Contracts have been awarded for the master/slave manipulators and periscope. These items should be delivered during the next reporting period.

\subsubsection{Receiving and storage}

\section{S. A. Meacham (Westinghouse Advanced Reactors Division) and E. C. Bradley}

Nondestructive assay. One of the goals of the receiving and storage task is to provide a nondestructive assay system that will provide a rapid determination of the total fissile material content of spent reactor assemblies. The system will utilize neutron source and proportional counters to determine fissile content. This subtask effort, however, is concerned with the conceptual design of mechanical portions of the system, and nuclear development is being pursued by the I\&C portion of the Technical Support Section (see Sect. 5). The design concept for the mechanical portion has been developed by Sundstrand Energy Systems, Inc., and the final report on the assessment study of the nondestructive assay (NDA) mechanical system has been submitted. The goal of the assessment study was to determine the preferred equipment development approach for the NDA mechanical system. The recommended system consists of two support structures - one that supports the 28 interim storage fuel canisters and the fuel handling machine and the other, the NDA device, detector enclosure, and source positioning mechanism. Both are structural steel weldments that are bolted into position. A typical operating scenario includes a series of three neutron measurements. One measurement determines the neutron background resulting from the fuel assembly; the second one measures the neutron background attributable to the neutron source device; and the third includes both of these backgrounds plus the neutrons generated by the tission of the fissile material in the fuel assembly as a result of being exposed to these neutron sources. Four neutron detectors measure this data. These units are inserted into the NDA device from outside the cell through long, sealed tubes. Motor drivers with rate feedback, temperature measuring devices, and proximity switches are included to provide the required motions and feedback signal information. Devices that are tolerant of a radiation environment were selected. The required signal conditioning modules and motor controllers are located out-of-cell and are to be part of the local instrumentation and control system. A microprocessor-based digital process unit controller will control and monitor the operation of the NDA station components.

Storage. The Westinghouse-ARD/ORNL Corrosion III experiments with irradiated stainless steel cladding specimens continued this quarter. The surface characterization of selected post-test irradiated claddings continued; the extended water exposure of the remaining cladding specimens was also continued. The purpose for extending the water exposure program is to provide information on an additional eight- to ten-months' water storage for the prototypic cladding specimens. 


\subsubsection{Special remote systems}

R. Blumberg and W. F. Schaffer, Jr.

The objective of this task is to develop special remotely operable components and systems that are common to the major needs established by the requirements of the HEF conceptual design or by other tasks in Component or Systems Development. There are three systems currently being developed: remote connectors and jumpers, remote welding, and remote sampling.

Remote connectors and jumpers. The development program for improving remotely operated connectors, which has been described in previous progress reports, is updated below.

Modification of the Hanford-Purex (HP) connector. Design work has been started to provide improved remote change-out capability for the seals which are presently held in place by conventional retainers. The " $C$ " ring seal is also being modified to accept metal "O" rings for improved sealing capability under the low pressure conditions typical of the majority of the process piping systems. The sealing surfaces of this connector are also being relocated for better protection against inadvertent damage. Helium leak tests on the Grafoil seal in the HP connector were oompleted.

Alternate designs. Two different advanced connector design prototypes, designed and fabricated by MBAssociates (MBA), failed to pass a requirement of the quality assurance preshipment tests. MBA has attributed the failure to insufficient seal preload resulting from frictional forces in the clamping mechanism that were higher than predicted by engineering calculations. Subsequently, a detailed inspection of the connector parts at ORNL uncovered dimensional errors which could account for part of the operability problem. A dimensional analysis and study of material and mechanical improvements has been started.

The ORNL-designed connectors using the Gamah seal have been received from the fabricator, Gamah Division of Stanley Aviation Corporation. The seal has been modified to improve remote assembly by changes in guiding surfaces and to facilitate remote replacement of the seal. Preshipment leak tests by the vendor were acceptable. These connectors will be incorporated in a jumper assembly and tested for remote handling and operation in 'IURF'.

Remote handling tests. Preliminary remote handling tests are being conducted in cell $\mathrm{E}$ of TURF to evaluate both connector performance and remote handling equipment. A structural steel stand is provided to simulate spatial configurations of removable connecting piping, known as jumpers*, between fixed pipe terminations and equipment modules, between fixed pipe terminations, or between equipment modulcs. Improved remotc handling equipment consisting of a three-axis, computer-positioned-controlled $\mathrm{PaR} 3000$ manipulator and a torque-limiting impact wrench, along with a 4500-kg remotely operated crane, are being used for the jumper handling tests. Time and motion studies have been conducted on all available jumpers. Both manual control and computer position control systems have been used for comparison studies. The system is currently being operated from inside the cell. Under these conditions, the manual operation is faster than the computer control. Later when closed-circuit TV is installed, the time and motion studies will be repeated with the operations controlled from outside the cell for comparison using the procedures now developed. Figure 4.1 is a photograph of the test stand and equipment. Three jumpers are shown in the installed position. The impact wrench is shown in position over a horizontal connector with the manipulator. Two three-bolt, remotely operated, in-line flange connectors are also shown. Preliminary pressure decay leak testing is in progress.

*A jumper can be defined as a removable section of piping used to join two or more fixed pipe connections in a process cell. It consists of two connector female parts, connecting pipe, support bracket, and lifting bale. 


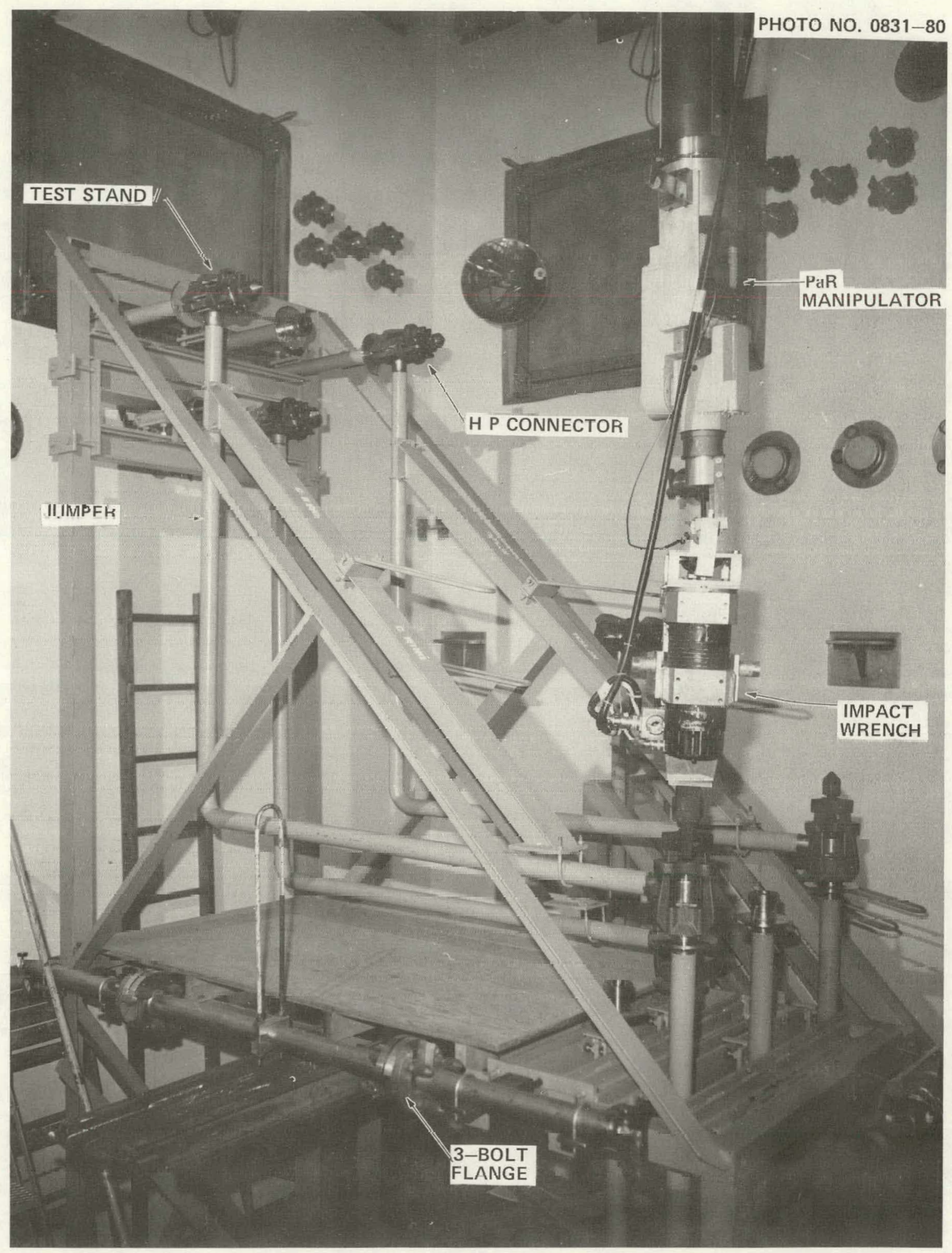

Fig. 4.1. Cell E, TURF remote handling tests. 
Seal performance tests. The procurement of equipment for the conncctor environmental test stand (CETS) is now complete. The procurement package was placed in five parts to expedite delivery of the diverse systems as follows: load frame and machine parts, hydraulic system, leak detector, microprocessor and signal conditioners. Many discrepancies were found in the load frame and machine parts. These will require correction before installation.

Instrumentation (W. F. Johnson and L. E. Ottinger). The test plan for initial startup and checkout of all CETS instrumentation has been prepared. A revised software program requirements document outlining the new modes of operation, alarm conditions, and data logging demands has been issued. The necessary programs are being written to implement these changes and are about $75 \%$ complete.

Remote cutting and welding. A conceptual design study has been initiated by a subcontractor to develnp remnte pipe cutting and welding. This study is bascd on criteria developed by ORNL and is scheduled for completion by April 1980. Commercial equipment that has potential applicability will be included in a pipe repair scenario. Welding for pipes up to $5 \mathrm{~cm}$, using autogenous procedures, is not expected to present a major development problem. Emphasis is being given to pipe preparation, alignment, and inspection of the finished weld. These are considered the major technical problems. Very little experience exists in the application of weld inspection methods to small pipes $(2.5$ to $5 \mathrm{~cm})$ in a remote environment.

Sampling system. An automated liquid sampling system has been included in the HEF conceptual design report as the reference sampling system. This system consists of individual automated sampling stations that receive liquid from vessels and circulate that liquid through sample bottles, a remotely operated vehicle that handles the bottles at the station and delivers them to the analytical facilities, and the track system for the vehicle that runs along the perimeter of the cells.

In a study performed by Los Alamos Technical Associates, the interfaces between the sample system and the HFF cell structure were defined. In this study, the physical location and the installation of the track and the sample stations were coordinated with the HEF layouts for the service penetration plugs and the process module jumpers. Other interfaces such as the operation, control, and the load/unload area were also defined.

The next step in the newly established development program is to design, build, and test a prototype system for ultimate demonstration in the ROMD. It is expected that the final version for the $\mathrm{HEF}$ will require additional work in the areas of the method of signal transmission, the amount of shielding, and the degree of automatic control. In the design work done to date, the vehicle structure, the bottle handling mechanisms, the propulsion subassembly, and the station location system are well defined. There are other subsystems that require further work such as the identification system, the data communication system, and the internals of the sampler station.

\subsubsection{Remote control engineering task}

J. Garin (Westinghouse Advanced Reactors Division), B. J. Bolfing, H. W. Harvey, and G. E. Smith

The remote control engineering task was established to improve the technology for remote control and manipulation system in the radioactive environment of nuclear fuel reprocessing plants. The primary goals of reducing personnel exposure and the requirements 
for-minimizing the need for human entrance to the cell can be obtained by the improved application of remote system technology. These improvements are aimed at making the remotely controlled systems more reliable, more easily maintained, and more efficient all of which contribute to a more efficient plant. Because of changes in the evolving design of the HEF, increased emphasis to provide higher dexterity is being placed on the electrically driven master/slave manipulators. This sytem includes integrated viewing and improved end effector systems.

Crane control and telemetry systems (K. Sharp and P. E. Satterlee). A commercially available electromechanical manipulator arm (Model PaR 3000) is being converted for use in a computer-controlled, closed-loop positioning system. The goal of this work is to investigate the effects of computer supervisory manipulator control on operator fatigue and efficiency. Position sensors have been selected and are being mounted on the manipulator arm joints. Servoamplifier motor drives have been specified and are being procured. A replica mini-master control arm is being designed for use as the operator interface with the slave manipulator arm.

A minicomputer has been interfaced with the overhead handling system control microprocessor. The functions of the minicomputer will be supervisory in nature and will include zone control (i.e., prevent access to certain areas), obstacle avoidance, and teachplayback. The software has been developed on the minicomputer for the overhead handling system teach-playback routine and this function is now operational. A statement of work has been written to determine proper obstacle avoidance techniques based on system requirements.

A commercially available command and sensor signal telemetry system is being specified for use with the overhead handling and manipulator systems. Functionally, this system multiplexes and demultiplexes the manipulator system data so that commands and sensor data can be transmitted to a single data link.

Wireless methods of signal transmission are being investigated. A statement of work has been written to study in-cell signal reflection problems associated with wireless signal transmission and to determine signal transmission hardware requirements. An inductive loop method for signal transmission is being investigated.

A simple wireless signal telemetry system is being breadboarded for laboratory testing of an inductive loop signal transmission scheme. The data transmission capabilities of the system will be investigated by sending and receiving data on already installed loop antennas. The advantages of this system over the optical signal transmission link presently used in the TURF, cell $\mathrm{E}$, overhead handling system include reduced alignment problems and the elimination of a need for radiation-hardened optics. In addition, the system is thought to be immune to in-cell signal reflections.

Viewing system (D. Bible). A study with the Univerisity of Florida to develop methodology for hand/eye coordination is in progress. This study will integrate and optimize closed-circuit TV (CCTV) viewing systems and the manipulator controls. This study will lead to the conceptual design of an improved man/machine interface control system. Black and white, color, 3-D monitors, and associated positioning pan-and-tilt mount television equipment are being procured for use in experiments to demonstrate the required CCTV features. Currently, the literature search and system design requirements documents have been completed.

Servomanipulator development (S. Gould). The procurement of a commercially available, force-reflecting servomanipulator system has been initiated in a contract with Central 
Research Laboratories. The first review meeting was held in December to review program plans. Delivery is projected for the first quarter of FY 1981.

The Brookhaven master/slave servomanipulator system is currently being reactivated. The system's servoamplifier electrical control package, position, force transducers, and wiring harnesses were repaired and modified as necessary. Final servo-loop tuning, calibration, and check-out are in progress. This system is being reactivated to experiment with different control systems to determine preferred control methods for the advanced servomanipulator.

The master/slave servomanipulator closed-loop controls analysis has been computer simulated to determine tuning parameter requirements for force-feedback systems.

Remote maintenance studies. The study for an advanced electromechanical handling system is continuing. This study, the rigid hoist articulated grapple, is $90 \%$ completed. Some key items that are included in the system are:

1. detailed study of the control system architecture;

2. boom configuration and rigid hoist, to position the manipulator to the work place and minimize operator fatiguo;

3. actuator design, an innovative pancake motor, and revolute gearing system.

The final report will be issued in February 1980.

\subsubsection{Uranium for tests}

\section{N. R. Grant and R. W. Knight}

This task is divided into three areas: (1) the procurement of dummy assemblies as feed material for the disassembly/shear tests, (2) the procurement of depleted uranium dioxide as feed material for the voloxidizer and/or the dissolver, and (3) the disposal and/or recycle of uranyl nitrate.

As reported previously, the second half of the vendor order for dummy assemblies was delayed by fabrication problems in the manufacture of hex ducts from type 446 stainless steel. During this reporting period, the problems were not resolved. Several attempts at fabrication, using both the spinning and expansion method and the commercial draw-bench method, met with failure. The vendor has hired a metallurgy consultant whose first observation was that the starting material for fabrication had the wrong grain size. His full evaluation will be completed in January. Other alternate fabrication techniques are also being investigated. Although delivery of the last ten assemblies, and the date for exercising the option to fabricate an additional 27 assemblies in 1980, have not been determined, it is certain that neither event will occur before April.

\subsection{HEF Conceptual Design}

\section{J. R. White}

The conceptual design of the Hot Experimental Facility (HEF), a pilot-scale fuel reprocessing plant, is being performed by ORNL with the assistance of an architect-engineer (A-E) and other subcontractors. The HEF is conceived as a versatile reprocessing test facility capable of handling the complete spectrum of breeder reactor fuels for the various fuel cycles now being considered. This will allow testing of various breeder fuel cycles consistent with the overall breeder development program. The HEF will allow the demonstration of 
advanced fuel reprocessing technology under plant operating conditions with irradiated fuel and will establish a basis for projection of reprocessing capability to the breeder industry.

Planning and scheduling of the HEF Conceptual Design Report (CDR) has been completed. This planning has included specific definitions of the output products (drawings, studies, narrative descriptions, etc.); the milestones for review and approval of the products; and assignment of work responsibilities. A list of the major HEF milestones that have been established for planning purposes has been issued to DOE-ORO for approval.

Drawings of the process building and cell complex have been prepared by the A-E (Bechtel National Inc.) and issued for use as the basis for the CDR. Contracts have been placed with a number of subcontractors to complete conceptual designs of specialty systems. The subcontractors include General Atomic Company, Sundstrand Energy Systems Inc., Planning and Research Corp., and Los Alamos Technical Associates.

The conceptual design criteria for major HEF systems are nearing completion and should be issued to DOE-ORO for review during the next quarter. A concentrated effort is underway to establish the procedures and outline to be applied to the HEF cost estimate. The intent is to obtain a computerized cost estimate which is usable throughout the life of the project (Title I, II, and III) and versatile enough to assess the impact of proposed design revisions.

\subsubsection{Site and support buildings \\ O. A. Rogers}

All conceptual design criteria documents for site and support buildings have been completed in draft form with the exception of those criteria relating to site selection, communications, and site monitoring. These documents should be finalized by UCC-ND and submitted to DOE for approval during the next quarter.

The HEF plot plan for the CDR is being prepared. Space is being allocated on the site for a future fuel refabrication facility and a cask maintenance facility. Preliminary layout sketches for all of the support buildings have been completed by Bechtel and reviewed by UCC-ND.

A study of the primary water supply and emergency cooling systems concepts is continuing. The current preferred approach is to use a hardened cooling tower and basin rather than to draw emergency water from the Clinch River.

\subsubsection{HEF process buildings}

J. N. Herndon and G. F. Kalb

The HEF process building concept was revised significantly during FY 1979. The revision provided improvements in function, cost, physical protection, and the reduction of radiation exposure to operating personnel. The revised concept was described in detail in the previous quarterly report.

Detailed process building arrangement drawings were issued by Bechtel during September. 'These drawings have been reviewed by the HEF design team and lead engineers from the CFRP development tasks. The comments were compiled, issued to Bechtel, and the building configuration was frozen for the CDR. A set of revised process building drawings was issued at the end of December for use by the engineering disciplines as a basis for FY 1980 design efforts. 
A set of cell complex arrangement and equipment placement drawings was also reviewed simultaneous with the process building arrangement reviews. Comments were compiled, and the cell complex arrangement (as shown in Fig. 4.2) was then frozen for the CDR.

General Atomic has begun a study to define shipping cask handling requirements and equipment for the HEF. The work task descriptions, milestones, and other outputs required to support the concept's design have been established. In addition, a survey has been initiated to identify shipping casks that the HEF could potentially be required to handle. The survey will document pertinent data on these casks for the design of handling equipment. Work has also begun on schematic diagrams depicting cask handling and servicing sequences in the HEF.

\subsubsection{General purpose cell systems D. Macdonald and K. L. Walker}

Detailed plans and schedules have been prepared for the FY 1980 conceptual design activities. Subcontractor engineering is being used to develop conceptual designs for remote handling, viewing, maintenance, and disposal of in-cell equipment. Approved work tasks have been issued for each of these tasks including a definition of the specific drawings, design descriptions, and cost estimates to be included in the Conceptual Design Report.

Prcliminary discussions have been held with each of the subcontractor design groups, and a scope of work compatible with the available funding has been defined. The subcontractual effort planned is as follows.

Planning Research Corp. will develop concepts for in-cell viewing, including television viewing in all cells and on mobile equipment, shielded window and periscopes at work stations, and all in-cell lighting. Remote handling systems will include overhead cranes, manipulator systems, repair hoists, and mobile recovery equipment. The remote handling system will incorporate the floor-mounted vehicle transport system for remote manipulator coverage of process cells developed from a design study compiled in October 1979. The recommended system consists of three interactive subsystems: the remote maintenance. vehicle, the in-cell facility support system, and the command control system. The remote maintenance vehicle consists of a rotary telescoping tower supported by and guided on a monorail track system. This transporter gives full volume coverage of the $10 \times 12 \times 50$-ft process modules with bilateral force-reflecting electric master/slave manipulators and with the television maintenance system.

Sundstrand Energy Systems will define decontamination equipment including high pressure spray chambers, immersion tanks, module flush stations and decon transfer locks. Concepts will be developed for equipment disposal systems located in the scrap cell including equipment for cutup of process assemblies, vessels, piping, etc., and for the decontamination and packaging of the resulting scrap. Sundstrand will incorporate the results of a design study completed in October 1979 on methods of reducing process modulcs to scrap and of handling this scrap.

General Atomic Company will define the maintenance facilities for the HEF cell complex. Remote repair stations, contact maintenance shops, and manipulator repair facilities are included. Special tooling, fixtures, and spare parts storage requirements will be defined for each cell.

Los Alamos Technical Associates are defining the automated liquid sampling vehicle and the required dedicated systems for sample container load/unload and handling and for vehicle maintenance. 




\section{PROCESS BLDG. ISOMETRIC}

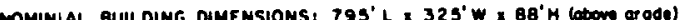

Fig. 4.2. HEF cell complex arrangement. 
Design concepts for selected cell penetration systems are being undertaken with UCC-ND Engineering. Major systems such as shielded transfer systems will be defined. The A-E (Bechtel) will complete the utility feedthrough development based on preliminary UCC-ND design concepts.

\subsubsection{HEF process systems}

\section{E. D. North, F. L. Peishel, and M. V. Keigan}

The process systems design work is concentrating on equipment sizing and equipment location. Elevation drawings have been prepared for all in-cell equipment. Some equipment relocation resulted in more efficient use of the cell volume without compromising accessability for maintenance.

The flowsheet for $\mathrm{ThO}_{2}$ production has been revised to eliminate the oxalate precipitation process. Thorium nitrate solution will be concentrated and thermally denitrated.

Testing of piping arrangements associated with a segment of a full-size process module mock-up has been started at Los Alamos Scientific Laboratory using electric master/slave manipulators. The intent of these tests is to determine the spatial requirements between modules and between components within a module for remote maintenance. A work task has been started at Bechtel to establish a concept for dimensionally locating in-cell process equipment for remote installation of pipe jumpers.

\subsubsection{Project support}

B. F. Bottenfield, F. C. Davis, and D. P. Reid

The preparation of conceptual design criteria documents under subcontract to Los Alamos Technical Associates (LATA) is proceeding approximately on schedule. The effort is approximately $50 \%$ complete.

The conceptual design quality assurance plan for the HEF was submitted for DOE approval during the last quarter. No comments and/or approvals have been received.

The document setting forth the basic functional guidelines for design of the HEF, "Functional Design Requirements for the CFRP Hot Experimental Facility, Revision 4," has been revised again and is being reviewed.

An early staffing study, projecting the personnel requirements for the operation of the HEF, was reviewed and revised by Bechtel and reissued. Detailed scheduling for the conceptual design effort in FY 1980 and early FY 1981 was agreed to among the A-E; DOEORO, and the UCC project staff.

Preparation of a cost code of accounts manual for HEF cost estimating is underway by UCC-NU Engineering cost estimating staff and the HEF project staff. 


\section{TECHNICAL SUPPORT}

\section{O. O. Yarbro}

The various generic studies reported in this section are not specific to functional research and development areas but are important to the overall program. The areas being studied include facility operations, safeguards, nuclear engineering, the development of nonspecific process instrumentation and controls, and environmental assessment relative to the Hot Experimental Facility (HEF) design.

\subsection{Facility Operations}

\section{J. M. Chandler and D. E. Dunning}

Activities in the area of facility operations were focused on energy conservation efforts and building and equipment modifications.

Office space in the 7600 complex has been increased with the completion of the Integrated Equipment Test (IET) office area on the first floor of Building 7601 and the modification of some offices on the second floor. The temporary office area located on the mezzanine level of Building 7601 is to be upgraded to provide additional permanent office space.

Facility modifications included the completion of a dummy fuel storage area, providing additional storage areas for supplies, and the installation of an $\mathrm{NO}_{x}$ monitor on the facility stack.

\subsection{Safeguards}

\section{H. T. Kerr}

The CFRP safeguards task is responsible for assuring the development of effective safeguards technology for nuclear fuels reprocessing plant applications as may be necessary to satisfy both domestic and international safeguards objectives. The task activities include:

1. identification of safeguards objectives for reprocessing plants,

2. application of existing technology as available,

3. identification of technological deficiencies,

4. initiation of the development of advanced safeguards concepts to remedy deficiencies,

5. integration of comprehensive safeguards systems into reprocessing plant designs. 
The pursuit of these activities is consistent with this task's role as an interface between the reprocessing plant designers and the safeguards technology specialists. Considerable effort has recently been expended in developing appropriate interfaces with other Department of Energy (DOE) funded safeguards groups at the Los Alamos Scientific Laboratory (LASL), Sandia Laboratories, and with Allied-General Nuclear Services. Many of these activities are generic in nature while others are in direct support of the HEF design effort.

\subsubsection{Dynamic accounting instrumentation studies}

R. D. Hurt, A. B. Crawford, and T. L. Hebble

A substantial interaction has developed with LASL for the purpose of assessing the applicability of dynamic accounting to the HEF. The interaction has been divided into two projects. The first has the objective of determining the measurement accuracies that must be attained in order to achieve various levels of dynamic accounting system performance in the HEF. Once the necessary measurement accuracies have boen determined, the LASL and the CFRP staffs will jointly evaluate the capabilities of instruments that exist or can be developed to perform such measurements. The conclusions drawn in the course of this project should be generally applicable to any large, remotely-operated reprocessing plant.

The second part of the LASL interaction will focus on the practical aspects of applying specific measurement instruments to a potential HEF dynamic accounting system. Two instruments being developed at LASL, the absorption-edge densitometer and the passive neutron coincidence counter, have been selected as initial candidates. The LASL staff will investigate various features of these instruments for potential application to the HEF concept.

\subsubsection{Microscopic process monitoring}

\section{R. D. Hurt, A. B. Crawford, T. L. Hebble, and J, W. Wachter}

Microscopic process monitoring (MPM) is a material control methodology being developed by the CFRP for application to any heavily-instrumented reprocessing facility. The MPM methodology compares the measured values of a wide variety of process control parameters to their respective predicted values. The predictions are based on simple models describing either the time dependence of a parameter or the relationships between different parameters. The discrepancies between prediction and measurement are subsequently combined and correlated to provide an indication of the status of the nuclear material in the. proctess.

A pair of rotary dissolvcr product collection tanks is being used in a preliminary demonstration of the MPM concept. The tanks are well-instrumented and provide a useful opportunity to evaluate the basic MPM methodology. A data base containing the measured values of various process parameters and thcir associated uncertaintics is continuuusly updated by an interactive computer. This measurement data is inserted in relatively simple equations describing the dynamics of each measured parameter or its relation to other measured parameters in order to calculate predicted values of future measurements. The uncertainty of each prediction is also estimated. Each current measured value of a parameter is then compared with its corresponding predicted value and the significancc of the difference between them is quantified. The individual values are then weighted and combined in a way that emphasizes their expected safeguards importance and exploits correlations between measurements made at different points in the process. 
Microscopic process monitoring offers several distinct advantages. First, the methodology is designed to detect diversions of nuclear material from a chemical process using existing process control instrumentation. Second, the MPM strategy provides a mechanism for applying nearly all process control measurements to safeguards purposes, thus permitting the material control system to be based on the fullest possible understanding of the status of the process. And third, by using the many correlations between different process variables as part of the diversion detection system, an attempt by the diverter to tamper with the measurement instruments or their transmitted data could probably be detected by MPM. This feature is especially important in the international safeguards environment.

\subsubsection{Safeguards material balance experiments on the rotary dissolver}

\section{J. W. Wachter, A. B. Crawford, R. D. Hurt, and G. A. Cotsonis}

The objective of the safeguards experiments on the CFRP dissolver is to demonstrate the computation of real-time material balances utilizing process instrumentation. The dissolver system is well instrumented for such experiments; information on process variables is accumulated by a Bristol UCS-3000 computer, converted to engineering units, and transmitted at three-minute intervals to the PDP-11/40 CODEDACS computer. A computer code written for the PDP-11 computer calculates the current inventory in the dissolver system and computes the total material balance around the dissolver.

The balance program has been improved by incorporating measurement uncertainties into the computation to enable error estimates to be attached to the calculated mass balances. A more accurate method of calculating acid-water mass fractions has been devised for computer use. In addition, computer programs were written for the PDP-11 which enable data recorded during previous dissolver runs to be used for computer program development at times when the dissolver is not operating.

\subsubsection{Penetration monitoring}

D. W. Swindle, Jr. and J. N. Cooley

The initial draft of the preliminary assessment of containment penetration for the HEF was completed. The initial draft included the results of a complete engineering hydraulics analysis of process service and transfer lines that penetrate the cell-wall containment. Also identified were the number and type of penetrations in the HEF that could be used to divert nuclear material from the process. The results of this study will be used in the conceptual design of a penetration monitoring system for the HEF.

A subcontract has been initiated with Science Applications, Inc., (SAI) of Palo Alto, California, to document radiation monitor characteristics which will help safeguards system designers in specifying a penetration monitoring system for a reprocessing plant. The SAI staff will conduct a literature survey and provide documentation on radiation monitor operation, performance, and maintenance requirements.

\subsubsection{Participation in the International Atomic Energy Agency's (IAEA) International Working Groups for Reprocessing Plant Safeguards (IWG-RPS) \\ H. T. Kerr, R. D. Hurt, and D. W. Swindle, Jr.}

Six reports were prepared as contributions to the IWG-RPS Facility Design Subgroup. These reports examine IAEA safeguards and reprocessing facility design considerations in the following areas: 
1. batch vs continuous dissolution,

2. hulls measurement,

3. centrifuging of dissolver solution,

4. coprocessing,

5. cell-wall penetration design and monitoring, and

6. contact vs remote maintenance.

These contributions are part of the United States contribution to the IWG-RPS.

5.2.6 Safeguards demonstration in the Radiochemical Processing Pilot Plant, Building 3019 W. J. Armento, H. G. Kitts, A. M. Krichinsky, and J. A. McEvers

Improved instrumentation and computer interfaces will eventually permit a volume and fissile mass balance to be performed around the solvent extraction system of the Building 3019 Radiochomical Processing l'ilot Plant. A volume balancing capability will be demonstrated in the near future. Computer software for a static volume balance and its error propagation has been tested. The final format for the volume balance report has been selected and final checkout of the electronic transmitters that convert pncumatic data into electrical signals has been completed. The existing pneumatic lines are being replaced in order to stabilize previously unreliable signals.

Several meetings have been held to define the scope of the operations monitoring concept. Operations monitoring is perceived to involve surveillance and verification of personnel locations, status of operating and maintenance equipment (i.e., cranes, manipulators, etc.), and general activities in areas where nuclear materials exist in nonsolution forms.

\subsubsection{The HEF safeguards system design support}

D. W. Swindle, Jr.

Classification guidelines. Interim classification guidelines for the HEF's conceptual design were prepared and issued for program use. The guidelines were prepared to provide interim classification guidance for subcontractor and CFRP personnel involved in work aimed at the completion of the HEF conceptual design. The document has been distributed to personnel involved with HEF conceptual design.

IAEA material accounting safeguards. The final report from SAI on the impact of international physical inventory accounting requirements on the HEF was distributed. The report summarizes considerations that could impact the HEF conceptual design should the HEF be designated a candidate facility for IAEA safeguards under the agreement between the United States and the IAEA. A detailed summary of the document and an action plan for incorporating the recommendations of the report was prepared for use by the HEF design team.

Safeguarded emergency evacuation. A draft CFRP report has been completed entitled, Safeguarded Evacuation from the Hot Experimental Facility: A Conceptual Evaluation. This 
report documents the joint evaluation by the CFRP safeguards staff and Sandia Laboratories Advanced Facilities Protection Division of alternative emergency evacuation system concepts for the HEF.

\subsection{Nuclear Engineering}

\section{J. F. Mincey}

The nuclear engineering task function is to provide criticality and radiation-level/ shielding guidance and computational support to the CFRP, particularly to the HEF design effort.

5.3.1 Interim validation report using existing, breeder-typical, $\mathrm{U}+\mathrm{Pu}$ critical benchmark data J. F. Mincey and R. T. Primm III

Any major design effort which involves conducting criticality evaluations relies upon the accuracy of an assortment of neutronics codes. These codes are used to predict the critical conditions of $\mathrm{K}$-eff values for systems of interest as well as for processing neutron cross-section data used for the K-eff calculations. The American National Standards Institute (ANSI 16.1 and $16.9,1975$ ) requires that such codes and cross-section data be frozen or archived and then gauged or validated against well-defined critical experiments.

The biases or differences between the predicted and actual $\mathrm{K}$-eff values for a set of neutronic conditions (determined by the experiments) are resolved by this process. This process, as indicated in applicable standards, is to be done before formal criticality evaluations of hardware are made. With these validated codes and biases, the evaluation of equipment, neutronically similar to the experiments used for validation, may proceed.

Therefore, in order to perform criticality evaluations of the HEF equipment, two tasks must first be completed. An experimental, critical benchmark data base must be generated containing experiments which are sufficiently representative of (or neutronically similar to) HEF equipment. Otherwise, the codes may not necessarily be validated for analyzing portions of the plant in a defensible manner. Secondly, validation against this data base must be completed and biases established.

Some $\mathrm{U}+\mathrm{Pu}$, breeder-typical, benchmark data exist but are judged (by the criticality community) as inadequate for a validation effort of the breadth HEF will require. In order to spot code inaccuracies and as an aid in determining where more experimental data are needed, the nuclear engineering task has begun calculating the existing $\mathrm{U}+\mathrm{Pu}$ benchmarks (applicable to the reprocessing of breeder-typical fuels) with frozen codes and cross sections. Presently, these codes and cross sections include: the AMPX-II ${ }^{1}$ cross-section processing system, KENO-IV, ${ }^{2} \mathrm{CHERIE}^{3}$ (an in-house Monte Carlo program with greater geometry flexibility than KENO-IV), an upgraded, 27 energy-group subset of the Criticality Safety Reference Library, ${ }^{4}$ and the ORNL- $4938^{2}$ cross sections.

During this reporting period, validation efforts have either continued or been initiated against three distinct classes of experiments. The first classification is loosely described as the Fast Test Reactor (FTR) fuel pin experiments. There are four subtypes of these experiments, the first being water-moderated and water-reflected FTR fuel pin arrays. Validation efforts against these data are virtually complete. The second subtype is composed of the partially concrete-reflected, water-moderated FTR fuel pin experiments; validation against these is about $75 \%$ complete. 'The third subtype involved water-moderated and reflected 
FTR fuel pin experiments with fixed neutron poisons (absorbers like gadolinium, cadmium, and Boral). Validation against the third subtype data is about $50 \%$ complete. The fourth subtype consists of FTR fuel pins which are moderated by fissile solutions (some of the solutions containing gadolinium) with water reflection. Validation efforts against these data are about $50 \%$ complete. These four subtypes encompass about 112 FTR fuel pin experiments.

The second class of experiments includes all existing, breeder-typical homogeneous $\mathrm{U}+\mathrm{Pu}$ solution criticals $(\sim 60)$. During this reporting period input files, descriptive of these experiments, have been completed and the computational process automated. Several of these experiments have been calculated to debug the automated procedure. Validation against this class of experiments is about $50 \%$ complete.

The third and final class of experiments consists of the breeder-typical, homogeneous $\mathrm{U}+\mathrm{Pu}$ oxide experiments. At present, input files for these data are being prepared.

The validation results against these three classes of experiments will be collected and compiled as an intcrim validation report. The report's shjectives are threefold: (1) to examine the breeder-typical, U+Pu critical data; (2) to identify any biases that may exist and suggest experiments which might reduce such discrepancies; and (3) tn identify where the existing data base is inadequate for claiming that the mentioned codes and cross sections are validated for the HEF.

\subsubsection{Interim HEF criticality philosophy report J. F. Mincey and R. T. Primm III}

The purpose of this companion report will be to go beyond the previously described interim validation report and address HEF criticality topics. Specifically, the report will comment on whether the HEF design should be based on the single-contingency criticality principle (ANSI 16.8-1975) as all operations will be remote and behind substantial biological shielding or stay with the time-honored, double-contingency principle necessarily developed and used for plants relying, to some degree, on contact maintenance and operations. The report will also examine, in some detail, some of the HEF's more prominent criticality problems (i.e., the rotary dissolver, $\mathrm{Pu}+\mathrm{U}$ product storage). Attempts will be made to incorporate what using double, instead of single, contingency and computational uncertainties mean in terms of the design and operation of such equipment. Comments will also be made as to what criticality-related instrumentation and additional critical cxperimentation may be needed based on the findings of these preliminary analyses.

During this reporting period, preliminary criticality analyses of various $\mathrm{U}+\mathrm{Pu}$ product storage tank designs have been conducted. In particular, evaluation of a proposed slab-tank module design was completed. The design was found conditionally acceptable (pending recommended modifications and code validation). However, the design is inefficient in the way cell space is utilized; the fissile solution volume-to-module volume ratin is about 0.25 . A second design has also been tentatively evaluated from a criticality viewpoint. This design resembles a shell and tube heat exchanger, a large cylindrical tank $(\sim 1.8 \mathrm{~m}$ diam $)$ containing neutron absorbers sealed in immersed tube banks. The volumetric efficiency ratio for this second design is about 0.75 , about a factor of three improvement. Both designs have a common disadvanlage, that is, the neutron absorbers, upon which both designs rely for subcriticality, must be verified periodically as effective. Verification for the second design, however, is expected to be appreciably more difficult (due to the number of neutron absorber rods that must be checked). The second design has an additional complication in that 
it neutronically resembles using raschig rings (see ANSI N16.4-1971) for criticality control. The standards require that raschig rings be periodically inspected to ensure that fissile deposits on the ring surfaces are kept below specified levels. This plating out of fissile material on the raschig rings (or outer tube surfaces for the second design) can degrade the neutron absorber's effectiveness. This is a result of the thermal portions of the system's neutron spectra causing fissions in deposited materials on such surfaces and hence, greatly reducing the fraction of the low-energy neutron flux being absorbed within a raschig ring by the neutron absorber. Therefore, a similar type of inspection, as required by the raschig ring ANSI standard, will probably also be required for the shell and tube design's tube bank surfaces.

Also during this reporting period, a series of calculations was begun to examine the behavior of K-eff as a function of reduced moderator (water) density in arrays of FTR fuel elements. This study addresses whether or not it is possible to make an FTR fuel pin system, subcritical at full water density moderation, more reactive, and perhaps critical or supercritical (might be possible for light water reactor fuels ${ }^{\mathbf{5}}$ ) by reducing the water density to about $0.05 \mathrm{~g} / \mathrm{cm}^{3}$. If this is the case, at least two problems must be addressed. The first is that this behavior is suggested by unvalidated calculations; no experimental data for any type fuel rods exist for such a system. Experiments to confirm and to provide benchmark data will be necessary. Second, this type of condition could conceivably occur in the rotary dissolver where dripping, undissolved fuel is routinely forced out of a gadolinium-poisoned solution and into a saturated steam environment. The effective moderator density could widely vary; equivalent water densities speculated as being in the $0.05 \mathrm{~g} / \mathrm{cm}^{3}$ range at this time seem plausible. A dry hull blockage would even bring a larger fissile mass out of solution and into this type of moderator. Calculational investigations into this type of problem are about $25 \%$ complete.

\subsubsection{Uranium + plutonium solution experiments R. T. Primm III}

The general description of this experimental series remains unchanged from that previously reported. One modification was made at the suggestion of the Battelle Pacific Northwest (PNL) Critical Mass Laboratory to reduce the $76-\mathrm{cm}$-diam cylindrical tank to a 68.6-cm-diam tank to allow more neutron leakage, which will permit the use of external control plates. This modification will have minimal impact on the experiments.

The PNL has completed its designs for these experiments, and the design has been reviewed by the nuclear engineering task. No significant changes are anticipated. The drawings have been put out for subcontractor bids.

\subsubsection{Uranium + plutonium oxide experiment design}

\section{J. F. Mincey and R. T. Primm III}

The critical masses of most systems with low $(<5)$, but nonzero, moderator-to-fissile material atom ratios are notoriously difficult to calculate accurately. This follows as the result of uncertainties in energy-dependent cross-sectional data used to calculate nuclear reaction rates and hence $\mathrm{K}$-eff. Complicating this problem, standard computational procedures that work well for more moderated systems are often inadequate for such undermoderated conditions. Consequently, cross-sectional data and mathematical representations of the governing neutron physics that are adequate for more thermalized systems are to be used cautiously and with experimental verification for highly under-moderated systems. 
As the HEF design calls for the production and short-term storage of appreciable quantities of damp $\mathrm{U}+\mathrm{Pu}$ oxide, critical experiments are needed to validate codes used to analyze equipment designs. Consequently, the task has begun a conceptual design (during this reporting period) of the necessary experiments. Both the Rocky Flats Critical Mass Laboratory and the LASL Critical Mass Laboratory are being examined as a site for this work.

\subsubsection{Interim HEF in-cell radiation level report}

\section{E. J. Allen, S. N. Cramer, and J. V. Pace}

The first version of an engineering-design computer code was completed in order to provide timely, radiation-damage estimates for the design of in-cell remote handling equipment. Existing computational techniques for predicting in-cell radiation levels were (1) more elaborate than required for conceptual designs of the HEF and (2) used excessive computer time. Work is being continued toward improving the code's input data and testing it against sample problem results obtained with more elaborate (and less design-suited) calculations.

The computational model requires, as input, radiation leakage rates from sources within the HEF (e.g., process tanks, spent fuel assemblies, etc.). One-dimensional, gamma transport calculations have been used to determine these leakage. rates. Two-dimensional calculations are currently in progress; the results will probably replace and be an improvement over those obtained with the one-dimensional code. Based on such leakage rates, the engineering-design code calculates radiation levels and dose rates at points of interest within the HEF using point-kernel techniques. Test cases have been calculated and preliminary radiation levels within the HEF have been predicted. The code is now being updated to treat cylindrical source geometries with more accuracy.

A detalled calculational study of the radiation levels near the remote sampler was started. Input for an elaborate Monte Carlo calculation was prepared with the sampler assumed to be located above the high-activity feed tank. These calculations will be used to test the engineering-model of the HEF as well as to estimate the shielding requirements of the remotc samplcr.

A literature search of the radiation-damage data on plastics, elastomers, and insulator materials was also performed. A number of reports were identified and obtained that describe damage mechanisms and data for these organic materials. This information will be applied toward determining which organic materials should or should not be used in HEF equipment designs.

\subsection{Instrumentation and Controls Systems}

\section{S. M. Babcock}

This task will develop instrumentation systems and engineering techniques for the CFRP and provide basic instrumentation and control technology applicable to commercial plants. Instrumentation and control systems are required in support of laboratory experiments and in other highly specialized tests associated with the component and process development tasks of the CFRP. 


\subsubsection{Systems development}

\section{J. A. McEvers, R. M. Tate, and R. W. Tucker, Jr.}

One major objective of this subtask is the development and evaluation of techniques for communication between computer systems. Minicomputer to microcomputer communication, minicomputer to minicomputer communication, and system resource monitoring and sharing between computer systems are major areas being addressed.

The down-line loading and execution of a task from the CFRP Development Computer System (DEC PDP 11/34) to a microcomputer system (DEC LSI-11) has been accomplished. A test task was written and stored on the system disk of the development system and then transmitted over a hard-wired link at 9600 baud into the memory of the LSI-11. The task was then successfully executed. The down-line loading was accomplished with the use of the DECNET network communications system. Normally, an operating system such as RT-11 or RSX-11/s is down-line loaded into a lower level system. In this case however, a specific effort was being made to down-line load a software component not supplied by DEC. The success of the effort opens the way for the development of special purpose software which can be down-line loaded and executed without the need for an executive software system. This activity has primarily dealt with achieving down-line load and execute, whereas further effort will be aimed at providing full communications between non-DEC software residing in a lower level computer and a higher level "host" computer. This will result in the bidirectional transmitting of data between minicomputer and microcomputer systems.

The hardware for the evaluation of high speed ( $\geqslant 1$ megabaud) intersystem communication via DEC DMC-11 communication interfaces has been ordered and a partial shipment received. Installation of the equipment will be performed upon receipt of the remainder. A one-megabaud, full-duplex, synchronous, fiber optic communications link has been ordered and received. Evaluation of the link will be initiated upon installation of the communication hardware.

Participation in the International Purdue Workshop on Industrial Computer Systems at Purdue University in Lafayette, Indiana, is continuing. Of special interest is committee work in computer system safety and security, reliability, communications, man-machine interfaces, and distributed control systems. Representatives from England, France, Germany, and Japan were present at the recent meeting.

\subsubsection{Sensor development}

H. H. Ross, J. E. Strain, D. T. Bostick, M. L. Bauer, D. W. McDonald, D. D. McCue, J. T. DeLorenzo, R. L. Anderson, and G. N. Miller

Analytical sensor development. A method is being optimized for the potentiometric determinations of $\mathrm{HNO}_{3}$ in TBP and will be used to prepare accurate $\mathrm{U}-\mathrm{HNO}_{3}$ standards in $30 \%$ TBP for subsequent spectral analysis. Nitric acid in 100 and $30 \%$ TBP solutions can be accurately analyzed in a concentration range of 0.1 to 5 milliequivalents in the absence of uranium. However, the initial acid concentration in the organic sample is over estimated by as much as $10 \%$ if uranium is present. The elevated results are due to uranyl hydrolysis in the presence of trace amounts of water contained in the organic sample. Future efforts will be directed toward the removal of the water prior to the analysis of $\mathrm{HNO}_{3}$ in $\mathrm{U}-\mathrm{HNO}_{3}$ TBP samples. 
The completed prototype of the neutron poison monitor is now undergoing bench testing and calibrations. The in-cell portion of the monitor is complete, except for incorporating a suitable electrical connector for the HEF environment.

A new investigation has been initiated that is aimed at the detection of low levels ( 1 to $100 \mathrm{ppm}$ ) of uranium in high-level waste streams. This will make use of a nanosecond laser pulse to excite the uranium fluorescence. The effect of quenching agents will be minimized by the analysis of the fluorescence both in time and in wavelength.

The initial design of the sapphire/metal seal at the uranium monitor process interface proved to be unreliable. Redesign with closer mechanical tolerances of the component parts is expected to solve this problem. Preparations for "wetting" the in-cell component with simulated process material are being made. Plans are being made for an initial wet test of the photometer with short (3-m) quartz fiber optic signal links in December or early January. This test will provide a very good estimate of the sensitivity and signal/noise ratios to be encountered in the final instrument design.

A Plcxiglas model of the frec acid monitor in cell component is being fabricated. When subjected to simulated process material tlow, the flow and residence time characteristics of the design will be evaluated. A modified Hilch tube for the condensate portion of the package demonstrated suitable performance on bench test and is included in the design.

Physical sensor development. Test were conducted on a clamp-on ultrasonic flowmeter from Controlotron, both alone and in parallel with the Polysonics Doppler ultrasonic flowmeter. The performance of the clamp-on meter was substantially better than the du Pont ultrasonic flowmeter due, at least in part, to the higher flow range of the du Pont flowmeter. The random error measured at the low flow-rate of $50 \mathrm{l} / \mathrm{h}$ was about $5 \% \mathrm{com}$ pared to about $100 \%$ with the du Pont meter.

A thermal mass flowmeter was ordered and received and testing was initiated. The asreceived instrument has proved to be reproducible with a random error of $1 \%$ or less around $50 \mathrm{l} / \mathrm{h}$ and about $0.5 \%$ at $250 \mathrm{l} / \mathrm{h}$. It has been repeatedly calibrated from about $10 \mathrm{l} / \mathrm{h}$ to $250 \mathrm{l} / \mathrm{h}$ and the day-to-day repeatability has been excellent. This meter is simple in principle and should be readily radiation-hardencd. The meter will be adjusted to optimize its performance, and evaluation will be continued.

The liquid level measurement test stand was completed and has been put into operation. Two prototype ultrasonic, torsion-wave sensors were received for testing, one of which has been installed in the test stand. The necessary ultrasonic measurement modules were also received. Specitications are being drawn up for ultrasonic level probes for holding tanks in the IET. We plan to submit these to the Atomic Energy Research Establishment (AERE), Harwell, England, for an estimate and possible purchase of AERE designed probes.

\subsubsection{Special measurements}

G. L. Ragan, C. W. Ricker, G. G. Slaughter, E. D. Blakeman, M. M. Chiles, C. M. Smith, and D. N. Fry

Nondestructive assay. This subtask consists of the following four parts: (1) the demonstration and verification, using spent fuel, of the performance capabilities of the head-end nondestructive assay (NDA) system developed in FY 1978; (2) the development of a nondestructive method for the measurement of the isotopic composition of spent fuel subassemblies; (3) the investigation of other possible applications of nondestructive assay of fissile material within the HEF; and (4) the execution of a proof-of-principle experiment which could lead to the development of an NDA system for leached hulls in the HEF. 
The demonstration of the performance capabilities of the head-end assay system was scheduled for FY 1979 but has to be postponed because of the unavailability of spent fuel. Preparations for the demonstration including extensive computer calculations were made with the expectation that spent fuel from the Browns Ferry plant would be shipped to ORNL. After several shipment delays, the laboratory was informed that the plan to transfer spent fuel to ORNL was cancelled. It was therefore necessary to find an alternate source of spent fuel for the assay demonstration. Spent fuel from the Oconee and Dresden power stations is being considered for the demonstration.

Studies that will lead to the development of a nondestructive method for the measurement of the isotopic composition of spent fuel subassemblies were focused on the Neutron Filtering method during this reporting period. This method is based on the measurement of the ratio of the signals resulting from the placement of two different neutron filters around a subassembly. One or more filter pairs can be used thus providing ratios that are related to the isotopic composition of the fuel in the subasscmbly.

The problem is the selection of appropriate filter characteristics and filter materials. A calculational effort is underway on this problem which initially will involve the development of necessary calculational tools. A preliminary criterion for the selection of filters has been developed by the analysis of the propagation of measurement errors using a hypothetical system composed of two fissile isotopes. An additional criterion for the selection of filters was determined by parametric analysis of the probability that a resonance of the filter material will overlap a resonance in the fissile material. Based on these preliminary criteria, calculations using the ANISN code have been made for various filter materials and neutron moderating conditions. The results of these calculations are being evaluated.

The investigation of other applications of NDA of fissile material in the HEF is progressing with current attention being concentrated on the active neutron method of assay. The leached hulls proof-of-principle assay equipment has been set up, and the applicability of this apparatus for the investigation of other measurements in the HEF is being studied.

During this reporting period, experiments were performed with the leached hulls proof-of-principle apparatus for the purpose of optimizing the operating configuration of the system. The results of these experiments indicate good counting rates (approximately $10^{2}$ counts per second per detector for a $100-\mathrm{Ci} \mathrm{Sb}$ source), reasonably uniform spatial response ( $<10 \%$ for different radial and angular locations), and an acceptable signal-tosource background ratio (5:1 for a $500-\mathrm{mg}$ fissile sample). Although optimal conditions were not established for these measurements, the system with a 5:1 signal-to-source background ratio is capable of assaying quantities of fissile material as low as $20 \mathrm{mg} / \ell$. With the optimal configuration, it is expected that the signal-to-source background ratio will be significantly improved; therefore, the quantity of fissile material which can be assayed will also be reduced significantly.

Mechanical surveillance. The major objective of this subtask for FY 1980 is to analyze vibration data recorded during a 32 -h prototype dissolver run and record data from specific test runs to be made in order to determine if vibration monitoring can be used to monitor material transfers between stages of the prototypic dissolver. Efforts for this reporting period have focused on establishing a subcontract for technical support for the analysis of the baseline data from the $32-h$ run. 
In addition, initial estimates for several approaches to periodically transmitting RMS vibration data to CODEDACS for automatic recording during dissolver operation have been made. This data would be recorded at a rather slow rate and would be used to monitor the dissolver for mechanical anomalies, such as bearing failures. Approaches considered include transmission to the dissolver's unit process controller and then to CODEDACS, direct transmission to CODEDACS via a high speed analog input system used currently for shear data, and intermediate transmission to a data logger.

\subsection{Environment and Safety}

\section{B. Sears}

This task includes the activities related to site selection, the safety analysis, and the environmental impact assessment for the proposed $\mathrm{HEF}$. A preliminary draft of the site evaluation criteria has been prepared and circulated for internal review. An effort has been initiated and a subcontract let for the identification and preliminary evaluation of potential sites for the HEF.

The risk assessment of the HEF by Savannah River Laboratory was continued with significant accomplishments including: review and approval for issue of the first of a series of reports covering head-end operations through feed adjustment and the completion of draft report on solvent extraction and process conversion.

Informal discussions were held with A. T. Clark of the NRC concerning the possible role of the NRC in reviewing the safety, safeguards, and environmental matters related to the HEF. Dr. Clark was given an overview of the program through a series of formal presentations at the HEF Status Review Meeting and a tour of the Building 7601 facilities.

\subsection{IET Operational Planning}

\section{W. W. Evans}

The basic plan for arranging the equipment installation and demonstrations scheduled for the IEI' facility has been selected. Three plans were proposed and the options reviewed prior to the selection. The major differences in the plans related to how the ROMD pit would be used and where equipment would be located during the remotc demonstrations and the integrated process runs. The plan selected will use the ROMD pit area for the headend processing in a remote operating mode during the integrated process runs as well as for the development and demonstrations of remote maintenance lechniques.

Plans have been initiated to identify the options for the integration of the existing CODEDACS computer and IET IDACS computer into the DDACS for the IET. Four options are currently under consideration for the situation appraisal.

A cursory survey was conducted to locate an area that could be used for remote development work with the current process module design outside of the ROMD pit area. Favorable locations were found at the 910 elevation in Building 7600 and in an area in Building 7603 where component development is currently in progress. 


\section{$5-13$}

\section{References}

1. N. M. Green et al., AMPX-II: Modular Code System for Generating Coupled Multigroup Neutron - Gamma-Ray Cross-Section Libraries from Data in ENDF Format, RSIC PSR-63 (November 1978).

2. L. M. Petrie and N. F. Cross, KENO-IV: An Improved Monte Carlo Criticality Program, ORNL-4938 (November 19.75).

3. Personal communication from N. F. Landers, Union Carbide Corporation Computer Sciences Division.

4. W. E. Ford III et al., A 218-Group Neutron Cross Section Library in the AMPX Master Interface Format for Criticality Safety Studies, ORNL/CSD/TM-4 (July 1976).

5. F. M. Alcorn, "Criticality Evaluation of Low-Density Moderation in PWR Fuel Storage," ANS Transactions 27, 416-417 (November-December 1977). 


\section{HTGR FUEL REPROCESSING}

\section{B. L. Vondra}

Process research and development activities on high-temperature gas-cooled reactor (HTGR) fuel reprocessing technology are being conducted at General Atomic Company (GA) with supporting hot-cell studies at ORNL. These programs are devoted to studies and analyses of reprocessing requirements for HTGR and gas-cooled breeder reactor (GCFR) fuels and HTGR-specific head-end studies.

\subsection{Studies and Analyses}

\section{H. C. Carney and L. Abraham, General Atomic Company}

The objectives of this task are (1) to evaluate waste treatment options for GCFR spent fuel fission product traps and recommend a process for Hot Experimental Facility (HEF) conceptual design considerations, (2) to assess the applicability of HEF process systems to the demonstration of HTGR spent fuel processes, (3) to continue an assessment started in FY 1979 of alternatives leading to decreased solid waste generation in HTGR head-end processing, and (4) to evaluate off-gas treatment requirements for fast breeder reactor (FBR) carbide fuel.

\subsubsection{Evaluation of GCFR fuel reprocessing}

V. H. Pierce and L. Abraham

The assessment task for GCFR fuel reprocessing in the HEF was completed, and a topical report is being prepared.

For the assessment, GCFR and LMFBR mechanical design information and fuel cycle data were compiled from several sources. Information and data on FBR reprocessing technology and the HEF were provided by the staff of the Consolidated Fuel Reprocessing Program (CFRP). The HEF Interim Conceptual Design Report (ICDR) has been used as the spent fuel reprocessing system and facility design basis.

The assessment showed that reprocessing GCFR spent fuel is practicable in the HEF. Since sodium is not used in the GCFR and is not utilized in the spent fuel shipping concept, the cask unloading and fuel assembly cleanup operations at the HEF, prior to water storage, are simpler and do not involve the HEF sodium waste handling system.

The GCFR fuel design incorporates fission product charcoal trap sections in the core fuel rods and in the core and radial blanket assemblies. Process development is required (1) to separate the trap sections from the fuel and assembly hardware, and (2) to process the traps suitably for waste disposal.

It was recommended that the HEF disassembly and shear systems equipment prototype design be reviewed in order to confirm their capability for handling the GCFR fuel and traps. A single trap handling and waste process system must be selected for the HEF conceptual design, and the trap waste process system must be added to the HEF development and demonstration program. 


\subsubsection{HTGR fuel reprocessing development requirements}

V. H. Pierce, B. B. Haldy, N. D. Holder, and L. Abraham

Both volumes of the user's manual for the HTGR commercial recycle plant data base are in the process of publication. Volume $I$ is an executive summary of cost data base capabilities. Volume II explains the capabilities in detail and contains the instructions for the use of the cost data base to generate specific data reports and to obtain direct costs. Internal review of the waste treatment material balances, based on the waste streams identified in reprocessing material balances, has been completed.

\subsubsection{HTGR fuel reprocessing headend alternatives}

\section{J. S. Rode, D. M. Bender, N. D. Holder, V. H. Pierce, and L. Abraham}

This study evaluates a numbcr of methods for their potential to reduce the volume of ${ }^{14} \mathrm{C}$-containing solid carbonate waste resulting from the reprocessing of spent HTGR fuel. The dratt of an interimi report was completed. Preliminary assessment of candidate methods narrowed the number of promising approaches to several head-end process modifications and one fuel element design concept. The interim report includes FY 1980 follow-on assessment recommendations and a description of the methodology for making this assessment. The follow-on assessment of alternative head-end processes and fuel designs will include evaluation of a number of different process options.

\subsection{Head-End Studies}

\section{W. S. Rickman, General Atomic Company}

\subsubsection{United States-Federal Republic of Germany Cooperative Program on graphite-based nuclear fuel reprocessing}

W. S. Rickman, J. B. Strand, and N. D. Holder

A Joint Prototype Head-End Facility (JPHF), which will be a cold, remotely maintainable, full-size facility, is in the early stages of conceptual design. It will be cooperatively designed, built, and operated, using both U.S. and FRG reference fuel types. Tasks required to complete the conceptual design are described in work packages (WPs). These are assigned by mutual agreement and approved by each country after completion.

A program plan has been written for a joint fucl processing demonstration (JFPD), in which nonirradiated FRG fuel (spherical elements) will be processed through the General Atomic (GA) HIGK Fuel Reprocessing Pilot Plant. An experimental plan for completion of the test work is bcing written. This program will be an important verification of design concepts currently being incorporated in the JPHF. Commonality of reprocessing equipment for both spherical and prismatic fuel elements is one of the major goals of the cooperative program. The total quantity of fiel elements to be processed will excoed a mctric ton. This will provide adequate equipment operating time to ensure the validity of the results.

\subsubsection{Crushed fuel element burning}

\section{W. S. Lessig and U. E. Fields}

The major tasks of crushed fuel element burning during FY 1979 have been to develop the necessary computer hardware and software and to identify the process variables required to automate the primary burning process. As the final step, control systems were developed 
for the shutdown (tailburn) regime. The beginning of tailburn is characterized by a breakthrough of oxygen in the off-gas; consequently, in tailburn, the controlling variable becomes the oxygen concentration in the off-gas rather than the burn rate. Also, the bed temperature must be controlled to sustain combustion of residual carbon in the bed.

Several burner operations were conducted under full automation with minimal operator intervention. Although the results proved satisfactory, several hardware items and controlrelated areas have been identified which require further study.

A second objective of this task was to connect a supervisory computer to a process computer for use in automation and data acquisition. The process computer would act as a proportional, integral, derivative controller in a combination of simple and cascade controlloop configurations. The supervisory computer would (1) perform more complex calculations; (2) make decisions regarding startup, steady-state, or tailburn modes of operation; and (3) perform data acquisition, material accountability, and final data analysis and presentation.

\subsubsection{Particle classification, crushing, and crushed-particle burning}

\section{J. B. Strand}

Air classification. The design of advanced fuel types will affect the efficiency of separation of fissile and fertile particles by air classification in proportion to the differences in the densities and diameters of the particles. Parametric studies on current fuel particles were completed earlier. In addition, fuel particles of an advanced design for a middle-enrichment uranium (MEU) fuel cycle were produced for classification tests. Separate determination of particle terminal velocities was accomplished. These test results were used to separate particle blends successfully. Confirmation by wet chemical analysis is pending.

Separation of fissile and fertile particles produced by FRG has been studied using the $\mathrm{GA}$ air classification system. These fissile (TRISO-coated $\mathrm{UO}_{2}$ ) and fertile (TRISO-coated $\mathrm{ThO}_{2}$ ) fuel particles were successfully separated in a series of tests after their terminal velocities were determined. Analytical results confirmed these tests.

Particle crushing. A new design of the fuel particle crusher was completed, and construction of the assembly is almost complete. In addition, an in-line sampler was designed to facilitate determination of crusher product characteristics during testing of the new unit.

Secondary (crushed fuel particle) burning. The initial gas distributor in the $0.10-\mathrm{m}$ (4-in.) secondary burner has been replaced by a remotely removable distributor. In addition to the remote features, the flange connection was relocated outside of the high-temperature zone. The initial testing of the new distributor was completed with no operating problems. Observation of the distributor will be an ongoing task in conjunction with use of the burner for further process data.

\subsubsection{Dry solids handling}

N. D. Holder and H. H. Yip

Component testing. A pneumatic transport component test loop is being used to determine wear in pipe bends and failure rates of typical solids transport equipment. The test loop previously operated successfully for 3900 out of 4000 cycles, transporting crushed graphite. The failures typically involved material holdup problems associated with degradation to a fine powder. After $275 \mathrm{~h}$ of operation with graphite, the test material was replaced with a mixture of crushed graphite and BISO- and TRISO-coated fuel particles typical of a 
large HTGR spent fuel element. The rig has been operated for an additional 1000 cycles using the fuel element mix. Pipe bend wear rates with pure graphite were negligible; about $1 \%$ weight reduction by wear was noted on the first pipe bend.

Remote and nonremote coupling devices were evaluated for their applicability to HTGR reprocessing dry solids handling and their suitability for remote maintenance activities. A general evaluation eliminated those that might cause particle breakage and/or material holdup problems. The remaining couplers were tested at the GA hot-cell cold manipulator station for ease of handling. A topical report describing the results is in progress.

HEF voloxidizer isolation valves. The current voloxidizer inlet and outlet isolation valves in the HEF are flapper valves, which do not give sufficient sealing for the voloxidizer against acid vapor leak from the rotary dissolver. Fines agglomerating around the seat area prevent proper operation of the valve. The test program objective is to develop a doublevalve system that would seal properly to isolate the voloxidizer product from the dissolver.

The valving requirements inolude threc valves - one fol gravily drup of shear product to the voloxidizer and two for gravity drop of voloxidizer product to the dissolver. The shear valve will normally be open, closing only when maintenance is required on the system. The first valve out of the voloxidizer receives product cooled to $100^{\circ}$ to $150^{\circ} \mathrm{C}\left(200^{\circ} \mathrm{C} \max \right)$. The second valve must seal to prevent dissolver off-gas from leaking into the voloxidizer system. All lines are $20.3 \mathrm{~cm}$ ( 8 in.), and the flow is about $1.8 \mathrm{l} / \mathrm{h}$.

A test apparatus is currently under construction. The first test configuration will be a knifegate-Gemco valve combination. The Gemco valve has been in use in the coal industry and has a unique internal sweeping action that should minimize jamming of the valve seat with solids. All valves and piping are $15.2 \mathrm{~cm}(6 \mathrm{in}$.$) in diameter. However, the test results$ are expected to be conservative and will be applicable to the $20.3-\mathrm{cm}(8-\mathrm{in}$.) diameter design configuration.

\subsection{I aboratory Development}

\section{R. D. Zimmerman and G. E. Benedict (General Atomic Company)}

\subsubsection{Dissolution of $\mathrm{ThO}_{2}$ in dissolver with airlift recirculator H. H. Yip and L. J. Olguin}

It was shown previously that adding an internal airlift recirculator to the $0.1-\mathrm{m}$ glass dissolver would reduce dissolution time of $\mathrm{ThO}_{2}$ beads by more than $50 \%$. To further evaluate the reliability and scale-up effects of this type of dissolver mixing technique, a larger airlift recirculator was built and incorporated in the $0.2-\mathrm{m}, 12-\ell$ stainless-steel dissolver. The recirculator is designed for a recirculation flow of $500 \mathrm{ml} / \mathrm{min}(5 \%$ of the dissolver volume) and is equipped with a pulse-sparge tube for eliminating sluggish flow due to solids buildup in the return pipe. A bubbler level monitor provides measurement of hydraulic head and recirculation rate. Figure 6.1 shows the equipment arrangement inside the airlift bundle which has no moving parts.

Three runs in the $0.2-\mathrm{m}$ dissolver indicated a $50 \%$ reduction in dissolution time with the use of the recirculator. Six and one-half hours were required to reach the $1 M$ thorium concentration vs the $14.5 \mathrm{~h}$ needed for the base case. However, a certain amount of channeling is suspected, because the result did not approach the $4.3-\mathrm{h}$ dissolution time observed in the $0.1-\mathrm{m}$ glass dissolver study. 


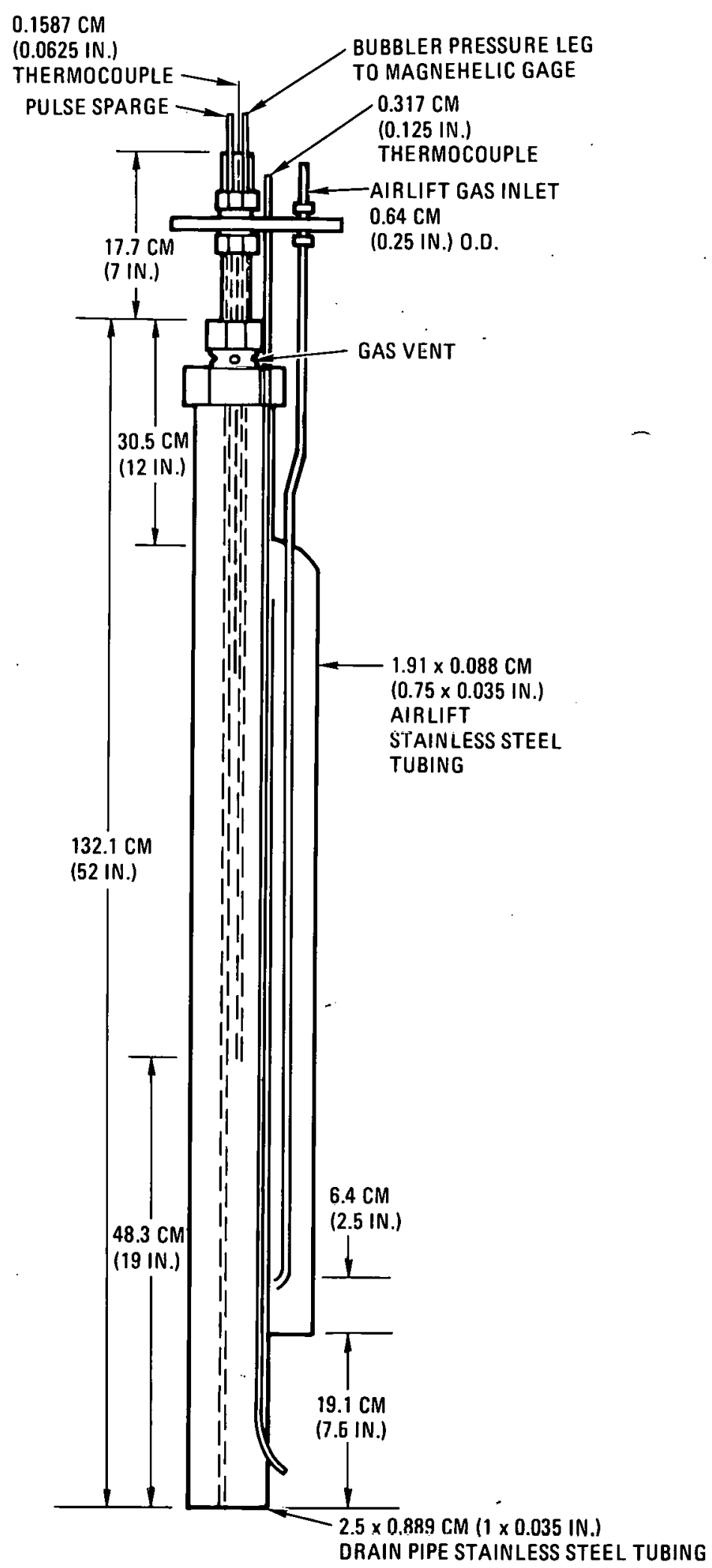

Fig. 6.1. Equipment arrangement. (Courtesy General Atomic Company) 
Three runs were made with one fresh feed, followed by two heel-mode cycles in sequence, to determine whether the $\mathrm{ThO}_{2}$ heel left in a dissolver would eventually cake and affect the recirculator operation. The results show that the performance of the recirculator was not affected by the heel. However, trouble was encountered in removing the product because of solids blockage of the dump valve.

Initial tests in $0.5-\mathrm{m}$ dissolver. Using a $40 \%$ heel-mode operation, $88 \mathrm{~kg}$ of $\mathrm{ThO}_{2}$ were dissolved in $200 \mathrm{l}$ of Thorex solution in $32 \mathrm{~h}$. Figure 6.2 shows the dissolution rate curve for Run 50-1 and also shows the effect of sparge rate on dissolution time. The data indicate $24 \mathrm{~h}$ would be needed to reach a $1 M$ thorium product, assuming a continuous nitrogen sparge rate $\geqslant 17 \mathrm{\ell} / \mathrm{min}$. Future reference tests will be performed to confirm the expected increase in dissolution rate using a continuous sparge rate of $\geqslant 17 \mathrm{l} / \mathrm{min}$. Solution heating from ambient temperature to boiling $\left(\sim 120^{\circ} \mathrm{C}\right)$ required 37 min using $308 \mathrm{kPa}$ (30 psig) steam supply for both the botton cone and side heating jackets. Cooling the solution from boiling to $35^{\circ} \mathrm{C}$ required $56 \mathrm{~min}$ using a cooling water flow rate of $2.3 \mathrm{l} / \mathrm{s}$ in the side jacket of the $0.5-\mathrm{m}$ dissolver.

Leaching of weak acid resin (WAR) fissile ash iı n.5-m הissolver. The WAR fissile aslı campaign (Kun 50-2) in the 0.5-m dissolver centrifuge system was completed during the quarter; $98 \%$ of the uranium contained in the fissile ash was dissolved in $7 \mathrm{~h}$ using an operaling temperature range of $50^{\circ}$ to $70^{\circ} \mathrm{C}$ for $5 \mathrm{~h}$ and $103^{\circ} \mathrm{C}$ for the last $2 \mathrm{~h}$. An initial $2.54-\mathrm{M} \mathrm{HNO}_{3}$ solution (200 l) was used to leach $39.4 \mathrm{~kg}$ of WAR fissile ash that contained about $64 \% \mathrm{SiC}$. The dissolution of uranium in this test was more rapid than that obtained previously in the $0.2-\mathrm{m}$ dissolver at $19^{\circ} \mathrm{C}$ but much slower than that obtained at $103^{\circ} \mathrm{C}$.

Approximately $200 \mathrm{l}$ of product slurry was transferred to the centrifuge with a nominal $2.3 \mathrm{l} / \mathrm{min}$ submerged steam jet that had a $653 \mathrm{kPa}(80 \mathrm{psig})$ steam supply. Following the slurry transfer, visual inspection of the dissolver internals revealed solids cake formation in the lower cone area which apparently was a composite of $\mathrm{SiC}$ hulls and crystallized uranium nitrate. Additional transfer tests are needed to improve the transfer of slurries cuntaining SiC. hulls.

\subsubsection{Dissolution of (U-Th) $\mathrm{O}_{2}$ pellets}

\section{S. A. Dunlap}

Pellets of $(\mathrm{U}-\mathrm{Th}) \mathrm{O}_{2}$ that contain denatured uranium are being considered for use in proliferation-resistant fuel cycles. The rate of dissolution in Thorex solution of some pellets with $25 \%$ uranium was studied to extend the data base for pellets with relatively livgh $\mathrm{UO}_{2}$ contents.

Two sets of $\left(25 \%\right.$ U $75 \%$ Th) $\mathrm{O}_{2}$ pellets were made for this study by the GA-GCFR Fabrication Development Department. The first set of pellets contained 0.5 wt $\% \mathrm{CaO}$ which was added to increase the pellet density and possibly to increase the dissolution rate. The diameter of the pellets was $1.33 \mathrm{~cm}$ with axiul lengths varying between 0.846 and 0.941 $\mathrm{cm}$, and the density averaged $88.1 \%$ of theoretical. A second set of similar pellets but without $\mathrm{CaO}$ was also prepared; the density of pellets in this set was $83.2 \%$.

Dissolution of the pellets without calcium was essentially complete in $8 \mathrm{~h}$, but only about $85 \%$ of the higher-density calcium-containing pellet material was dissolved in this time period. Apparently, the density of the pellets has a larger effect on the dissolution rate than does the addition of calcium.

Dissolution of $\mathrm{ThO}_{2}$ in Thorex solution is usually accomplished under reflux in the GA pilot plant dissolvers. During dissolution, all condensed liquids are returned to the dissolver, 


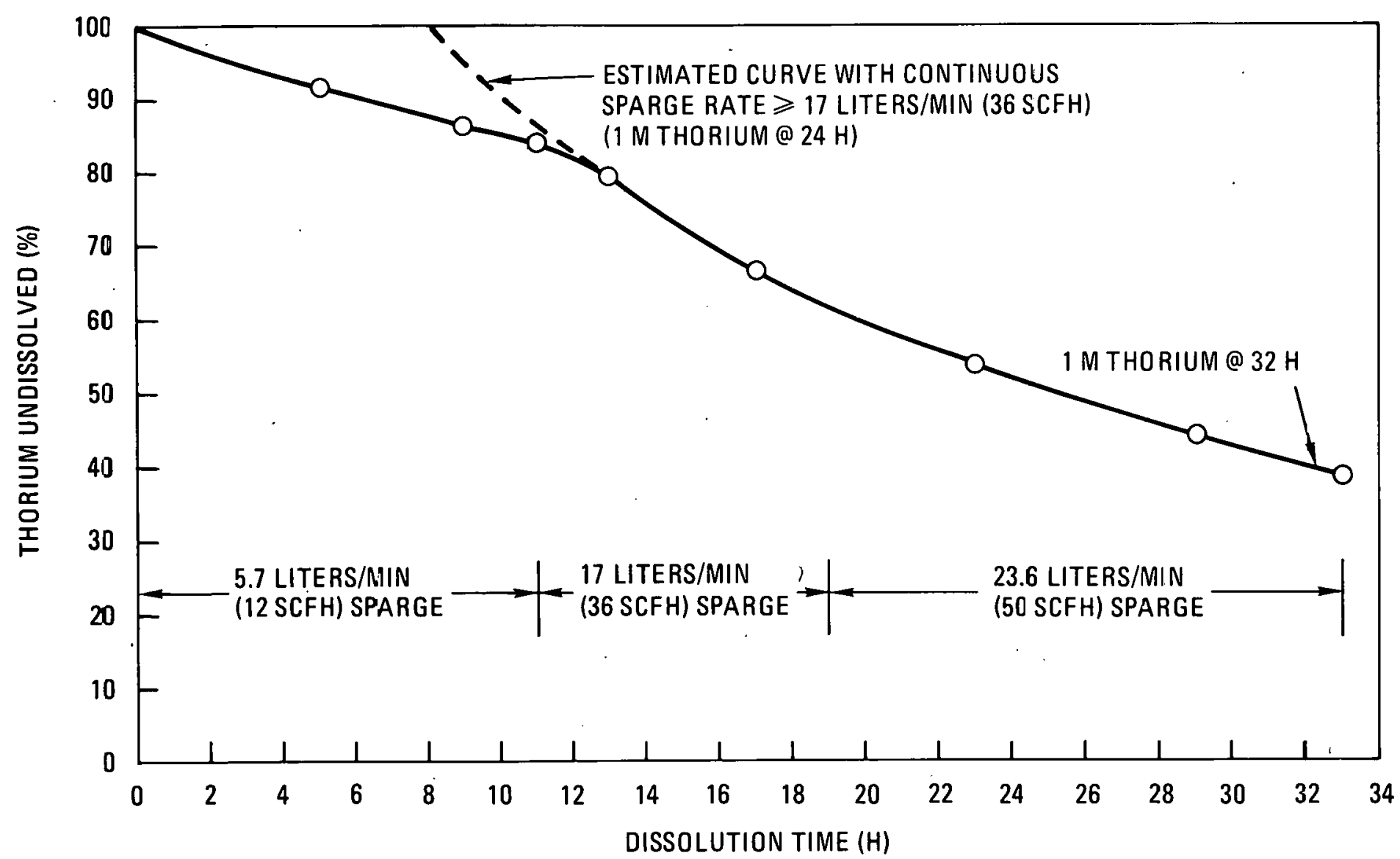

Fig. 6.2. Dissolution of $\mathrm{ThO}_{2}$ in 0.2-m dissolver (BISO reference run 50-1). (Courtesy General Atomic Company) 
and no gaseous products are formed. Therefore, there is no change in the total weight of material charged to the dissolver. The progress of a dissolution experiment is usually monitored by withdrawing solution samples for thorium analysis by EDTA titration. The feasibility of determining the thorium concentration from solution density measurements was evaluated during this quarter. The recently acquired Mettler density meter (DMA46) was used to measure product solution densities as a function of time.

A plot of dissolver product thorium concentration vs solution density showed the relationship to be linear over thorium concentrations of 0 to $1 M$. Over this range, the density increased from 1.38 to 1.65 . Simple determination of the density, possibly with an in-line instrument, appears to be a feasible method for following the thorium concentration during dissolution.

\subsection{Hot Laboratory Studies}

\section{C. A. Vaughen, Oak Ridge National Laboratory}

\subsubsection{Fuel rod crushing and primary burning}

C. L. Fitzgerald and O. L. Kirkland

Upgrading of the hot-cell and in-cell equipment was completed. New delivery lines, new thermocouples and leads, and a new device to accurately mcasure the rull crusher opening was installed. A multiprogrammer with pulse counters was added to measure all gas volumes directly, and a Ge-Li detector was calibrated and added to the system for online off-gas analyses.

- Experiments to study separation and particle breakage with fuel from FTE-13 were started. This fuel is a TRISO-TRISO carbide combination with a fissile particle Th:U ratio of 2.75 and was irradiated in the Peach Bottom reactor for 512 cffective full-power days (EFPD). The operations involved are the standard crush-burn crush-burn-leach. Duplicate cxperiments will be done such that both primary burns will be completed before starting the secondary operations.

In each experiment, the fuel rods were visually inspected, weighed, and crushed (separately) in the rod-crusher to prepare for fluidized bed primary burning. Crusher losses were $0.29 \%$ for the first batch and $0.58 \%$ for the second. The crushed fucl for the first experiment was loaded into the primary burner and burned at $850^{\circ} \mathrm{C}$ at $0.8 \mathrm{~m} / \mathrm{s}$ in $5 \%$ $\mathrm{O}_{2}-95 \% \mathrm{~N}_{2}$. The percentage weight loss during burning of the burner product was $39.6 \%$ of which $51 \%$ was carbon fines transferred to the cyclone and micromctallic filters, and $49 \%$ was carbon-burned. Equipment performance was good with only minor difficulties with two flow totalizers.

\subsubsection{Long-term fission product volatility \\ C. L. Fitzgerald and $O$. L. Kirkland}

The experiment to measure fission product deposition as a function of temperature has been in progress for abnut four months. One morc period of operation is planned with the original fuel. (A second series will be made with a fresh batch of fuel.) Fission product deposition was analyzed according to position along the length of the deposition coil. The predominant isotope was ${ }^{106} \mathrm{Ru}$ with $82 \mathrm{mCi}$, followed by smaller amounts of ${ }^{125} \mathrm{Sb}$ and ${ }^{134-137} \mathrm{Cs}(<1 \mathrm{mCi})$. These results suggest that the cesium is deposited at the 
inlet $\left(500^{\circ} \mathrm{C}\right)$ of the tube, and the ${ }^{125} \mathrm{Sb}$ and ${ }^{106} \mathrm{Ru}$ are deposited at about $400^{\circ} \mathrm{C}$. The results are characterized by a very steep concentration gradient with temperature and indicate that the region of interest is the $350^{\circ}$ to $500^{\circ} \mathrm{C}$ zone.

\subsubsection{Processing of high-level HTGR-specific solid waste}

\section{K. H. Lin, W. B. Howerton, C. L. Fitzgerald, and O. L. Kirkland}

The average leach rates for selected radionuclides were calculated from recent hot-cell experimental data at 140,177, 203, and $231 \mathrm{~d}$ of leaching. The cesium leach rates for all the samples remained unchanged during the leach times from 140 to $231 \mathrm{~d}$. The ${ }^{125} \mathrm{Sb}$ leach rate showed a pronounced decrease with leach time. In general, the sample containing $50 \%$ clay $-50 \% \mathrm{SiC}$ hulls as the Inatrix still maintains the lowest leach rates of ${ }^{125} \mathrm{Sb},{ }^{134} \mathrm{Cs}$, and ${ }^{137}$ Cs. 
ORNL/TM-7192

Dist. Category UC-86

INTERNAL DISTRIBUTION

1. W. I. Armento

2. W. D. Arnold

3. S. M. Babcock

4. J. T. Bell

5. M. Bender

6. M. R. Bennett

7. J. E. Bigelow

8. R. E. Blanco

9. J. O. Blomeke

10. R. Blumberg

11. B. J. Bolfing

12. W. D. Bond

13. B. F. Bottenfield

14. J. T. Bradbury

15. E. C. Bradley

16. N. C. Bradley

17. R. E. Brooksbank

18-22. W. D. Burch

23. D. O. Campbell

24. D. D. Cannon

25. J. A. Carter

26. J. M. Chandler

27. E. D. Collins

28. L. T. Corbin

29. D. A. Costanzo

30. R. M. Counce

31. A. B. Crawford

32. D. J. Crouse

33. B. F. Crump

34. B. C. Duggins

35. D. E. Dunning

36. R. D. Ehrlich

37. W. E. Eldridge

38. J. H. Evans

39. W. W. Evans

40. M. J. Feldman

41. R. L. Fellows

42. D. E. Ferguson

43. L. M. Ferris

44. C. L. Fitzgerald

45. C. M. Gallaher

46. J. Garin

47. E. H. Gift
48. R. Glass

49. J. H. Goode

50. N. R. Grant

51. J. C. Griess

52. W. S. Groenier

53. G. L. Haag

54. M. J. Haire

55. D. C. Hampson

56. B. A. Hannaford

57. W. O. Harms

58. F. E. Harrington

59. H. W. Harvey

60. T. L. Hebble

61. J. N. Herndon

62. D. Holladay

63. W. D. Holland

64. S. J. Hurrell

65. R. D. Hurt

66. R. A. Jacobus

67. R. T. Jubin

68. P. R. Kasten

69. M. V. Keigan

70. H. T. Kerr

71. L. J. King

72. J. Q. Kirkman

73. A. J. Klein

74. J. A. Klein

75. C. H. LaMaster

76. C. E. Lamb

77. R. E. Leuze

78. B. E. Lewis

79. M. H. Lloyd

80. D. K. Lorenzo

81. A. L. Lotts

82. R. S. Lowrie

83. J. C. Mailen

84. A. P. Malinauskas

85. J. L. Marley

86. J. T. Martin

87. J. D. McGaugh

88. C. P. McGinnis

89. L. F. McNeese

90. S. A. Meacham 
91. J. R. Merriman

92. J. F. Mincey

93. A. D. Mitchell

94. J. G. Morgan

95. . E. L. Nicholson

96. R. E. Norman

97. E. D. North

98. W. H. Pechin

99. F. L. Peishel

100. R. L. Philippone

101. H. Postma

102-105. R. H. Powell

106. B. E. Prince

107. D. J. Pruett

108. G. L. Ragan

109. R. H. Rainey

110. D. P. Reid

111. G. W. Renfro

112. H. H. Ross

113. A. D. Ryon

114. W. F. Schaffer, Jr.

115. C. D. Scott

116. T. W. Semple

117. J. H. Shaffer

118. G. E. Smith

119. J. W. Snider

120. B. R. Spencer

121. R. G. Stacy
122. E. G. St. Clair

123. M. J. Stephenson

124. J. R. Stokely

125. J. G. Stradley

126. D. W. Swindle

127. O. K. Tallent

128. L. M. Toth

129. D. B. Trauger

130. W. E. Unger

131. J. E. Van Cleve, Jr.

132. V. C. A. Vaughen

133. B. L. Vondra

134. J. W. Wachter

135. F. E. Weber

136. B. S. Weil

137. T. D. Welch

138. M. F. Whatley

139. J. R. White

140. R. G. Wymer

141. O. O. Yarbro

142. Manson Benedict (consultant)

143. W. H. Lewis (consultant)

144. A. Schneider (consultant)

145. M. J. Szulinski (consultant)

146-147. Laboratory Records

148. Laboratory Records, ORNL RC

149. ORNL Patent Office

150. Nuclear Safety

Information Center

\section{EXTERNAL DISTRIBUTION}

151. W. W. Ballard, Chief, Nuclear Fuel Cycles Programs Branch, Division of Nuclear Power Development, DOE, Washington, Dr. 20545

152. Office of Assistant Manager, Energy Research and Development, DOE-ORO, Oak Ridgc, TN 37830

153-266. Given distribution as shown in TID-4500 under UC-86, Consolidated Fuel Reprocessing Category (25 - NTIS) 